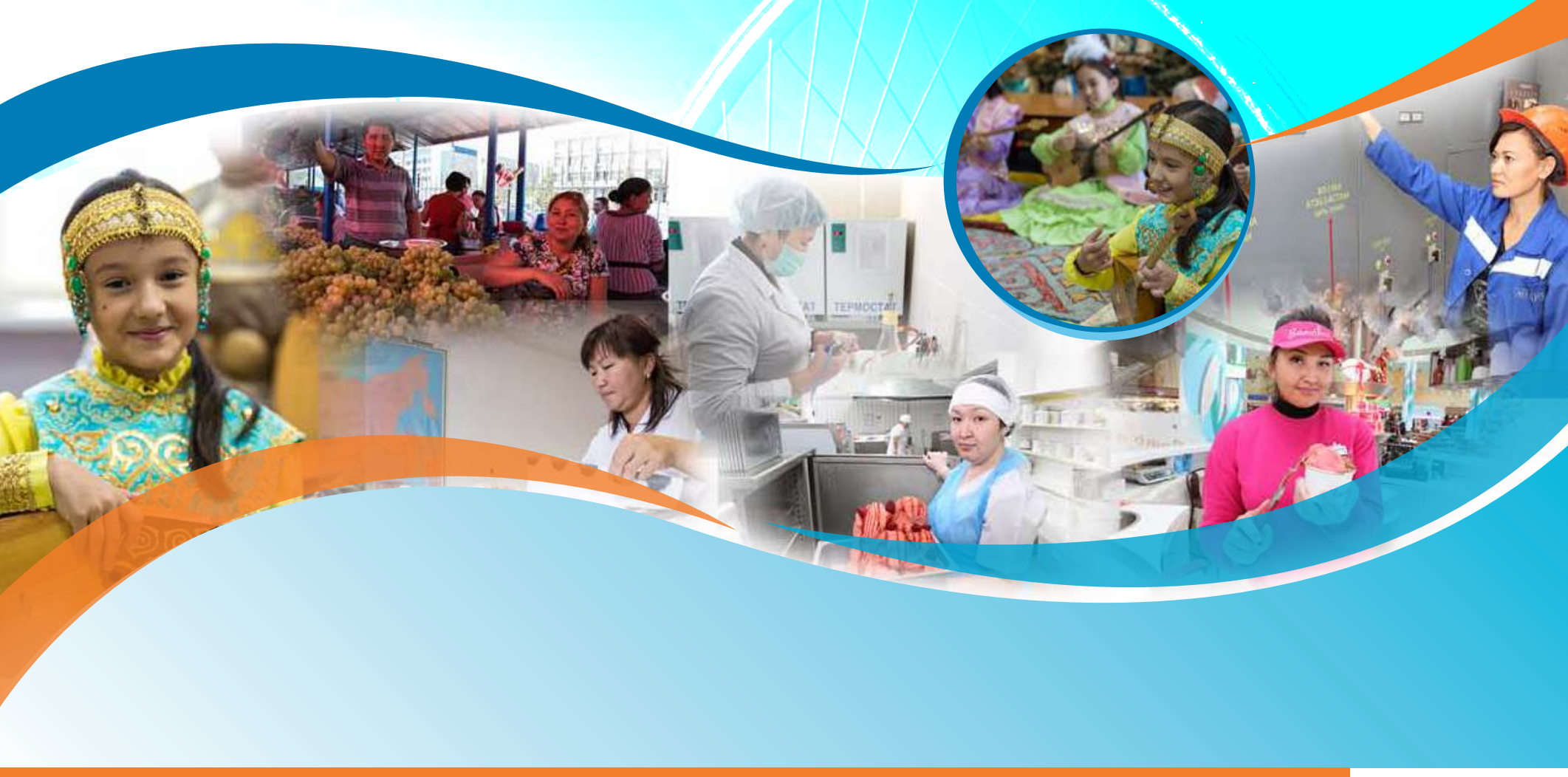

\title{
KAZAKHSTAN \\ COUNTRY GENDER \\ ASSESSMENT
}

DECEMBER 2018 


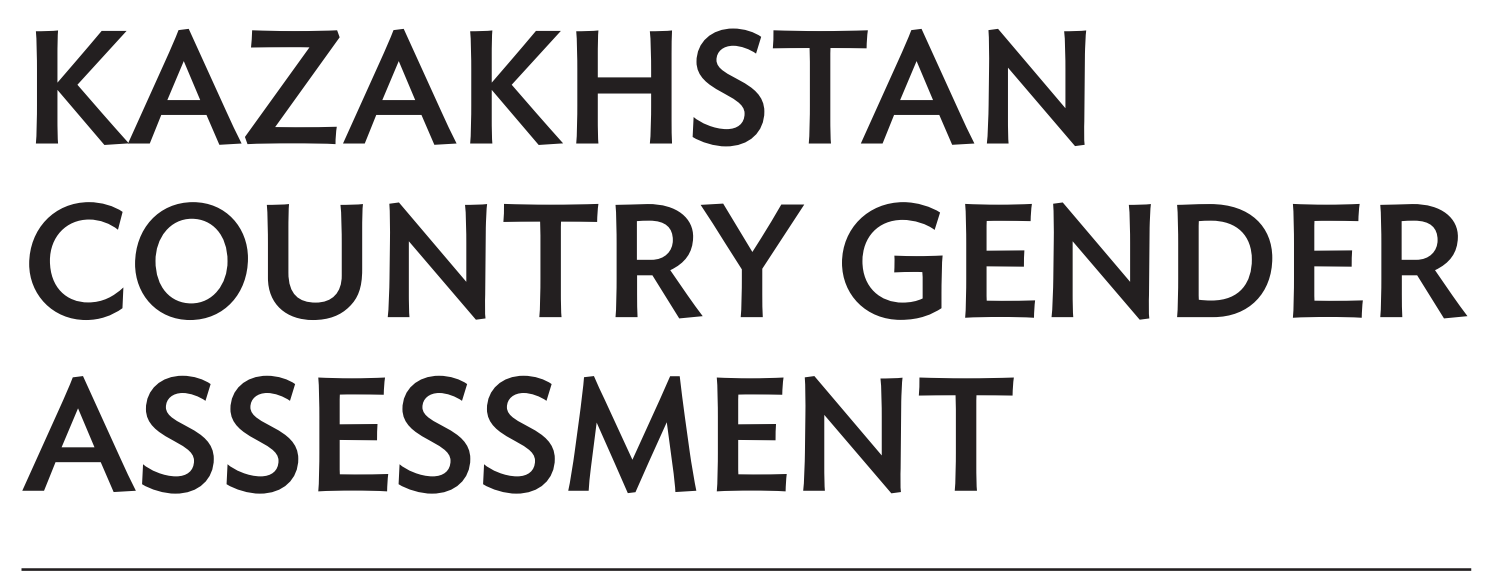

DECEMBER 2018 
(C) 2018 Asian Development Bank 6 ADB Avenue, Mandaluyong City, 1550 Metro Manila, Philippines

Tel +632632 4444; Fax +6326362444

www.adb.org

Some rights reserved. Published in 2018.

ISBN 978-92-9261-306-8 (print), 978-92-9261-307-5 (electronic)

Publication Stock No. TCS179181

DOI: http://dx.doi.org/10.22617/TCS179181

The views expressed in this publication are those of the authors and do not necessarily reflect the views and policies of the Asian Development Bank (ADB) or its Board of Governors or the governments they represent.

ADB does not guarantee the accuracy of the data included in this publication and accepts no responsibility for any consequence of their use. The mention of specific companies or products of manufacturers does not imply that they are endorsed or recommended by ADB in preference to others of a similar nature that are not mentioned.

By making any designation of or reference to a particular territory or geographic area, or by using the term "country" in this document, $A D B$ does not intend to make any judgments as to the legal or other status of any territory or area.

This work is available under the Creative Commons Attribution 3.0 IGO license (CC BY 3.0 IGO)

https://creativecommons.org/licenses/by/3.o/igo/. By using the content of this publication, you agree to be bound by the terms of this license. For attribution, translations, adaptations, and permissions, please read the provisions and terms of use at https://www.adb.org/terms-use\#openaccess.

This CC license does not apply to non-ADB copyright materials in this publication. If the material is attributed to another source, please contact the copyright owner or publisher of that source for permission to reproduce it. $\mathrm{ADB}$ cannot be held liable for any claims that arise as a result of your use of the material.

Please contact pubsmarketing@adb.org if you have questions or comments with respect to content, or if you wish to obtain copyright permission for your intended use that does not fall within these terms, or for permission to use the ADB logo.

Notes:

In this publication, "\$" refers to United States dollars and "T" refers to Kazakhstani tenge.

ADB recognizes "China" as the People's Republic of China.

Corrigenda to ADB publications may be found at http://www.adb.org/publications/corrigenda.

On the cover:

Empowering women and girls. ADB projects in Kazakhstan help improve women's access to livelihood opportunities, including jobs in nontraditional sectors (photos by ADB). 


\section{CONTENTS}

Tables and Figures v v

Acknowledgments $\quad$ vi

Abbreviations vii

Executive Summary viii

$\begin{array}{ll}\text { I. Introduction } & 1\end{array}$

A. Purpose of the Country Gender Assessment 1

B. Assessment Methodology 2

II. Background and Context 4

A. Country Situation 4

B. Indicators on Gender and Development 5

C. National Policies and International Commitments on Gender Equality 8

1. Legal Foundations for Gender Equality 8

2. Policies on Gender Equality 9

D. Institutions and Mandates 12

$\begin{array}{ll}\text { E. Collection of Gender Statistics } & 13\end{array}$

III. Cross-Cutting Gender Issues 15

$\begin{array}{ll}\text { A. Voice and Decision-Making } & 15\end{array}$

1. Women's Representation in Public Life 15

2. Claiming Rights and Having Voice in the Legal System 16

3. Gender Roles and Norms 17

B. Economic Empowerment 19

$\begin{array}{ll}\text { 1. Labor Force Participation } & 19\end{array}$

2. Wages 21 
3. Employment Status $\quad 21$

4. Migrant Workers 23

C. Reduced Time Poverty 24

D. Human Development 26

$\begin{array}{ll}\text { 1. Education } & 27\end{array}$

2. Health 30

3. Persons with Disabilities $\quad 32$

4. Gender-based Violence 33

E. Reduced Vulnerability to Risks and Shocks 38

1. Economic Shocks 38

2. Disaster Risks $\quad 39$

IV. Mainstreaming Gender in ADB Operational Priorities 41

A. Strategic Pillar 1: Economic Diversification 42

1. Micro, Small, and Medium-Sized Enterprise Development 42

2. Countercyclical Support $\quad 50$

B. Strategic Pillar 2: Inclusive Development 56

1. Agriculture 56

2. Transport 61

3. Health 69

$\begin{array}{ll}\text { C. Strategic Pillar 3: Sustainable Growth } & 73\end{array}$

1. Green Growth and Sustainable Energy 73

2. Urban Infrastructure and Services 76

D. Cross-Cutting Themes: Knowledge Building $\quad 79$

$\begin{array}{ll}\text { 1. Context } & 79\end{array}$

2. Key Gender Issues $\quad 79$

3. ADB's Knowledge Portfolio 80

4. Recommended Strategies for Mainstreaming Gender Equality 80 in Knowledge Building

$\begin{array}{lrl}\text { V. Conclusion } & 82\end{array}$

$\begin{array}{ll}\text { References } & 83\end{array}$

Appendix 1: Summary of Recommendations 89

Appendix 2: Agencies Participating in Key Informant Interviews 94 


\section{TABLES AND FIGURES}

\section{Tables}

1. Gender Gap Rankings by Region, $2016 \quad 6$

2. ADB's Portfolio in Micro, Small, and Medium-Sized Enterprise Development 45

3. ADB Countercyclical Support Project Description 50

4. ADB's Transport Portfolio 64

5. ADB's Energy Portfolio 75

\section{Figures}

1. Percentage of Women and Men by Sector of Employment 20

2. Percentage of Economically Active and Non-Active Population by Sex, 201522

3. Reasons to Migrate by Sex 24

4. Women and Men by Age Groups 26

5. Education Indicators by Sex, $2015 \quad 28$

6. Technical and Vocational Education Specialties of Female and Male Students 29

7. University Specializations by Female and Male Students 30

8. Reported Incidence of Violence against Women in Kazakhstan, 2015 


\section{Acknowledgments}

This Country Gender Assessment (CGA) was researched and written by Kathleen McLaughlin with assistance from Raushan Nauryzbayeva.

The CGA was prepared under an Asian Development Bank (ADB) regional technical assistance for Strengthening Gender-Inclusive Growth in Central and West Asia. The overall CGA process was supervised and managed by a team in the Central and West Asia Department (CWRD) comprising Mary Alice Rosero (social development specialist on gender and development); Ketevan Chkheidze (international implementation consultant/gender specialist based in the region); and Leavides G. Domingo-Cabarrubias (technical assistance gender coordinator). Maria Ava Golda Destura and Fritz Tadeo Tuliao helped the team navigate ADB's financial and logistical systems. We also acknowledge the important contributions of staff from ADB's Kazakhstan Resident Mission in Astana, particularly Aliya Ibadildina, external relations officer and resident mission gender focal point, who provided guidance on Kazakh issues, and organized informant and stakeholder meetings.

The Kazakhstan CGA could not have been produced without the full support of the CWRD management team: Giovanni Capannelli (Kazakhstan Resident Mission country director); Nianshan Zhang (advisor and head of the Portfolio, Results, Safeguards and Gender Unit); Hong Wei (deputy director general); Sean O'Sullivan (former director general); and Werner Liepach (director general).

The report benefited from valuable inputs of sector specialist peer reviewers from the different divisions: Meenakshi Ajmera (former senior social development specialist for safeguards, CWOD-PSG; currently principal safeguards specialist, SEOD); Gia Heeyoung Hong (principal urban development specialist for finance, CWRD); and Kristian Rosbach (economist for Regional Cooperation, CWRC). The SDTC-Gender team and Gender Equity Thematic Group (GETG), led by technical advisor on gender equity, Sonomi Tanaka, and GETG member Francesco Tornieri, principal social development specialist for gender and development, provided insightful comments.

The CGA team would like to convey appreciation and gratitude to the Government of Kazakhstan and the staff and representatives from the various ministries and government agencies-DAMU Entrepreneurship Development Fund, the Ministry of Agriculture, Ministry of Energy, Ministry of Finance, Ministry of Healthcare, Ministry for Investments and Development - Committee of Roads, Ministry of Labor and Social Protection, Ministry of National Economy, and the National Commission for Women's Affairs and Family and Demographic Policy-for participating in the interviews and shedding light on the policies and programs contributing to gender equality and women's empowerment in Kazakhstan. We are also grateful to our development partners, and civil society organizations, who provided fresh perspectives on the issues. Finally, we express our gratitude to the individual women in the communities, who shared their stories and insights on how ADB projects and other social interventions improved their lives. 


\section{Abbreviations}

$A D B$

CAREC

CEDAW

CGA

COR

CPS

CSO

DRR

EBRD

ECE

ECEC

GAP

GBV

GDP

GGGI

GII

KEEP

MDG

MSMES

NGO

OECD

PPP

SDG

SMES

UN Women

UNDP

UNICEF
Asian Development Bank

Central Asia Regional Economic Cooperation

Convention on the Elimination of All Forms of Discrimination against Women

country gender assessment

Committee of Roads

country partnership strategy

civil society organization

disaster risk reduction

European Bank for Reconstruction and Development

early childhood education

early childhood education and care

gender action plan

gender-based violence

gross domestic product

Global Gender Gap Index

Gender Inequality Index

Knowledge and Experience Exchange Program

Millennium Development Goal

micro, small, and medium-sized enterprises

nongovernment organization

Organisation for Economic Co-operation and Development

public-private partnership

Sustainable Development Goal

small and medium-sized enterprises

United Nations Entity for Gender Equality and the Empowerment of Women

United Nations Development Programme

United Nations Children's Fund 


\section{Executive Summary}

T

he purpose of the Kazakhstan Country Gender Assessment (CGA) is to develop a strategic focus for integrating gender concerns into programs and operations in Kazakhstan of the Asian Development Bank (ADB). This CGA updates the one conducted in 2013 and incorporates a review of ADB's experiences in implementing gender mainstreaming in its portfolio since that time. The assessment method has two main components: the first is a review of the status of gender equality and women's empowerment in the country, based on a literature review, key statistics, policy documents, and key informant interviews; and the second analyzes the achievements and challenges in mainstreaming gender equality in ADB's programs and operations, and recommends the way forward to improve outcomes.

Country Situation and Policy Environment. After gaining independence following the breakup of the Soviet Union in 1991, Kazakhstan restructured and grew its economy at an accelerated pace. The quality of life has improved drastically during the last 2 decades with rising incomes and decreasing unemployment. The series of economic shocks in the last decade revealed structural vulnerabilities that threaten sustainability and inclusive growth. These risks are present in sectors where women are concentrated, such as agriculture and services. Advancing equality of women and men, in keeping with the government's commitment to the United Nations' Sustainable Development Goal 5 on gender equality and women's economic empowerment, will require a more systemic and integrated approach in the political sphere as well as across key sectors in the economy and government investment programs.

Indicators on Gender and Development for Kazakhstan. Kazakhstan ranks high overall in key gender and development indicators, with a female Gender Development Index (GDI) of 0.795 , compared with 0.790 for men; this cumulative GDI of 1.006 places Kazakhstan in Group 1 , indicating high equality between women and men. Kazakhstan steadily reduced its Gender Inequality Index (GII) value from 0.405 in 2000 to 0.202 in 2015, bringing it lower than the 0.279 average for Europe and Central Asian countries. Despite its higher ranking for Central Asia and Caucasus, Kazakhstan is not continuing to narrow its gender gap. Low rankings on indexes from the World Economic Forum for political representation of women, women's labor force participation, and gender wage differences indicate how the country still needs to reduce gender gaps.

National Policies, Commitments, Institutions, and Statistics on Gender Equality. Kazakhstan has ratified key conventions such as the Convention on the Elimination of All Forms of Discrimination against Women (CEDAW) in 1998 and is reporting to the CEDAW Committee on its progress in line with international commitments. Kazakhstan has developed policy and legal frameworks-rights guarantees, legal provisions, national strategies, action plans, and programs - that are designed to advance gender quality as a national goal. The country's Constitution recognizes gender equality. Furthermore, Kazakhstan implemented a Strategy on 
Gender Equality from 2006 to 2016 and recently updated its policy framework for the next phase of planning: the Concept on Family and Gender Policy 2030. This policy reaffirms the government's focus on key gender gaps in women's political representation, labor force participation, career advancement, and work-family balance, as well as its commitment to combating violence against women.

The country's legal and policy framework enables women's empowerment and gender quality. At the same time, more attention is needed to ensure policies and laws are applied across various regions and sectors. Streamlining policy feedback from civil society and working toward continuous gender equality improvements are essential. The National Commission for Women's Affairs, Family and Demographic Policy is an advisory body to the President of the Republic of Kazakhstan that is tasked with the implementation and monitoring of the country's gender equality policies. Progress has been made in the collection and dissemination of sexdisaggregated statistics with a gender unit in the national statistics agency. However, most sector agencies and national programs still do not systematically include gender indicators, nor provide gender-specific information for the purposes of monitoring and evaluation.

Voice and Decision-making. Increasing women's political representation and ensuring their voice at senior levels of decision-making in the government at the national, regional, and local levels is key to advancing Kazakhstan's gender equality outcomes. In the 2016 elections, women's representation in the Majhilis (the lower house of the bicameral Parliament) was less than a third at $27 \%$, with 29 out of 107 seats filled by women, and representation in local bodies was even lower. Women, who comprise the majority of civil servants, are underrepresented at higherlevel decision-making positions. Women are a majority of those working in the judiciary, but face challenges in securing their legal rights. Cultural norms in Kazakhstan are generally positive toward gender equality, but women are less likely to be seen as political and business leaders and are more likely to be seen as having roles associated with the family. To further progress on gender equality, Kazakhstan has to ensure that all women, including those with disabilities and those who experience gender-based violence, can secure their rights. Women must also have more inputs into shaping how laws and policies address their priorities and needs.

Economic Empowerment. Kazakhstan has maintained a steady women's labor force participation rate that compares well with that of other countries, but the gap between male and female labor force participation and wages is not narrowing. To empower women, the country needs to break down educational and occupational stereotypes, promote women's career advancement to decision-making positions, and reduce wage gaps.

Reduced Time Poverty. Women are more likely than men to take time off for children, thus potentially limiting their career advancement. Women in Kazakhstan spend more time on domestic tasks than men, even though most are also economically active. The government has taken some actions to balance work and family life. At the same time, additional measures for both maternity and parental benefits and more educational programs to address gender stereotypes are needed to emphasize the shared role of women and men for childcare and domestic tasks.

Human Development and Reduced Vulnerability to Risks and Shocks. From 1990 to 2015, Kazakhstan increased its human development rating by $15 \%$ - evidence of its concerted efforts to reduce poverty and improve the social and economic well-being of its citizens. Generally, women and men have enjoyed the impacts of higher human development in Kazakhstan. However, progress in human development requires a deeper analysis of how human development issues affect men and women differently, as well as programs and policies that address these 
differences. For example, preventive health programs that consider the specific health risks and behavior change influences on women and men are critical to improved health. Improving social protection and health-care access in rural areas is also essential.

Mainstreaming Gender in Key Sectors. ADB has the potential to advance gender equality goals due to its strategic positioning in key economic and social sectors. Introducing more measures that specifically respond to the needs of existing women entrepreneurs in the small and mediumsized enterprise (SME) sector could further contribute to women's economic empowerment. Enhancing women's voice and economic activity in critical areas of infrastructure investmenttransport, irrigation, urban development, and energy-would greatly enhance their participation in development decisions that affect them. Such measures are necessary to ensure that women fully benefit from project interventions.

Finance: Micro, small, and medium-sized enterprises (MSMEs) are a key foundation of Kazakhstan's business sector and a core element of ADB's portfolio. ADB has contributed to increasing credit for women entrepreneurs. DAMU, the government agency responsible for MSME promotion, has steadily increased the share of women borrowers. Women entrepreneurs are now a third of those accessing ADB-financed concessional loans.

ADB's financing for MSME promotion through DAMU will continue under the new country partnership strategy. While DAMU has shown steady progress in increasing the share of women borrowers, the target could potentially be set even higher in light of their share as $42 \%$ of all SME owners. As women face more barriers to accessing commercial credit through banks, they are more in need of favorable loan conditions. Further advancing gender equality in future initiatives will also require more business development services geared to address the specific constraints that women face in starting and expanding their enterprises.

To weather a cycle of downturns since the 2008 economic crisis, ADB has provided the Government of Kazakhstan with credit lines to stabilize the banking sector and ensure continued lending to the private sector. This financing also supported several social objectives, including reduced unemployment, microcredit for rural women, and maintaining social transfer programs.

Countercyclical support contributes to the government's national budget priorities. This type of financing instrument is an effective way for ADB to influence state programs and empower women. However, indicators for countercyclical support need to target gender gaps. In addition, gathering more sex-disaggregated data on who is benefiting in what ways from state programs would allow for better targeting and monitoring of gender equality outcomes.

Agriculture: ADB's renewed financing to the agriculture sector in Kazakhstan creates new opportunities for contributing to gender equality given the importance of this sector to rural women's economic empowerment. Under past reform efforts, women were less likely to receive land. As a result, women are at a disadvantage in the sector. An in-depth gender analysis of agriculture is needed to assess how to ensure women can fully participate in a more dynamic agriculture economy.

Transport: ADB's transport projects are aligned with regional cooperation and national policies to transform the country into a regional economic hub. Consequently, the government and its development partners tend to view transport as gender-neutral in terms of improving the economy and bringing benefits to the whole population. However, due to their role differences in work and family life, women and men have differing transport needs. Women generally have 
more domestic tasks that require local travel, and are more likely to be pedestrians than to own a vehicle. Women are also more likely to use public transport. Investments in rural roads that link people in villages to the nearest markets and service centers benefit women.

Women are less likely to work in construction and transport. Women are also underrepresented in political and senior government positions involved in transport decisions. As a result, women's perspectives are often missed in transport investment planning and construction design. However, transport is key to enhancing women's economic participation and supporting them in accessing social services. Identifying ways to engage women in transport decisions is critical.

Health care: Kazakhstan is reaching its goals for improved maternal and infant health and has increased life expectancy for women and men over the last 10 years. However, the country's overall health indicators are low. The government has recognized the need for improving its health services, and has been introducing reforms through the Salamatty Kazakhstan 2011-2015 program and the Ministry of Health and Social Development's updated strategic plan for 20142018. The reforms emphasize restructuring health sector investments toward primary care, promoting healthy lifestyles, and reducing risk factors.

Because the factors affecting the health of women and men differ, the Government of Kazakhstan needs support to implement gender-responsive approaches to its health-care reforms.

Green growth: Kazakhstan's economy is highly energy-intensive and uses 2-3 times more energy than the average for the member countries of the Organisation for Economic Co-operation and Development. Kazakhstan has set targets to reduce its emissions and produce a green economy, and ADB has committed to assist with this goal. Kazakhstan has 100\% electricity rates, but access to the country's network of gas and district heating systems remains largely uneven between urban and rural households. As a result, many rural households still rely on coal, wood, and liquid petroleum gas for heating and cooking. At least $70 \%$ of the country's electricity comes from coal.

Many communities, particularly in rural areas, are affected by frequent outages, and these unstable services have a greater effect on women's workload. Women are more responsible for daily household tasks that depend on electric appliances and must source alternative fuels if heating systems fail. Efforts to promote green growth while ensuring energy access need to take into account the different impacts on women and men, and ensure women have a voice in decision-making in energy investments.

Urban infrastructure and services: Kazakhstan has an aging urban infrastructure, and improving services to the population, in both urban and rural areas, is a priority as the country reaches middle-income status. Women are more affected by poor municipal infrastructure or disruptions in public utilities such as water, sanitation, and electricity. Women are underrepresented in local and regional bodies and so have less opportunity to provide inputs into municipal planning priorities. Incorporating gender concerns in urban infrastructure and services not only improves living conditions, but also addresses women's time poverty and enables more livelihood activities. Municipal officials are taking on more decentralized responsibility and need guidelines on genderresponsive urban planning. 
Knowledge building: ADB is supporting Kazakhstan to become a regional knowledge hub on inclusive economic growth. Building synergy between ADB's support to both regional knowledge hub initiatives and strengthening gender-inclusive growth could catalyze gender-equality objectives in Kazakhstan and in the region. Such initiatives could include improving capacity in government, academic institutions, and civil society for undertaking gender-related research and analysis in $\mathrm{ADB}$ programming sectors.

Conclusion. With more than a decade of experience implementing a comprehensive gender equality strategy and a renewed policy addressing gender issued in 2017, Kazakhstan has shown a continued commitment to advancing gender equality. As Kazakhstan continues on its path to reach a high economic development status, efforts to remove barriers to women's full economic, social, and political participation will need to deepen. Kazakhstan is at a pivotal stage in setting its future directions and further integrating gender equality across its laws, policies, and programs will be key to achieving its overall socioeconomic development goals. 


\section{Introduction}

\section{A. Purpose of the Country Gender Assessment}

In 2017, the Asian Development Bank (ADB) updated its 5-year country partnership strategy (CPS) with the Republic of Kazakhstan. The updated CPS aims to assist Kazakhstan to achieve its medium-term development targets and fulfill its global obligations under the Sustainable Development Goals (SDGs) agenda. The focus is on three main pillars: (i) economic diversification and private sector development to lessen the country's dependency on commodity exports; (ii) improved public services, strengthened governance institutions, and construction of infrastructure to reduce structural inequalities; and (iii) promotion of more sustainable growth in line with the country's greenhouse gas mitigation targets and commitments to improve resilience to climate change. In both ADB's policies and Kazakhstan's development agenda, gender equality is to be mainstreamed into each of these programming pillars.

ADB has a plan for women's empowerment that sets forth its strategy for achieving gender equality outcomes across its country partnerships by 2020.' Under this plan, the country gender assessment (CGA) considers the extent to which women and men enjoy the same rights and opportunities to contribute to and benefit from national, political, economic, social, and cultural development. ADB's concept of gender equality acknowledges that women and men may require different treatment to achieve similar results due to differences in life conditions or sociocultural and economic circumstances. The analysis also considers the extent of women's political, social, and economic empowerment, which pertains to women's sense of self-worth, and their right to determine choices, access opportunities and resources, and control their own lives, as well as the ability to influence social change.

The Kazakhstan CGA is being undertaken to update ADB's knowledge of the key gender equality issues and develop a strategy for integrating gender concerns into its programs and operations. The primary purpose of this CGA is to enhance the strategies outlined in the CPS by incorporating analysis on the effects of development initiatives on women and men and recommending measures to promote gender equality in ADB's sectors of intervention.

ADB completed a CGA in 2013 as part of the previous CPS. This 2018 Kazakhstan CGA provides recent information on the progress of gender equality in the country, and reviews ADB's experience in promoting gender equality during the past 4 years. This assessment also includes a gender analysis of new areas of programming proposed under the Kazakhstan CPS 2017-2021 and examines the potential entry points for ADB to intervene in the future to advance gender equality outcomes in Kazakhstan.

ADB. 2013. Gender Equality and Women's Empowerment Operational Plan 2013-2020: Moving the Agenda Forward in Asia and the Pacific. Manila. 


\section{B. Assessment Methodology}

This assessment gathered data and reviewed literature and analytical information from several sources to identify the policy and socioeconomic development issues of concern to ADB's portfolio. In addition, updated statistics, studies, and reports from diverse sectors from national and international sources were reviewed. The types of information consulted included

(i) national demographic, socioeconomic, and human development statistics for the country overall and for each ADB sector;

(ii) international and regional comparative statistics and indexes on gender equality and women's empowerment;

(iii) documents on laws, policies, strategies and programs relevant to gender equality issues and to ADB's sector of operations; and

(iv) research studies, surveys, best practices, case studies, and lessons learned on gender equality on a national and sectorial basis.

ADB's country program was analyzed through review of project documents and discussions with team members in country. The project documents included gender action plans, and gender and development monitoring reports from ongoing and completed ADB-financed projects. The purpose of reviewing ADB projects in Kazakhstan was to assess

(i) key gender issues identified at the design and planning stage,

(ii) how identified gender issues were translated into measures for gender integration,

(iii) any gaps in identification of relevant gender issues at the design and planning stage,

(iv) successes and challenges in implementation of gender equality measures and gender action plans,

(v) contribution of the gender action plan to strengthening overall project results;

(vi) trends and emerging opportunities and constraints on addressing gender equality in each sector, and

(vii) recommendations to improve gender mainstreaming in existing or new/planned projects in the future.

Key informant interviews with government stakeholders, ADB staff, civil society groups, development partners, and medical practitioners were conducted as part of the assessment. The list of agencies contacted to conduct key informant interviews is presented in Appendix 2. A select number of national government representatives were interviewed to discuss the opportunities and constraints identified under national programs and initiatives and to recommend gender equality entry points and measures for ADB's sectors of intervention. In addition, key representatives from agencies responsible for women's rights and mainstreaming gender equality nationally were interviewed. 
Key informant interviews were also conducted with other major development partners and civil society organizations (CSOs) in Kazakhstan. Representatives from development partners interviewed included those agencies also providing significant financing in ADB's sectors of operation, as well as agencies identified as having experience in promoting gender equality in these sectors. The CSOs interviewed were mainly those addressing gender equality issues. Perspectives from women, in particular women entrepreneurs benefiting from ADB programs, were gathered though surveys conducted in person or by telephone.

The CGA first assesses the status of gender equality and women's empowerment in the country based on literature review, key statistics, policy documents, and key informant interviews in country. The analysis involves review of relevant policies, laws, institutions, and practices in Kazakhstan that affect women's inclusion, equality, and empowerment in ADB's operations. Secondly, the CGA reviews ADB's portfolio in Kazakhstan to identify achievements and challenges in mainstreaming gender equality. This analysis reviews the experiences and lessons learned for integrating gender equality since the 2013 CGA, in particular regarding private sector development and access to finance and improving the transport network. 


\section{Background and Context}

\section{A. Country Situation}

After gaining independence following the breakup of the Soviet Union in 1991, Kazakhstan restructured and grew its economy at an accelerated pace, aided by high oil exports. As a result, Kazakhstan has emerged as an important economic and political power in Central Asia with per capita incomes approaching high-income levels.

On its growth trajectory, Kazakhstan oriented its economic policies to an inclusive economy, including allocating resources to poverty reduction and social protection. Even before 2015, Kazakhstan achieved most of its Millennium Development Goals (MDGs), including those related to poverty reduction, access to primary education, and improvement in children's and maternal health. ${ }^{2}$ The Human Development Index ranks Kazakhstan as one of the highest in the region-at rank 56 in 2015-14 ranks higher than the year before. ${ }^{3}$ Inequality remained at low levels due to the social transfers and subsidized public services in rural areas. Poverty declined throughout the country from $46.7 \%$ in 2001 to $2.7 \%$ in $2015 .{ }^{4}$ While low overall, the poverty rate is slightly higher for women at just above $2.7 \%$ compared with $2.6 \%$ for men. ${ }^{5}$

Kazakhstan has maintained a policy orientation to value and promotes gender equality as it transitions from its status as a Soviet planned economy. Policies to promote women's labor force participation, in particular to ensure a role for women in the growing micro, small, and mediumsized enterprise (MSME) sector, contribute to the country's economic success. ${ }^{6}$ Kazakhstan's relative successes in sustaining steady economic growth, reducing poverty, and meeting its MDG targets have positively impacted the well-being and economic situation of both women and men. Overall, the progress in development has been accompanied by a reduction in gender inequality (footnote 6).

While growth has been generally inclusive, a series of economic shocks-the Global Financial Crisis in 2008, the oil price drop in 2014, and the currency depreciation in 2015-revealed structural vulnerabilities. Continuing to social protection programs, including those for families, people with disabilities, and households headed by women, will require ensuring that such programs are targeting those most in need. ${ }^{7}$ Women are currently concentrated in the service

\footnotetext{
2 United Nations Development Programme (UNDP). 2010. Millennium Development Goals in Kazakhstan. Astana.

3 UNDP. 2016. Human Development Report: Human Development Index. New York. http://hdr.undp.org/en/data.

4 World Bank. 2016. Poverty and Equity. Country Dashboard: Kazakhstan. Washington, DC. http://povertydata.worldbank. org/poverty/country/KAZ.

5 R. Sarsembayeva. 2017. Implementation of the Strategy for Gender Equality in the Republic of Kazakhstan 2006-2016: The Sociological Analysis. Astana.

6 OECD. 2017. Review of Gender Policy Delivery in Kazakhstan. Paris.

7 ADB. 2017. Kazakhstan Country Partnership Strategy 2017-2021. Manila.
} 
sector, which has more part-time and temporary positions and is more affected by economic fluctuations. As a result, women are exposed to more economic shocks and unemployment than men.

Kazakhstan also struggles to balance disparities between the few centers and a vast periphery because of its large territory. According to Kazakhstan's National Human Development Report 2016, the high levels of inequality between regions creates challenges for achieving gender equality and empowerment for girls and women (SDG 5). Regional disparities are also a constraint to Kazakhstan achieving other SDGs, such as ensuring healthy lives and promoting well-being at all ages (SDG 3), inclusive and quality education (SDG 4), inclusive and sustainable economic growth (SDG 8), and resilient infrastructure and sustainable industrialization (SDG 9). ${ }^{8}$

Although Kazakhstan has a higher level of urbanization compared to other Central Asian countries, only half of the population is living in the 59 defined cities, oblast centers, and other urban settlements. In addition, the Soviet era has left the country with single-industry cities, infrastructure geared toward the transport of commodities to the Russian Federation, and uncompetitive state-owned enterprises. Kazakhstan has urban and rural infrastructure that dates back to Soviet times and is badly in need of improvements. Pollution increasingly limits the quality of life in Kazakhstan, especially in the cities. These challenges concern both genders. However, women have greater responsibility for household tasks and ensuring family health along with their economic role and so are particularly concerned by the quality of public utilities and municipal services.

Kazakhstan has developed a long-term plan, outlined in its Strategy 2050, ${ }^{9}$ to join the 30 most developed countries within 30 years. By 2050, it is projected to reach an urbanization rate of $70 \% .{ }^{10}$ To reach its goal of more rapid development, Kazakhstan is diversifying its economic base away from an overreliance on extractive industries toward a more robust small and medium-sized enterprise (SME) sector and becoming a hub of regional economic corridors. The potential to advance gender equality through this orientation exists to the extent that measures for promoting women's labor force participation, pay equity, social protection, reduction in regional disparities, and assistance to vulnerable and marginalized groups are integrated into future economic and social development strategies.

\section{B. Indicators on Gender and Development}

Kazakhstan is progressing toward gender equality according to international indicators used to measure and compare results across countries. TheGender Development Index (GDI) of the United Nation's Development Programme (UNDP) shows the male-female achievement ratio regarding the three Human Development Index (HDI) dimensions: health (measured by female and male life expectancy at birth); education (measured by female and male expected years of schooling for children and mean years for adults aged 25 years and older); and command over economic resources (measured by female and male estimated gross national income [GNI] per capita). According to the 2016 Human Development Report, Kazakhstan has a female GDI

\footnotetext{
8 Whiteshield Partners. 2016. Sustainable Development Goals and Capability-based Development in Regions of Kazakhstan: National Human Development Report. UNDP: Astana.

9 Republic of Kazakhstan. 2015. Strategy 2050. Astana.

10 OECD. 2017. Urban Policy Reviews: Kazakhstan. Paris.
} 
of 0.795 compared with 0.790 for men, resulting in a GDI value of 1.006. This rating places Kazakhstan in Group 1, indicating high equality in HDI achievements between women and men. ${ }^{11}$

The Gender Inequality Index (GII), ${ }^{12}$ developed by UNDP, measures the extent to which inequality is detracting from national development achievements. The measure is based on five indicators: maternal mortality ratio, adolescent fertility rate, seats in the national Parliament, population with at least secondary education, and labor force participation. The higher the Gll value, the greater the discrimination. Kazakhstan has steadily reduced its GII value from 0.405 in 2000 to 0.202 in 2015, bringing it lower than the 0.279 average for Europe and Central Asian countries (footnote 3). The Gll data show that Kazakhstan is particularly strong in education, with $99.7 \%$ of adult women having reached at least a secondary level of education compared with $100 \%$ of their male counterparts. The country also succeeded in reducing its maternal mortality from 65 for every 100,000 live births in 2000 to 12 by 2015 . Kazakhstan has lower indicators for other key dimensions of gender equality measured by UNDP. Kazakhstan has only $20.1 \%$ of parliamentary seats held by women, and female participation in the labor market is at $66.1 \%$ compared with $77 \%$ for men. Kazakhstan's overall GII ranking is 42 out of 159 countries (footnote 11).

Table 1: Gender Gap Rankings by Region, 2016

Eastern Europe and Central Asia

\begin{tabular}{c|c|c|c}
\hline & Country & Overall Rank & Overall Score \\
\hline 1 & Slovenia & 7 & 0.805 \\
\hline 2 & Bulgaria & 18 & 0.756 \\
\hline 3 & Latvia & 20 & 0.756 \\
\hline 4 & Belarus & 26 & 0.744 \\
\hline 5 & Lithuania & 28 & 0.742 \\
\hline 6 & Moldova & 30 & 0.740 \\
\hline 7 & Estonia & 37 & 0.731 \\
\hline 8 & Albania & 38 & 0.728 \\
\hline 9 & Poland & 39 & 0.728 \\
\hline 10 & Serbia & 40 & 0.727 \\
\hline 11 & Kazakhstan & 52 & 0.713 \\
\hline 12 & Croatia & 54 & 0.711 \\
\hline 13 & Romania & 58 & 0.708 \\
\hline 14 & Ukraine & 61 & 0.705 \\
\hline 15 & Bosnia and Herzegovina & 66 & 0.702 \\
\hline 16 & Macedonia, FYR & & 0.702 \\
\hline & & & continued on next page \\
\hline
\end{tabular}

1 UNDP. 2016. Human Development Report: Kazakhstan Country Profile. New York. http://hdr.undp.org/en/data.

12 UNDP. 2016. Human Development Reports: Gender Inequality Index. New York. http://hdr.undp.org/en/content/genderinequality-index-gii. 


\begin{tabular}{l|c|c|c}
\multicolumn{2}{l}{ Table 1 continued } \\
\hline & Country & Overall Rank & Overall Score \\
\hline 17 & Russian Federation & 71 & 0.696 \\
\hline 18 & Slovak Republic & 74 & 0.694 \\
\hline 19 & Montenegro & 77 & 0.693 \\
\hline 20 & Kyrgyz Republic & 85 & 0.691 \\
\hline 21 & Czech Republic & 88 & 0.688 \\
\hline 22 & Georgia & 94 & 0.679 \\
\hline 23 & Tajikistan & 95 & 0.678 \\
\hline 24 & Armenia & 97 & 0.677 \\
\hline 25 & Azerbaijan & 98 & 0.676 \\
\hline 26 & Hungary & 103 & 0.670 \\
\hline & & & \\
\hline
\end{tabular}

FYR $=$ Former Yugoslav Republic.

Source: World Economic Forum. 2017. The Global Gender Gap Report. Geneva.

The Global Gender Gap Index (GGGI), devised by the World Economic Forum, is another cross-country comparison of gender equality. ${ }^{13}$ It measures gender-based gaps in resources and opportunities independently from a country's level of development. The GGGI takes into consideration four basic categories: economic participation and opportunity, educational attainment, health and survival, and political empowerment. Compared to other countries in Central Asia, Kazakhstan is a positive example of progress in the region (Table 1). In 2017, Kazakhstan received a score of 0.713 , resulting in a ranking of 52 out of 144 countries and 11 out of 26 countries in Eastern Europe and Central Asia (footnote 13).

Despite its higher ranking for Eastern Europe and Central Asia, Kazakhstan is not showing signs of continuing to narrow its gender gap over time. In 2006, Kazakhstan had a GGGI score of 0.693 (only slightly lower than that in 2016) and was already ranked 32 out of 115 countries. Compared to other countries in Eastern Europe and Central Asia, Kazakhstan has moved down one rank, from 10th to 11th place, since last year's GGGI report (footnote 13).

National scores by subindex reveal where the gender gap is most acute. As with UNDP rankings, the GGGI scores for educational attainment and for health and survival are high. Low scores are evident for economic participation and opportunity and for political empowerment. Kazakhstan's scores for economic participation and political empowerment have remained consistently lower than those for the other two dimensions since 2006.

Another international comparison of gender equality is the Social Institutions and Gender Index (SIGI), which assesses gender-based discrimination in social norms, practices, and laws across 160 countries. The SIGI covers five dimensions: (i) discriminatory family code, (ii) restricted physical integrity, (iii) son bias, (iv) restricted resources and assets, and (v) restricted civil liberties. Kazakhstan falls in Group 2 in the SIGI, which means that it has low levels of discrimination (Group 1 indicates very low levels of discrimination). ${ }^{14}$

13 World Economic Forum. 2017. The Global Gender Gap Report. Geneva.

14 OECD. 2016. Social Institutions and Gender Index: Regional Report Europe and Central Asia. Paris. 
This rating shows again that Kazakhstan leads in addressing factors related to gender inequality compared to other Central Asian countries, but still needs to reduce gaps in key areas. In particular, Kazakhstan ranks lower in the subindexes for Restricted resources and assets that measure property, economic opportunity, equal wages, and other factors where it is in the medium ranking. The country ranks high for restricted civil liberties due to women's lower representation in the political sphere and some evidence of restrictions on women's mobility and access to work outside the home in some rural areas (footnote 14).

These international comparisons show that Kazakhstan's efforts to mainstream gender equality across various spheres are yielding results. At the same time, continued progress will require more strategic and targeted efforts to identify and address remaining barriers, systemic discrimination, and gender gaps that may be more challenging to first identify and then remove, particularly in the economic and political sphere.

\section{National Policies and International Commitments on Gender Equality}

Kazakhstan has shown a commitment to advancing gender equality and to engaging with the international community to demonstrate its progress. Kazakhstan endorsed the Beijing Platform of Action (1995), ratified the Convention on the Elimination of All Forms of Discrimination against Women (CEDAW) in 1998, and ratified the CEDAW Optional Protocol in 2001. The Government of Kazakhstan presented its initial report to CEDAW in 2002, and reported again in 2007 and 2014..$^{15}$ In 2016, the government pledged to uphold the Beijing Platform of Action at the UN Global Leaders' Meeting on Gender Equality and Women's Empowerment and at CEDAW. ${ }^{16}$ The government also recently participated in Review of Gender Policy Delivery of the Organisation for Economic Co-operation and Development (OECD) (footnote 6).

In line with its commitments, Kazakhstan has developed policy and legal frameworks that are designed to advance gender equality as a national goal. As explained in the following section, the frameworks enable continued advancement of women's empowerment and gender quality. At the same time, more attention to how policies and laws are applied across various regions and different sectors of activity is essential for further gender equality. Mechanisms for policy feedback and improvement also need to be developed.

\section{Legal Foundations for Gender Equality}

The Constitution of the Republic of Kazakhstan recognizes gender equality through a clause that prohibits discrimination based on sex. The Constitution proclaims that "everyone shall be equal before the law and court" and specifies that "no one shall be subjected to discrimination on grounds of origin, social and property status, sex, race and nationality, language, religion, creed, place of residence or any other circumstance." ${ }^{\prime 7}$ In addition, Kazakhstan's Criminal Code states that "violating the equality of citizens," including on the basis of sex, is a criminal offense. The country's National Human Rights Action Plan, initiated for 2009-2012, and again for

15 United Nations. Committee on the Elimination of Discrimination against Women. 2014. Concluding observations on the combined third and fourth periodic reports of Kazakhstan (CEDAW/C/KAZ/CO/3-4) 10 March.

16 Republic of Kazakhstan. 2016. Statement by the Republic of Kazakhstan on the Agenda item 27 "Advancement of Women," Third Committee, 71st session of the UN General Assembly, 11 October.

17 Government of Kazakhstan. 1995. Constitution of the Republic of Kazakhstan. Almaty. Article 14, part 2. 
2017-2020, also identifies the need to address gender equality in the labor market, in pension security reform to meet the needs of elderly women, in addressing domestic violence, in preventing human trafficking, and in increasing women's participation in elected positions and in senior levels of government. ${ }^{18}$

In 2009, the government enacted a Law on State Guarantees of Equal Rights and Equal Opportunities of Men and Women that established the legal principle of equal rights. This law defines basic concepts of gender discrimination and reiterates state guarantees in several spheres, including the civil service, the labor market, health care, education, and the family. The law also affirms that all state agencies are responsible for implementing gender policies. Kazakhstan has also taken steps to mainstream gender into the legislative process. ${ }^{19}$

While the country's constitutional and human rights provisions guarantee equality, implementation gaps exist. For example, the Constitution itself does not lay out the means by which women-and other groups-may invoke their rights, thus limiting application of the provisions (footnote 18). The government has approved a plan that requires a gender analysis of legislative and normative acts. This step should involve consulting with gender experts regarding new laws to analyze their differing impacts on women and men. The reviewers would then recommend revisions to any provisions that could result in gender discrimination. However, the lack of gender expertise among core legal staff who draft legislation in various sectors has hampered this initiative. ${ }^{20}$

\section{Policies on Gender Equality}

The Government of Kazakhstan has made efforts to advance gender equality objectives in political, economic, and social spheres through enacting strategies and action plans. In 2005, the President approved a Gender Equality Strategy for 2006-2016. The strategy articulated overarching objectives related to gender equality to transform the current paradigm in which one sex is dominant to one in which there is "partnership and cooperation between both sexes." The strategy also called for measures to ensure women could "participate equally in all processes of social development, realizing their personal and human potential." The strategy defined seven areas for strengthening gender equality: the political and public sphere, the economy, gender education, reproductive health, gender-based violence prevention, the family, and public awareness. Specific goals, strategic objectives, and indicators for monitoring were defined for each of these areas. ${ }^{21}$

The government later adopted a series of plans to implement the Gender Equality Strategy covering 2006-2008, 2009-2011, and 2012-2016. The plan for 2012-2016 consisted of nine chapters, including addressing the following:

- Strategy rationale

- Gender equality in the public and political sphere

- Gender equality in the economy

18 International Commission of Jurists. 2013. Women's Access to Justice in Kazakhstan: Identifying the Obstacles \& Need for Change. Geneva.

19 Asian Development Bank. 2013. Kazakhstan Country Gender Assessment. Manila.

20 A. llyasova. 2016. Assessment Report Strategy for Gender Equality of the Republic of Kazakhstan 2006-2016. Astana.

21 Order of the President of the Republic of Kazakhstan dated as of 29.11.2005: Strategy on Gender Equality for 20062016. Astana. 
- Gender education

- Improving reproductive health of men and women

- Prevention of gender-based violence

- Strengthening of the family

- Raising public awareness of gender equality through media

- Expected results and monitoring of the strategy (footnote 21).

The strategy also outlined the institutional mechanisms needed to enable equal rights and equal opportunities for men and women, calling for gender mainstreaming across various sectors. The action plan called for gender to be integrated into the country's strategic development plans at the oblast (region) level, into the formation of national and local budgets, and into national statistics gathering. The plan had specific goals relevant to women's entrepreneurship and microfinance for women in rural areas (footnote 6).

From its inception, the strategy had a few weaknesses: it did not specify the intragovernmental mechanism to implement mainstreaming and lacked budgets and accountabilities for assuring sector ministries addressed gender issues in their policies and programs. Also, missions are monitoring systems to follow progress on sector integration. While women's political and economic empowerment is a recurring subject in the strategy, the document frequently linked their role to motherhood, family, and demographic policies.

In 2016, the National Commission for Women's Affairs, Family and Demographic Policy engaged the researcher A. llyasova to undertake an independent evaluation of implementation of the Gender Equality Strategy 2006-2016 (footnote 21). In addition, the researcher R. Sarsembayeva, president of the Association of Business Women of Kazakhstan, undertook a sociological analysis of the results of the Gender Equality Strategy 2006-2016. ${ }^{22}$ Both researchers determined that overall progress was made in key areas of gender equality during the strategy's 10-year period. Achievements included gender parity in primary and secondary education, improving maternal health, maintaining women's labor force participation, increasing representation of women as business owners, raising the level of women's representation in national and local political bodies, and projecting more messages to challenge stereotypes and promote gender equality values through the media.

The researchers note that many changes targeted under the strategy need further attention. The sociological analysis by Sarsembayeva highlights that while women's level of representation in national and local bodies rose in this period, it remains well below that of men (footnote 22). The full range of reproductive health services, particularly for family planning, are not yet adequate in all areas of the country, and more measures are needed to promote a work-family balance for women and men (footnote 22).

Ilyasova's evaluation points to an overemphasis on quantitative indicators to measure gender equality during the implementation period (footnote 20). Indicators, such as gender wage gaps and labor force participation of women and men, were tracked at the beginning and end of the strategy. During implementation, no monitoring was in place. As a result, limited analysis is available on the causal connection between the status of indicators and gender equality, thus obscuring which actions did or did not work. In addition, targets set in the action plans were based on realities in Astana and Almaty and did not take into account regional differences. While oblast-

22 R. Sarsembayeva. 2017. Implementation of the Strategy for Gender Equality in the Republic of Kazakhstan 2006-2016: The Sociological Analysis. Astana. 
level governments were mandated to implement the plan, no process to adapt the strategy to each regional context was undertaken (footnote 20 ).

Some actions were initiated by the Ministry of Education and Science to integrate gender education into the formal school system, as outlined in the Gender Equality Strategy 2006-2016. However, by the end of the strategy's 10-year period, no official changes had been made to school textbooks to update knowledge on gender and to address stereotypes through the curriculum. Progress was made in increasing reporting of gender-based violence (GBV), but the availability of more trained support services is still underdeveloped (footnote 20).

According to the OECD Review of Gender Policy Delivery in Kazakhstan, governmental awareness of gender increased during the 10-year Gender Equality Strategy implementation period. Nonetheless, gaps exist at the level of legal and policy expertise required to integrate gender into laws and policies, especially at the regional level. For example, the concept of gender budgeting was introduced, but without training programs regarding what it entails or how to implement it in a decentralized system (footnote 6).

These analyses provide useful insights into how to improve key areas of gender equality policy in Kazakhstan. The next phase of planning the Concept on Family and Gender Policy 2030 continues to address key gender gaps. The stated goal of this policy is "the equality of rights, benefits, responsibilities, and opportunities for men and women in all areas of social life, and elimination of all forms and occurrences of discrimination by gender."23 This goal is to be achieved through a mix of measures including

- strengthening gender equality through state regulation and introduction of the gender evaluation in the system of state and budget planning,

- ensuring the equal access of men and women to all kinds of resources necessary for entrepreneurial activity,

- creating conditions for equal employment of men and women,

- preventing violence against women,

- promoting awareness on gender issues, and

- broadening women's participation in ensuring peace and security.

The new strategy identifies the need to do much more to improve women's political representation. The document aspires to narrow the gap in women's representation at senior government levels. The policy concept targets a 30\% representation of women at the decision-making level in the executive, legislative, and judicial branches of government, as well as in the public, quasigovernmental, and corporate sectors. The policy concept commits to gender budgeting and gender-sensitive public planning and establishes coordination mechanisms at the central and local government levels to mainstream gender equality into government policies and programs. Another goal is decreasing the gap between average salaries of men and women (footnote 23).

However, this new guiding policy on gender and family does not detail what the improved crossgovernment coordination will mean in practice. The setting of political and economic objectives follows a similar pattern to the last strategy where targets are set, but measures to create the underlying conditions to meet these, such as budget allocations or having more trained gender resources at the regional and sector levels, are not addressed.

${ }^{23}$ Republic of Kazakhstan. National Committee for Women's Affairs, Family and Demographic Policy. 2017. Concept of Family and Gender 2030. Astana. 
In addition, unlike the previous Gender Equality Strategy 2006-2016, the new policy concept combines gender equality and family portfolios rather than establishing a stand-alone gender equality strategy in Kazakhstan. The goals and activities for gender equality and for family are outlined in separate sections so that the directions and progress on each can be assessed separately. The rationale for combining the two issues is explained in the document: "Kazakhstan's approach creates an environment for expanding opportunities for the development of families and for overcoming difficult life situations by families." (footnote 23). This approach does recognize that addressing gender relations in the family is an important foundation for achieving gender equality in other spheres of activity. However, the combination of the two issues reinforces the message that gender equality is about strengthening families as opposed to being about women's rights and ensuring equality between women and men in all spheres.

The OECD review of gender equality policies in Kazakhstan noted that the continued government commitment to an overarching framework document was a positive trend. The new policy created an environment conducive to mainstreaming gender equality in various spheres of political, economic, and social activity (footnote 6). At the same time, the review team noted that gaps in implementation remain.

\section{Institutions and Mandates}

The National Commission for Women's Affairs and Family was created by a presidential decree in 1998 in conjunction with the development of the National Action Plan on Improving the Status of Women for the purposes of further implementing the Beijing Platform for Action.

In 2008, the Commission was restructured and renamed the National Commission for Women's Affairs, Family and Demographic Policy. It is an advisory body to the President of the Republic of Kazakhstan with the secretariat located under the administration of the presidency. The National Commission defines gender policy for the Republic of Kazakhstan, recommends priorities for state programs to promote equality between women and men, and works with all state structures to mainstream gender equality. When it was formed, the Commission was tasked with the implementation and monitoring of the Gender Equality Strategy 2006-2016. Currently, the National Commission is responsible for implementing the Concept on Family and Gender Policy of the Republic of Kazakhstan for 2030. The National Commission has an Expert Council consisting of nongovernment organizations (NGOs) and representatives from the academic sphere (footnote 19). It regularly partners with state agencies, as well as with NGOs and international organizations, to implement specific initiatives under its mandate.

The CEDAW Committee noted that, in reporting to the President, the Commission was strategically placed. At the same time, the CEDAW Committee expressed concern that the Commission lacked sufficient authority and financial and human resources to fully implement the Convention (footnote 15). This situation has not changed since the CEDAW review. Up to now, the National Commission has only three staff in its Secretariat to lead implementation.

The OECD Gender Policy Review highlighted the importance of reinforcing the Secretariat to ensure it has the required staff with competence in policy analysis, advocacy, communication, and monitoring to implement gender initiatives. These abilities are essential to the Secretariat to achieve the SDG for gender equality and women's empowerment by 2030 , in particular the target to adopt and strengthen sound policies and enforceable legislation at all levels for the promotion of gender equality and the empowerment of women and girls (footnote 6). 
Other key institutions that play a role in gender equality include the Commissioner for Human Rights and the Human Rights Commission under the President, both of which work jointly with the National Commission for Women's Affairs, Family and Demographic Policy. In 2008, a permanent Commission on Family Policy and Gender Equality was established within the Social Council of the majority party in Parliament, Nur Otan (the People's Democratic Party) that reviews legislation and budgets for gender-equality initiatives (footnote 19).

A gender focal point also exists in each ministry responsible for implementing gender policy. In addition to the National Commission, all regions in Kazakhstan, as well as the cities of Astana and Almaty, have regional commissions placed under the office of the akim (head of the local executive branch). The Academy of Public Administration under the President is mandated to implement the training of civil servants on the issues of family, demographic, and gender policies, and gender budgeting (footnote 19).

The gender equality strategy calls for each ministry to identify key persons to be responsible for the formation and implementation of gender policy in their sphere of activity. ${ }^{24}$ While officially the ministries have done so, it is not always possible to identify a gender focal person who is actively addressing mainstreaming in their ministry. The gender focal points frequently change positions, and government counterparts interviewed for this assessment were not able to identify whether they currently had such personnel in their ministry. At the oblast level, the structure of the Commission also includes regional commissions. However, the awareness and training on equality issues across gender focal points and across the regions is uneven (footnote 22).

The OECD recommends that the government "consider supporting a whole-of-government approach by regularly bringing together representatives from across ministries who also serve as gender focal points in their respective entities. Gender units may form an inter-agency network and can regularly participate in the work of the National Commission for Women's Affairs, Family and Demographic Policy to discuss documents to be adopted at the inter-agency level." (footnote 6). The National Commission and development partners concerned with gender equality need to make greater efforts to identify and engage more directly with these staff members to institute gender policy initiatives outlined in the strategy in each sector.

\section{E. Collection of Gender Statistics}

Kazakhstan has made important progress in the collection and dissemination of sex-disaggregated statistics and is the only country in Central Asia to have a specialized division managing gender statistics and indicators. This unit, located within the Department of Social and Demographic Statistics in the Committee on Statistics, publishes Women and Men in Kazakhstan, an annual compilation of sex-disaggregated data across several sectors that is available in Kazakh, Russian, and English (footnote 29). Despite this achievement, the gender equality strategy highlights that reliable sex-disaggregated data remains insufficient to fully monitor progress on gender equality across all sectors. The sharing of gender-sensitive information and data are not well coordinated among government agencies, and not all data are made available to the public (footnote 19).

The Republic of Kazakhstan's Committee on Statistics, the United Nations Children's Fund (UNICEF), and the United Nations Population Fund (UNFPA) completed the fourth Multiple Indicator Cluster Survey (MICS) in December 2016 to better assess and monitor the situation

${ }^{24}$ Government of Kazakhstan. 2006. Strategy on Gender Equality 2006-2016. Astana. 
of women and children in the country. ${ }^{25}$ This initiative includes data on access to water and sanitation, education, child health, reproductive health, and child protection, and provides data to benchmark the situation of women and children for cross-country comparisons. However, the MICS is based on a survey of women respondents, and is not intended for the purpose of comparing the situation of women and men that is needed for a full gender analysis of national progress on gender equality.

Most national programs do not systematically include gender indicators or provide genderspecific information for the purposes of monitoring and evaluation. Exceptions include the report on the state of SMEs produced by the DAMU Entrepreneurship Fund. ${ }^{26}$ The main economic indicators covering employment trends are reported with some level of gender disaggregation. ${ }^{27}$ However, the data that are provided only list figures without providing qualitative analysis to uncover the reasons for gender imbalances and how to address them more effectively.

25 UNICEF. 2016. Multi Indicator Cluster Survey. Astana.

26 DAMU Entrepreneurship Development Fund. 2016. Report on the State of Development of Small and Medium Enterprises in Kazakhstan and its Regions. Almaty.

27 Republic of Kazakhstan, Ministry of National Economy, Committee on Statistics. 2016. Kazakhstan in 2015. Astana. www.stat.gov.kz. 


\section{Cross-Cutting Gender Issues}

\section{A. Voice and Decision-Making}

\section{Women's Representation in Public Life}

Parliament and political bodies. While Kazakhstan has made progress overall on gender equality, it still has a way to go to achieve the SDG 5 target of ensuring women's full and effective participation in, and equal opportunities for leadership at all levels of, decision-making in political, economic, and public life (footnote 6). In particular, further steps are needed to continue to increase women's political representation and ensuring their voice at senior levels of decisionmaking in the government at the national, regional, and local levels. In the 2016 elections, women's representation in the lower house of the bicameral Parliament (the Majhilis) was 27\%, with 29 out of 107 seats filled by women. ${ }^{28}$ The figure shows an increase in lower house representation from 2006 when women made up only $10.4 \%$ of this body. However, for the upper house or Senate, the representation remains low at five out of 47 seats (10.6\%) (footnote 40). Overall, women represent $22 \%$ of parliamentarians (footnote 28 ). At the ministerial level, women held only $13 \%$ of positions in 2016 (footnote 29).

Within oblast-level elected assemblies (maslikhats), women made up only $12 \%$ of all deputies in 2014, with figures ranging from a high of 35\% in Mangistauskaya oblast to a low of 2\% in East Kazakhstan oblast. Representation is somewhat higher in local elected bodies, with women representing $21 \%$ of all municipal deputies and $19 \%$ of district deputies. ${ }^{29}$

Civil Service. Women make up the majority of the civil service representing $58 \%$ of all state employees at the central level and $55 \%$ of all state employees at the regional level (footnote 31 ). However, the vast majority of women in the civil service are in the midrange category of professional staff (97\%) and most senior positions are held by men (footnote 29). Women hold only $10.7 \%$ of executive political positions at the central level (footnote 29). No women ambassadors were appointed in 2015. Of the 36 heads of state bodies accountable to the President, only four were women. Under the category department heads and their deputies accountable to the President, only seven out of 57 positions were held by women (footnote 29). At oblast levels, only six women were akims or their deputies, compared to 84 men. No cities had a woman filling the position of akim or deputy (footnote 29).

${ }_{28}$ Inter-parliamentary union. Women in National Parliaments. http://www.ipu.org/wmn-e/arc/classif311206.htm. Tables for June 2017 and December 2006.

${ }^{29}$ Republic of Kazakhstan, Ministry of National Economy, Committee on Statistics. Women and Men in Kazakhstan 2015. Astana. 
Judiciary. The Government of Kazakhstan has succeeded in increasing women's representation in the judiciary. Women make up $54.8 \%$ of judges at the district, regional, and municipal courts and $36.4 \%$ of the Supreme Court judges (footnote 29 ). Over $70 \%$ of employees of the Judicial Department are women. Although women hold more than one-third of all leadership positions in the central and territorial bodies of judicial administration, only $8.5 \%$ of the top court positions of president and chair of the judicial board are held by women (footnote 29).

\section{Claiming Rights and Having Voice in the Legal System}

Despite women's representation in the judiciary, some gaps remain in women's claiming their rights to equality and nondiscrimination. The categorization of discrimination as a criminal matter requiring proof of intent is not in line with international norms where (i) discrimination does not require intent and may, indeed, be entirely unintentional; (ii) the burden of proof is not entirely on the plaintiff; and (iii) the outcome focuses on remedial action in favor of the plaintiff rather than punishment. ${ }^{30}$ The lack of a clear mechanism to put forward cases of discrimination and absence of effective remedial measures are a barrier to women taking action against discrimination or violation of their guaranteed rights.

The International Commission of Jurists highlights that while women have guarantees of equality, no cases are documented where women claimed their rights and sought legal redress against the State or private actors for discrimination. This absence of cases does not signify no discrimination exists. Rather, it is indicative of a deficit in justice where women's ability to voice matters related to their rights and seek redress is limited (footnote 15). In its concluding remarks to Kazakhstan's third and fourth reports, the CEDAW Committee noted its concern over the lack of court cases involving sex- and gender-based discrimination and that social stigma and lack of free legal aid remain obstacles to women exercising their rights. The Committee calls on Kazakhstan to do more to create a legal and policy environment where rights are not only guaranteed, but also fully enjoyed and protected. The CEDAW Committee recommended in particular that the state should increase women's awareness of their rights, train judges on sex discrimination and gender equality issues, and increase access to the justice system through legal aid and support to NGOs that could help women in bringing forward cases (footnote 15).

Civil Society and advocacy groups. Women are well represented among CSOs, and many nationaland oblast-level NGOs are active in advancing women's status, particularly in the economic and business sphere. Most leaders and staff of NGOs are women, and several women leaders are active in advancing gender equality and other social development goals through voluntary activities. ${ }^{31}$ Among Kazakhstan's NGOs, $42 \%$ offer services in the social sphere (education, public health, and culture); $24 \%$ in social protection of vulnerable groups; and $34 \%$ concentrate on issues of human rights, the environment, and gender policy. More than 200,000 people are employed in the NGO sector, and roughly 2 million citizens enjoy the services of Kazakhstan's NGOs (footnote 31). Women's health and well-being, promoting women's economic development, and supporting women victims of violence are among the services provided. When asked about participating in decision-making bodies, women key informants interviewed for this assessment were either involved in charitable groups or expressed interest in joining such groups. This finding

30 The Equality Rights Trust. 2014. Written submissions to the 57th session of the Committee on the Elimination of Discrimination against Women in relation to the combined third and fourth periodic reports submitted by Kazakhstan. Presentation to the United Nations Committee on the Elimination of Discrimination against Women.

31 A. Kabdiyeva. 2015. Development of NGOs in Kazakhstan. European Journal of Business and Social Sciences. 4 (2). pp. 159-169. http://www.ejbss.com/Data/Sites/1/vol4no02may2015/ejbss-1569-15-developmentofngosinkazakhstan.pdf. 
shows that women perceive civil society groups as a way to become more involved in social and economic issues.

The government has taken some initiatives to regulate NGO registration, resulting in some restrictions in civil society voice and actions. However, as civil society groups have consolidated into associations and federations, the government has started to more actively initiate or participate in forums to seek NGO views on policy initiatives, including on gender policy. Given women's lower political representation, the promotion of such forums creates an important entry point for women to have more say in policies that shape their lives. While such openings are occurring, the opportunities remain limited and the government tends to consult with a restricted group of NGOs that are also involved in the implementation of state programs (footnote 31 ).

\section{Gender Roles and Norms}

Cultural norms in Kazakhstan are generally positive toward the concept of equality between women and men. According to the European Bank for Reconstruction and Development (EBRD)'s Life in Transition survey, 83\% of respondents in Kazakhstan believe it is important for their daughter to achieve a university education, a view that was shared almost equally by male and female respondents. ${ }^{32}$ Kazakhstan public opinion results also showed that $81 \%$ of respondents think that female business executives are as competent as male business executives, with the percentage only slightly higher for women than for men (footnote 32 ).

The sense that women are strong and active members of society is part of the belief system in Kazakhstan. Women do have public and social spaces, and the majority do not experience religious or cultural restrictions to their physical mobility. The Soviet period saw the introduction of various social benefits favoring women's labor force participation, a substantial recruitment of women into the civil service, and the promotion of women's education at all levels. This history has created a foundation where gender equality has a grounding in social values and is associated with the country's development progress.

The researcher R. Sarsembayeva undertook a sociological analysis of the Gender Equality Strategy 2006-2016 that included a public opinion survey on women's and men's attitudes and beliefs toward gender. This survey found that most respondents agreed that respect for women is a moral value within Kazakhstan society (footnote 22). While men overwhelmingly agreed that respect for women was a moral value, women were split between agreeing definitely and being unsure if they agreed. ${ }^{33}$ In state declarations as well as key informant interviews during this assessment, women's equal access to education and labor market opportunities is underlined as a national achievement and a measure of the country's progress toward higher levels of development. The results of the public opinion survey also indicated that most men and women believed that women's situation had improved over the last 10 years (footnote 22).

Similar to many countries, notions of the traditional roles of women and men persist in Kazakhstan. According to Sarsembayeva's public opinion survey on beliefs and attitudes toward gender equality, a majority of respondents perceived women's role as associated with the family and home more than with the economic and political sphere. More women held this belief (39\%)

32 European Bank for Reconstruction and Development (EBRD). 2016. Life in Transition: Kazakhstan. Brussels. https://www.ebrd.com/what-we-do/economic-research-and-data/data/lits.html.

33 The response options to the questions "Do you think that respect for women exists as a moral value in Kazakhstan society?" were as follows: Yes, definitely; It is difficult to say for sure; No, does not exist; and Difficult to answer. 
compared to men (25\%) (footnote 22). Similarly, the EBRD Life in Transitions survey found that two-thirds of both male and female Kazakhstan respondents believe that men are better political leaders than women (footnote 32 ). As many as $86 \%$ of respondents believed that a woman should do the household chores, even if her husband is not working - a view that was shared by both female and male respondents. Finally, $68 \%$ of the population appears to favor a traditional family arrangement where the man works outside the home, and the woman takes care of the house and children (footnote 32).

The association of gender equality with the family risks reinforcing the notion that its result is promoting the latter as opposed to guaranteeing women their intrinsic human rights. The Concept on Gender Equality and Family 2017-2030 and the associated action plan propose measures to break down traditional stereotypes. These measures emphasize the need for increasing public awareness about the role of the father in child-raising. This action has been prioritized by the Commission in order to change attitudes about men's parenting role and encourage them to be more active in their children's upbringing. However, accompanying measures to change attitudes about women's roles, such as disseminating materials showing women in nontraditional occupations or in leadership positions are not included. Also, the Action Plan on Gender Equality and Family 2017-2030 includes a measure to "Monitor the court decisions on divorce cases to assess the level of respect for the equality of the rights of fathers to participate in the upbringing of children." However, no similar action is identified to address women's rights in divorce situations, although the researcher shows that many women face financial hardship after divorce due to the failure of spouses to pay alimony. ${ }^{34}$ The concept also omits mention of the value of the unpaid domestic work that is usually performed by women.

A perception that women have attained equal status when certain barriers and gender stereotypes continue to exist can in itself represent an obstacle to full gender equality. During key informant interviews conducted for this CGA, many government respondents stated their belief that actions to further remove barriers to inequality were not as high a priority for Kazakhstan as for other countries in the region given the progress already made.

Kazakhstan's Gender Equality Strategy 2006-2016 acknowledged that stereotypes are critical obstacles to gender equality, noting that the distribution of responsibilities inside the family is traditional and discriminates against women. The public opinion survey on beliefs and attitudes toward gender equality conducted by Sarsembayeva found that most male respondents considered the issue of women's equality as mostly not relevant (42\%), whereas only $16 \%$ of women felt this way. Most female respondents identified these issues as certainly relevant (44\%) compared to only $25 \%$ of men who saw it as certainly relevant (footnote 22 ).

The independent evaluation of the Gender Equality Strategy 2006-2016 by Ilsayova analyzed media coverage of gender equality in Kazakhstan (footnote 20). The media analysis found that the National Commission for Women's Affairs, Family and Demographic Policy had made extensive efforts to promote positive messages on gender equality. In association with International Women's Day, the Commission had arranged coverage through national and regional media of "neutral-positive" materials about women who had achieved success in various fields. Key gender policy and women's economic empowerment events were also featured in the media during 2006-2016 (footnote 21). The public opinion survey also found that most male

${ }^{34}$ A. Kapysheva. 2014. The Analysis of Women's Marital Rights in Kazakhstan: Challenges of Gender Equality. Nazarbayev University: Astana. 
respondents (83\%) and half of the female respondents were not aware that Kazakhstan had a gender equality policy (footnote 22).

However, the independent evaluation by llyasova notes that Kazakh mass media still present gender stereotypes that "prevent the flourishing of women's self-awareness and self-esteem." llyasova notes that media largely present two types of women: "a sexual object and a happy housewife" (footnote 20). According to the evaluation by llyasova, media in Kazakhstan cover men "as independent, self-sufficient persons" whereas women are "referred to in association with men-fathers, husbands, teachers, gently putting forward the idea that a woman alone cannot achieve anything, that behind her is always a man" (footnote 20).

\section{B. Economic Empowerment}

\section{Labor Force Participation}

Kazakhstan has maintained a steady women's labor participation rate that compares well with that of most other countries, including some high-development economies. The 2016 Human Development Report data shows women's labor force participation rate at $66.1 \%$ compared to $77.0 \%$ for men. ${ }^{35}$ The Global Gender Gap Index (GGGI) shows that the female-to-male labor force participation rate of 0.902 places Kazakhstan at a ranking of 28 out of 144 countries (footnote 13).

The gap between male and female labor force participation is not showing signs of narrowing. Since 2005, women had $64.4 \%$ participation compared to men at $75.2 \%$ (footnote 35 ). In 2010, the GGGI ranking of this indicator showed Kazakhstan at 17 out of 131 countries. By 2015, the ranking fell to 23 out 145 countries, indicating that Kazakhstan's progress in closing the labor force participation gap may be slowing (footnote 13). According to official data, the number of employed women increased by 126,535 from 2011 to 2015 compared to an increase of 195,584 for men (footnote 29).

Women's participation in the labor force remains concentrated in sectors defined as the service sphere with $71.4 \%$ of women employed in this sector compared to $52 \%$ of the men (footnote 29). Women and men are fairly evenly represented in agriculture, forestry, and fishery, where $17.1 \%$ of women are employed compared to $18.9 \%$ for men (footnote 29). The percentage of women employed in agriculture declined by 34\% from 2006 to 2016 (footnote 36). However, as women move out of agriculture, they are remaining in lower-paying service sector positions rather than accessing higher-paying industrial jobs.

Only 3.3\% of all women are employed in construction compared to $12.4 \%$ of all men (footnote 29 ). As shown in Figure 1, women represent 20.2\% of all construction employees compared to $79.8 \%$ of men (footnote 29). Women are just under one-fifth of employees in mining and quarrying, and in transportation and storage.

Women are underrepresented in executive positions in most spheres of the economy. The one sphere that has more women chief executive officers than men is education where women head $63.8 \%$ of companies. For health and social services, $46.3 \%$ are headed by women; for housing and

35 UNDP. 2016. Human Development Data (1990-2015). http://hdr.undp.org/en/data. 
food services, $42.7 \%$ of the chiefs are women. For finance and insurance, $41.7 \%$ have a woman as the top executive, followed by real estate (40.5\%) and art (36.5\%). Women had low representation as the top executive in agriculture (12.9\%), energy (12.6\%), and mining and quarrying $(11.6 \%) .{ }^{36}$

Kazakhstan has 287 jobs in which female employment is prohibited, including metalworking, selected construction jobs, mining, metallurgical works, and cement production. This will be updated this year and women will be allowed to work in jobs that no longer pose health hazards due to automation and technology. ${ }^{37}$ The announcement does not clarify whether women will continue to be barred from some professions and for what reasons. The announcement suggests that women's health will continue to limit their access to certain kinds of employment.

No data are collected on the reasons for entering and leaving the labor market, making it difficult to identify the reasons for women's lower labor force participation. Several factors could account for the difference. In particular, women take time out of the labor force to give birth and are more likely than men take extended parental leave. ${ }^{38}$ In addition, women are responsible for more domestic tasks, including caring for the elderly, which may take them out of the labor force. Women are more likely than men to seek higher levels of education and so could enter the labor

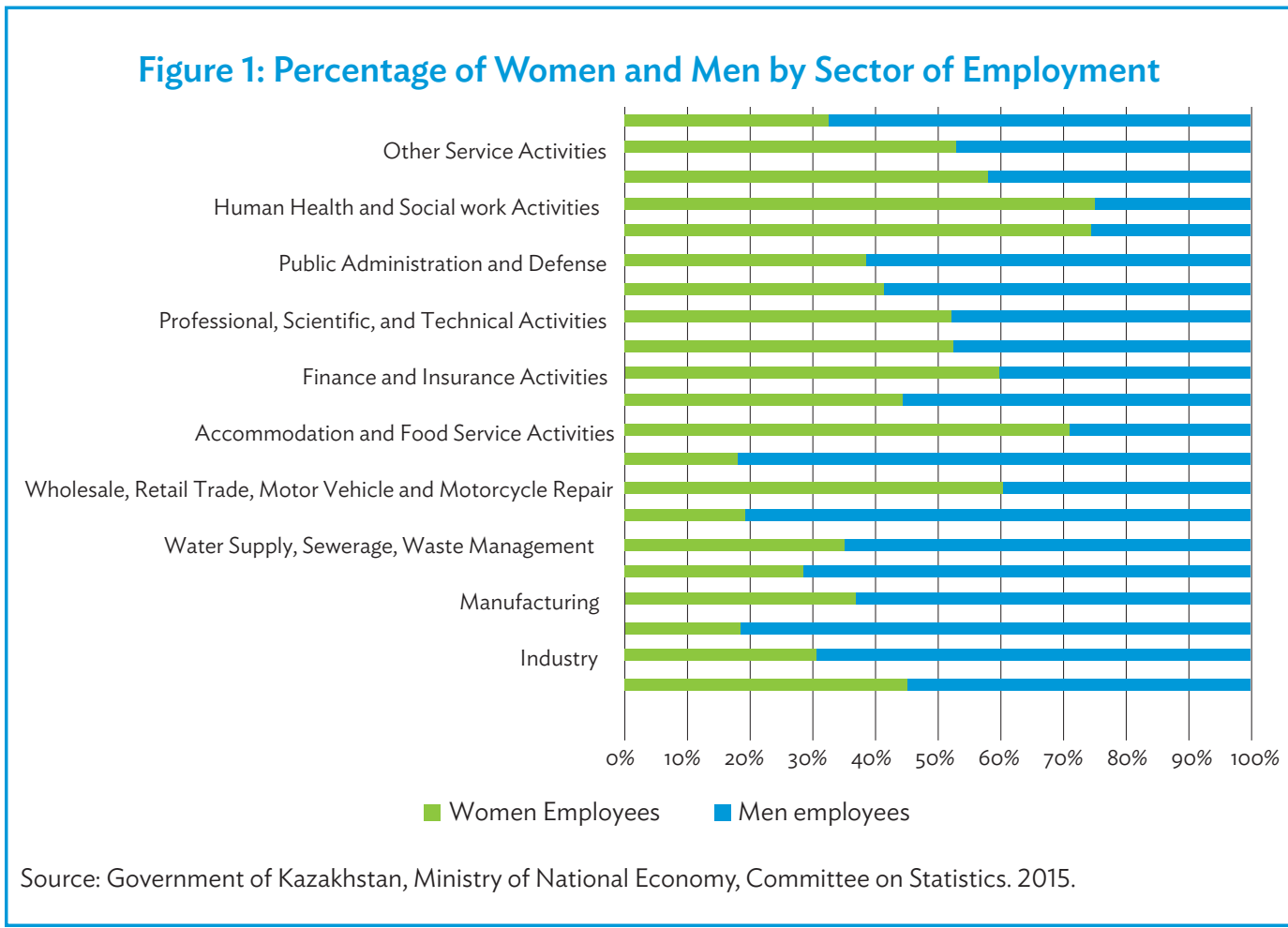

${ }^{36}$ A. Auelbekova. 2017. How Many Female Chiefs in Kazakhstan? Forbes. April. https://forbes.kz/stats/jenskoe_ otstuplenie_1.

37 Kazakhstan Pravda. 2017. List of banned occupations for women will be updated in Kazakhstan. 23 June. http://www.kazpravda.kz/en/news/society/list-of-banned-occupations-for-women-will-be-updated-in-kazakhstan/.

38 ILO. 2014. Maternity Protection and the Childcare Systems in Central Asia: National Studies in Kazakhstan and Tajikistan. Moscow. 
market later. On average, women retire sooner than men at 58 years compared to 63 years. ${ }^{39}$ This trend will change in 2018, when women's retirement age will increase by 6 months each year until it reaches the same as men's at 63 years. ${ }^{40}$

\section{Wages}

The wage gap between women and men is one sign that gender inequalities persist despite women's strong presence in the labor market. In 2015, women paid workers earned only $65.9 \%$ of what men earned, a figure that is less than it was in 2012, when women earned $69 \%$ of what men earned (footnote 22). Since the start of the government's gender equality strategy in 2006, the wage gap between women and men has only decreased 3.7\%, when women's earnings were $62.3 \%$ of men's (footnote 22 ). When comparing only those incomes below $\$ 75,000$ per year, women earn only $57 \%$ of what men earn based on 2017 data from the World Economic Forum (footnote 13).

The wage gap varies significantly by sector of employment activity. In employment sectors categorized as administrative and support services, women earn more than men at $111 \%$, and in education and health, the wage gap is small with women earning $90 \%$ of what men earn. In some areas such as information and communications, women's average income reaches only $67.2 \%$ of men's; in finance and insurance only $65.2 \%$. For professional, scientific, and technical activities, women's average income reaches only $59 \%$ of men's (footnote 29 ).

The gap in wages between women and men cannot be attributed to any single cause. Different factors contribute to this difference. Women are concentrated in areas such as administrative and support services, and in education and health that have lower levels of pay. While women are legally entitled to equal pay, they are often offered lower salaries for occupational safety reasons. Women are also barred from certain trades or construction-related professions that are higher paying. The wage gap is also explained in part by women having less time to devote to paid work as they must spend more time on unpaid domestic work. ${ }^{41}$ Also, in most sectors in both government and the private sector, women are less likely than men to reach senior-level positions with higher wages (footnote 22).

Wage gaps are also high between regions such as, for example, Atyrau and Mangystau, where the wage gap between women and men is approximately 50\%. As noted in the National Human Development report, high gender wage gaps in certain regions are a significant challenge for Kazakhstan to meet SDG 6 on gender equality and women's empowerment, as well as SDG 8 on inclusive economic growth.

\section{Employment Status}

Formal unemployment rates in Kazakhstan show distinct gender patterns. The unemployment rate for women was 5.7\% in 2015 compared to 4.3\% for men. As shown in Figure 2, according to official statistics, women made up 56.1\% of the unemployed population in 2015 and $63 \%$ of

39 Trading Economics. 2017. Kazakhstan Labor. https://tradingeconomics.com/kazakhstan/retirement-age-men.

40 A. Kazbay. 2013. President Signs Pension Reform Law Raising Women's Retirement Age from 2018. The Astana Times. 26 June. Astana.

41 Z. Urankayeva. 2016. The Difference in Salary between Men and Women in Kazakhstan is Reported. Pravda News. 12 April. http://www.kazpravda.kz/news/ekonomika/ozvuchena-raznitsa-v-zarplate-mezhdu-muzhchinami-izhenshchinami-v-kazahstane/. 
the economically non-active population (footnote 27). Part of this difference can be explained by women being more likely to take leave from work to care for children. However, women were $54 \%$ of the unemployed applying for a job placement in rural areas in 2014, indicating a tendency for unemployed women to be seeking work (footnote 29). Women may experience higher levels of unemployment due to their sectors of activity. For example, more women are represented in agriculture, which overall is experiencing an employment decline (footnote 27).

Self-employed women and men in Kazakhstan do not pay into the pension system or receive social insurance. As a result, the self-employed have less economic security and more irregular working conditions. Efforts to reduce informal self-employment, including among women, are having an impact. In 2010, women were just over $50 \%$ of the self-employed, but, as shown in Figure 2, by 2015 the percentage was reduced to $46 \%$ (footnote 29 ). In 2015, $24 \%$ of economically active women were self-employed compared to $27 \%$ of men (footnote 29 ). The majority of self-employed women work in two categories: (i) agriculture, forestry, and fishery (50\%); and (ii) wholesale and retail trade (33\%). Self-employed men are also more likely to be in these two sectors, but also work in transport and storage, and in construction (footnote 29).

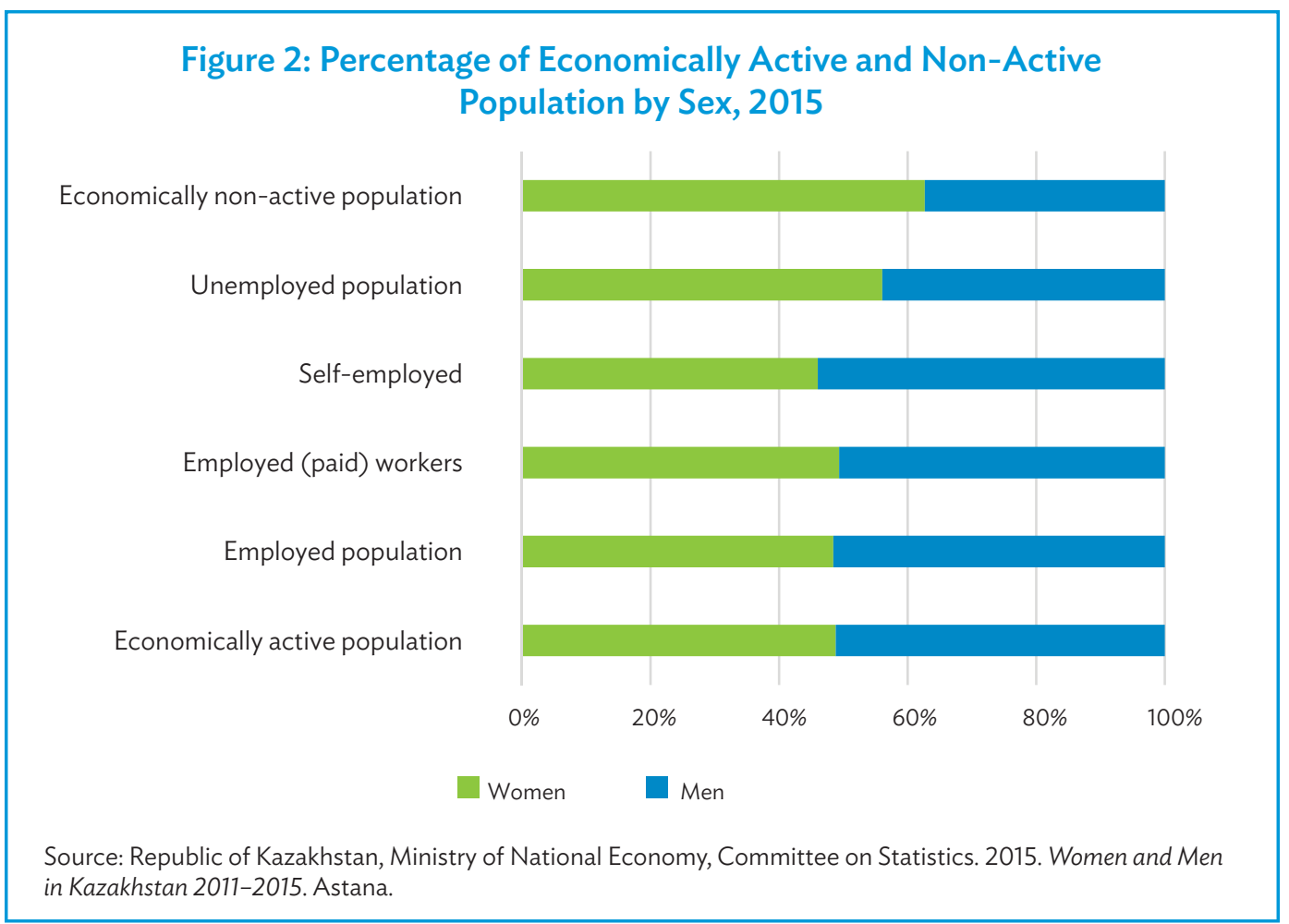

Government officials interviewed as part of this assessment noted that new pension reform initiatives are expected to result in equalizing women's and men's retirement age (currently at 58 years for women, and 63 years for men), providing more benefits to self-employed workers, and workers - mainly women-who take time out of the workforce for childcare responsibilities. These measures will improve the status of women self-employed workers as well as elderly women in retirement. 
Employment centers are managed by the district or municipal government and are key implementers of government strategies to increase employment. In 2014, the services across Kazakhstan placed 91,665 persons, of whom a slight majority were women (47,440 compared to 44,225 men) (footnote 27). In 2015, the number of persons placed increased by almost $50 \%$ to 153,529 , but most of these increased placements were reported for men, with 104,971 placements compared to 48,558 for women. Similarly, women represented a majority of those trained by employment centers from 2011 to 2014; in 2015, however, increases in the number of people trained benefited mainly men in these same provinces (footnote 27 ). The employment centers are active in placing the unemployed in government infrastructure programs, and the figures suggest that the placements are mainly targeting men despite the fact that women represent a higher percentage of the unemployed.

\section{Migrant Workers}

During the post-Soviet era, Kazakhstan became a destination country for migrants in Central Asia. Up to 2009, Kazakhstan had 41,511 immigrants, the majority from Commonwealth of Independent States ${ }^{42}$ countries and 33,985 emigrants. But by 2013, the flow of migration had changed with more people exiting the country $(28,946)$ than entering $(16,982)$. The majority of immigrants are returning Kazakh migrants, and the main destination country for emigrants is the Russian Federation. Women represent slightly higher than $50 \%$ of migrant flows. ${ }^{43}$

A study by the Institute for East and Southeast European Studies ${ }^{44}$ has shown that male and female migrants have different motives for moving. As shown in Figure 3, 34\% of males moved because of their work compared to only $21 \%$ of females. Women most often expressed their motive as moving with their family or to join their family (34\%) or to return to their ethnic homeland (34\%). In contrast, only $29 \%$ of men migrated due to family and only $3 \%$ gave returning to their homeland as a reason for moving. Females (12\%) were also more likely to migrate because of marriage than males (6\%). The same study did not find any earnings discrimination for internal migrants nor differences in household income between migrants and the host population. In general, people tended to move from villages or small towns to nearby medium-sized cities and from medium-sized cities to large cities. Migration flows from villages directly to large cities are generally much smaller. Studies have shown that the majority of internal migrants to large Kazakh cities enjoy a gradual increase in earnings and status after moving (footnote 44).

The report by the Institute for East and Southeast European Studies highlights that Kazakhstan lacks a framework to recognize the domestic labor market and, consequently, is without mechanisms to protect domestic workers (footnote 44). As a result, little information is available on the legal status of domestic workers. According to one study, $97 \%$ of domestic workers in Kazakhstan were either unaware or unsure of the laws protecting their rights (footnote 44). The domestic labor market functions primarily on the basis of oral agreements between the employer and the employee. As a result, there are almost no opportunities for any legal regulation of conflicts, leaving domestic workers - the majority of whom are women-vulnerable to labor rights violations.

42 The Commonwealth of Independent States was formed by former Soviet republics in 1991 and includes Armenia, Azerbaijan, Belarus, Kazakhstan, the Kyrgyz Republic, Moldova, the Russian Federation, Tajikistan, and Uzbekistan.

43 UNICEF. 2014. Migration Profiles: Kazakhstan. New York.

44 A. M. Danzer, B. Dietz, and K. Gatskova. 2013. Kazakhstan Migration and Remittances Survey: Migration, Welfare and the Labor Market in an Emerging Economy. Institute for East and Southeast European Studies. Regensburg, Denmark. 


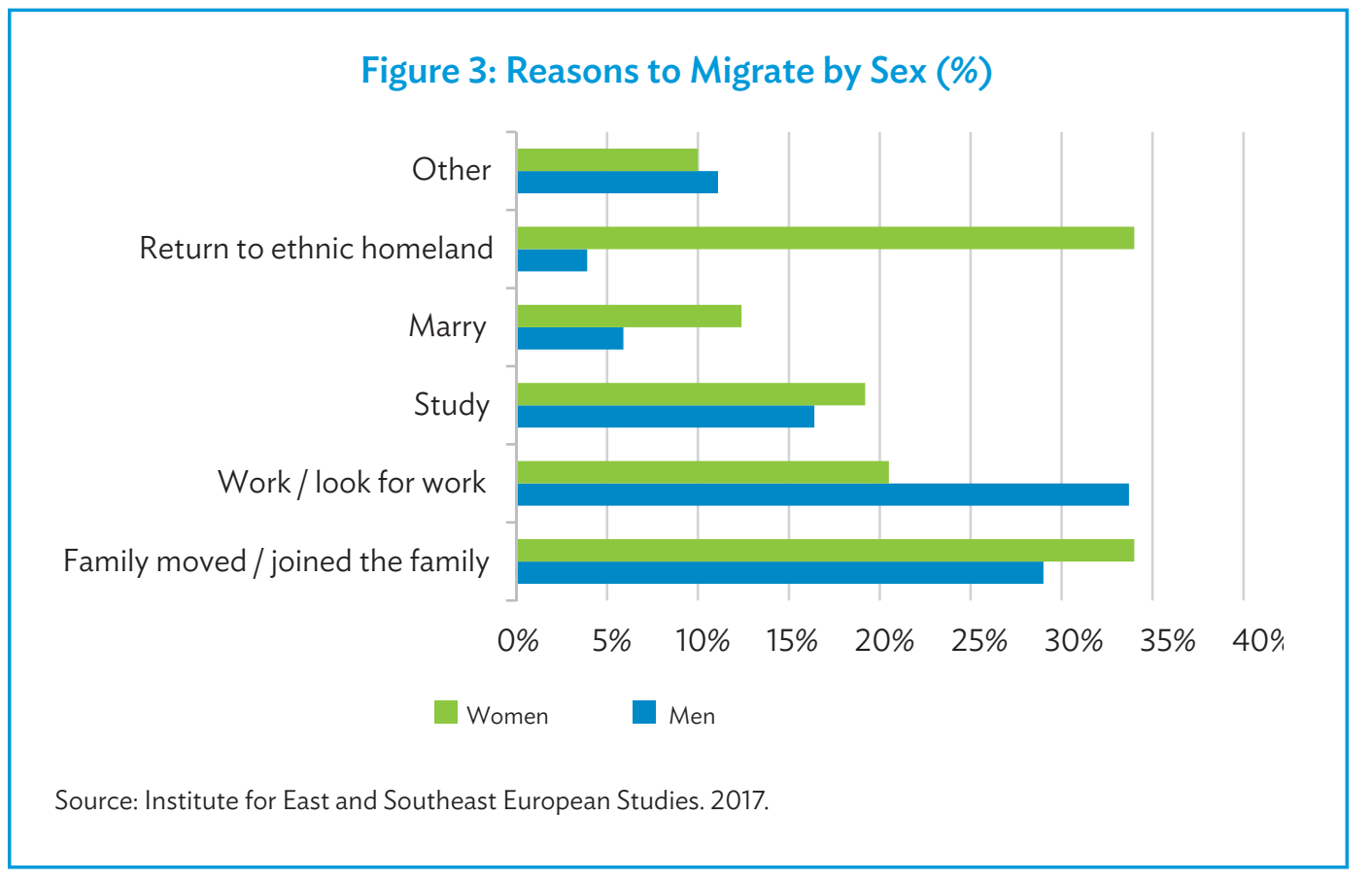

\section{Reduced Time Poverty}

Women in Kazakhstan, most of whom are economically active, spend more time on domestic tasks than men. Women surveyed by the Committee on Statistics indicated that they spent $17.1 \%$ of their time running the household compared to $7.1 \%$ indicated by men. Women reported having $15.8 \%$ of their time for leisure compared to $20.4 \%$ for men (footnote 29 ). In key informant interviews, women reported always doing or usually doing most of the domestic tasks such as childcare, taking children to schools, shopping, cooking, and cleaning. Men who shared domestic tasks usually take on tasks such as playing with children, gardening, and paying bills.

Kazakhstan has relatively high levels of access to utilities on or close to premises. As a result, the time burden of domestic tasks is not as onerous as in many developing countries. Many domestic and farm-related tasks are mechanized, resulting in reduced labor. However, utilities, including electricity systems and farm equipment, are aging and need investments. Women are more likely to feel the burden of increased labor for domestic or productive roles if utilities, services, farms, and workplaces are not modernized.

Women are expected to contribute economically to the household as well as take on the majority of household duties. The lack of shared responsibilities for domestic tasks creates pressure on women, and limits their potential for advancing their career to senior decision-making and higherpaying positions. According to a public opinion survey on attitudes toward gender equality, when asked what makes a successful woman, majority of the respondents indicated that a successful woman is one who performs well in all roles-family, social, and economic. This result reveals that women are facing more pressure than men to succeed in all areas of work and family life (footnote 22). 
Women are also more likely than men to take time off for raising children, a decision that can limit their career advancement. The government has taken several measures to balance work and family life. The Labor Code includes provisions for

(i) paid maternity leave of 126 calendar days including 70 days before childbirth and 56 days after,

(ii) paid adoption leave for a newborn child of 56 days, and

(iii) unpaid parental leave (childcare leave) for women or men until the child reaches the age of 3 (footnote 38).

The maternity and adoption leave is covered under the mandatory social security system to which employers contribute. In addition, parents-either mother or father-are entitled to 1 year of paid childcare leave and up to additional 2 years of unpaid leave. Employers are required to grant parents unpaid leave or allow for part-time work upon written request. Paid and unpaid leave is also to be counted in length of service (footnote 38).

Pregnant women and women with small children have protection from being laid off in case of staff reductions, and may not be assigned night duties, overtime, rotation-based work, working on weekends or during public holidays, or be required to go on business trips. Single fathers caring for children under 14 are protected from staff reductions. In addition, Kazakhstan has a legal entitlement whereby all children between ages 1 and 6 have a place in Early Childhood Education in Care (footnote 38).

Although national labor law guarantees family life, women can experience barriers to exercising such rights. The law lacks penalties for violations of women's labor rights, including maternity and childcare leave. The absence of clear procedures for pursuing discrimination cases threatens women's right to maternity and childcare leave. NGOs have documented cases of young women being required by employers to sign illegal contracts stating that they will not marry or apply for maternity leave during the term of employment, as well as cases of women over age 40 being subject to constructive dismissal and replaced with younger employees (footnote 18).

Social security assistance during maternity leave is provided by the state budget as well as by employer contributions to the Public Social Insurance Fund. Employees also contribute to state benefits and allowances that compensate for loss of income due to maternity and childcare, adoption of a newborn child or children, and caring for a child up to age 1 (footnote 38). Women outside of large cities and regional centers have reported difficulties in applying for child benefits, which requires travel to regional centers and long waiting times for processing documents (footnote 6).

Kazakhstan has not specified paternity leave, but either women or men can take parental leave. The Concept of Family and Gender Policy Action Plan 2017-2019 does propose an action to introduce paternity leave. If passed, this measure may contribute to balancing responsibilities for caring for infants since men are more likely to take time off to care for children when the law specifies the time as paternity leave rather than as parental leave (footnote 6).

As in many countries, the value of unpaid domestic work is not recognized. Women who take time out of the labor market for childcare or elderly care are classified as unemployed, although they are providing a contribution to the household that facilitates spouses or other members to be economically active (footnote 19). The majority of respondents to the public opinion survey on attitudes toward gender equality agreed that the value of domestic work was seen as lower than that for paid employment (footnote 22). The Action Plan 2017-2019 Concept for Family 
and Gender Equality identifies the need to "Make proposals on measures for the state to encourage the contribution of fathers to raising children, as well as to develop a mechanism for popularizing

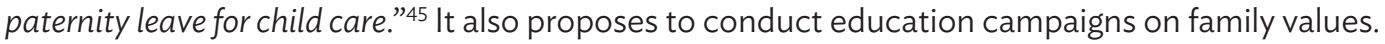
However, no specific reference is made to highlight the economic value of women's domestic work or propose more gender-balanced sharing of household tasks apart from caring for children.

\section{Human Development}

Kazakhstan is a high human development country, ranking 56 out of 188 with a human development index of 0.794 in 2015 (footnote 35). From 1990 to 2015, the country increased its human development rating by $15 \%$ (footnote 35 ), evidence of national efforts to reduce poverty and improve the social and economic well-being of the population. Generally, women and men have enjoyed the impacts of higher human development. However, continued progress requires more analysis of human development issues affecting men and women and setting specific targets to address them.

Kazakhstan's population of $17,670,000$ is composed of $9,128,000$ females and $8,542,000$ males. The male population outnumbers the female population in the age groups from 0 to 19 , suggesting that the sex ratio may be shifting (Figure 4) (footnote 29). For age groups from 20 to 30, female population is similar to that of male. Women comprise a higher share of the older population, outnumbering men from age 40 and above.

Figure 4: Women and Men by Age Groups

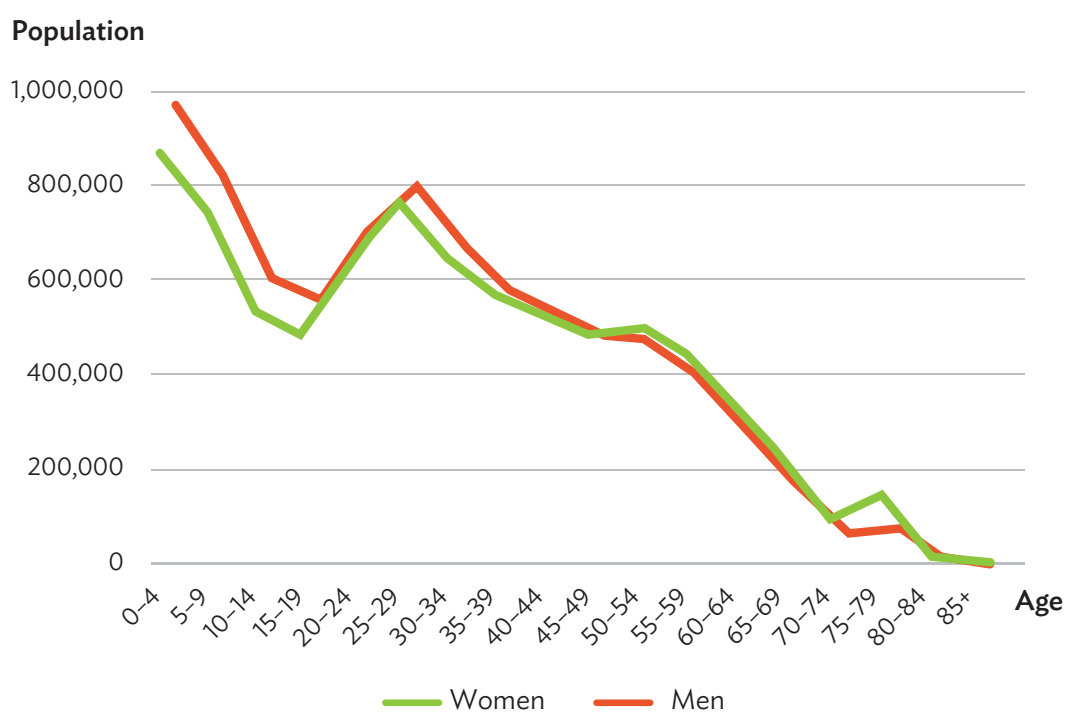

Source: Republic of Kazakhstan, Ministry of National Economy, Committee on Statistics. 2015. Women and Men in Kazakhstan 2011-2015. Astana.

45 Republic of Kazakhstan. National Committee for Women's Affairs, Family and Demographic Policy. Action Plan 2017-2019 Concept for Family and Gender Equality. Astana. 


\section{Education}

Early childhood education. Kazakhstan has a preschool system that includes services for different ages of infants and preschool children including private, family, and institutional nurseries, kindergarten, combined school-kindergarten facilities and preschool mini-centers. UNICEF's Multiple Indicator Cluster Survey (2014) (footnote 25)found that more than half (55.3\%) of children aged 36-59 months are attending an organized early childhood education (ECE) program of some kind. Urban and rural differences are evident in preschool attendance, with $62.2 \%$ of children from urban areas in ECE compared with $48.9 \%$ of those from rural areas footnote 25). Government statistics indicate that, overall, sufficient places are available in ECE centers for children: 100 places are available for every 95 children across the country (footnote 29). However, access varies by region with some parts of the country experiencing shortages. ${ }^{46}$

The government reported an increase in preschool education rates from $38.7 \%$ of 3- to 6-yearolds in 2010, to $73.4 \%$ by 2015 . While representing an improvement, this figure is still lower than the OECD average of $88 \% .{ }^{47} \mathrm{Also}$, participation of 0 - to 2 -year-olds in formal care is much lower at $16 \%$, a rate that is only half of the OECD average of $33 \%$. The total rate of preprimary participation is 58\% for both boys and girls (footnote 47) According to the National Human Development Report, 10 regions do not have the capacity to accept all children at preschools. This gap affects women's participation in the labor force and is a factor that can limit Kazakhstan's achievement of SDG 3 on inclusive education, SDG 8 on inclusive economic growth, as well as SDG 5 on gender equality and women's empowerment (footnote 8).

Kazakhstan has set a very ambitious goal of full Early Childhood Education and Care (ECEC) enrollment of all 3- to 6-year-olds by 2020. To achieve this objective, the country will need an influx of new ECEC teachers. Reviewing the lessons learned and the examples of strategies from other countries in attracting and retaining teachers in this field is an important step to improving the ECEC system. ${ }^{48}$ Many private preprimary schools are opening to meet the increased demand for ECE, but staff shortages are a key challenge. The lack of ECEC teachers is due to several contributing factors: low wages, a low number of entrants into the sector, and high staff turnover rates and attrition (footnote 48). More recruitment and training of ECEC teachers will be necessary if the country is to meet its goals to expand preprimary education. This expansion is important to improve the quality of education, as well as contribute to women's increased labor force participation.

Primary and secondary education. Kazakhstan has emphasized ensuring a high level of education for its population. According to national statistics, universal literacy is achieved for both women and men (footnote 29).

The UNICEF Multiple Indicator Cluster Survey shows that the country has achieved near gender parity in school readiness, and in primary and secondary education enrollment, attendance, and completion. As shown in Figure 5 (footnote 25), primary and secondary net intake rates are high for both sexes at $99.1 \%$ for boys and $99.3 \%$ for girls, as are the primary school attendance rates at $99.6 \%$ for boys and $99.5 \%$ for girls. The overall primary school completion rate is $102.1 \%$, but the

${ }^{46}$ OECD. 2017. Building Inclusive Labor Markets in Kazakhstan: A Focus on Youth, Older Workers and People with Disabilities. Paris.

47 OECD. Starting Strong IV: Early Childhood Education and Care Data Country Note: Kazakhstan. Paris.

48 OECD. 2017. Early Childhood Education and Care Staff Recruitment and Retention: A Review of Kazakhstan. Paris. 


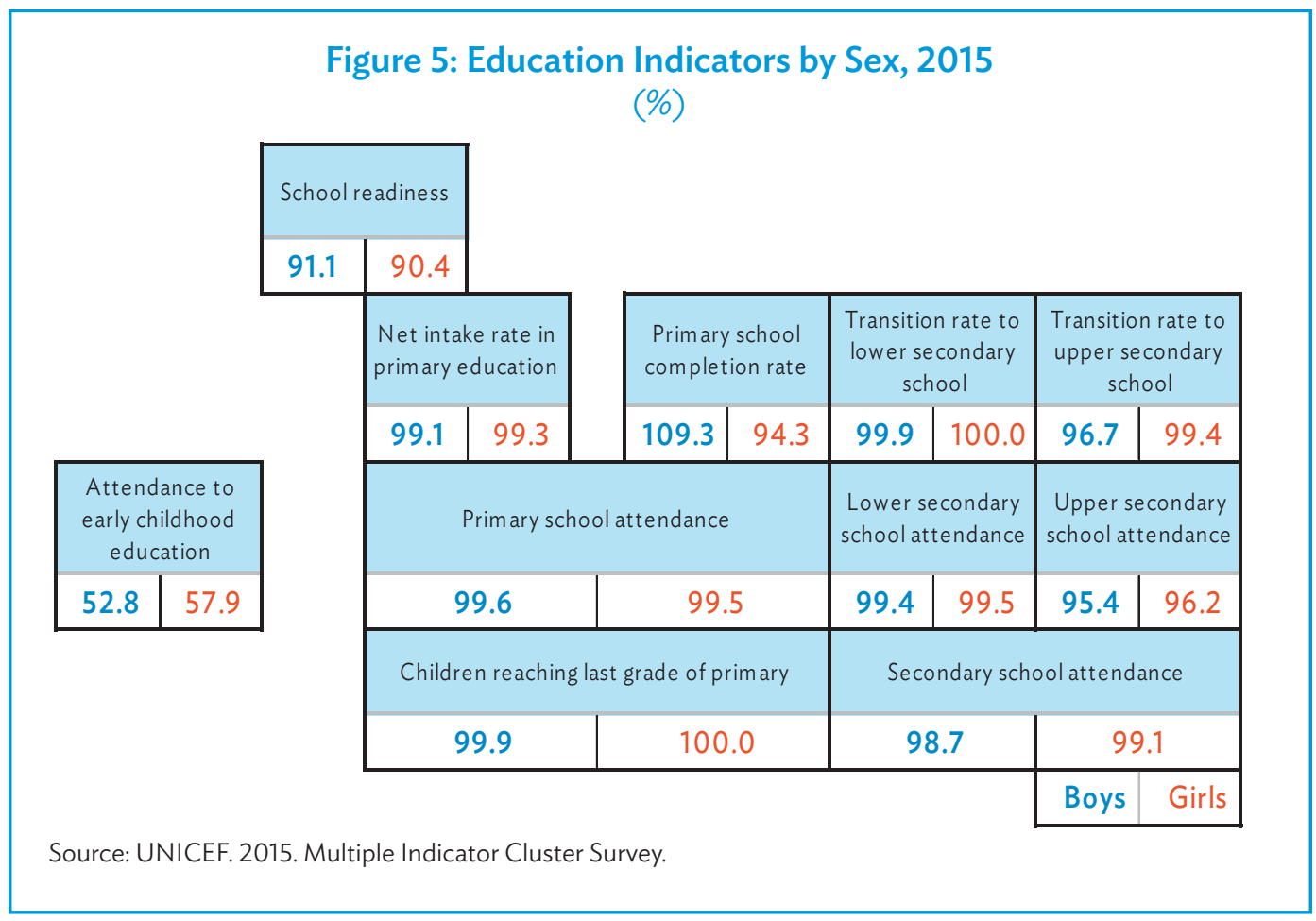

proportion of boys who finished primary school (109.3\%) exceeds that of girls (94.3\%). Almost all students complete primary school transition to lower secondary whereas slightly fewer boys (96.7\%) compared to girls (99.4\%) transition from lower secondary to upper secondary school. The upper secondary completion rate is similarly higher for girls at $96.2 \%$ compared to $95.4 \%$ for boys (footnote 25).

Almost all boys and girls proceed through each level of schooling. As the boys' rate is over 100\%, it can also point to a higher number of boys older than the standard age completing primary education. The difference in rates of primary school completion for girls needs to be further examined to understand whether any trends are emerging that would affect gender parity in education.

Tertiary education. In 2015, $48.4 \%$ of the population was enrolled in higher education (either university or technical and vocational school). Since 2011, the rate of enrollment in higher education (53.1\%) has declined slightly. In 2015, a higher percentage of women (53.8\%) aged 18-22 enrolled in higher education compared to men (43.2\%). Overall, 55.9\% of higher education students are women (footnote 29). Studies have shown that rural young people are two times less likely to access higher education than urban young people. ${ }^{49}$

Women represented the majority (55.9\%) of those enrolled in university, but were less than half (47.7\%) of those enrolled in technical and vocational education. Women are much more likely to

49 N. Shedenova and A. Beimisheva. 2013. Territorial Availability of Social and Economic Infrastructure in Kazakhstan: Comparative Analysis of Urban and Rural Households. World Academy of Science, Engineering and Technology. International Journal of Social, Behavioral, Educational, Economic, Business and Industrial Engineering. 7 (2). pp. 426-431. 
proceed to postgraduate education: with $61.2 \%$ of master's-level students and $60.9 \%$ of doctoral students being women (footnote 29).

Higher education fields of study in Kazakhstan are highly gender-segregated, as shown in Figure 6.

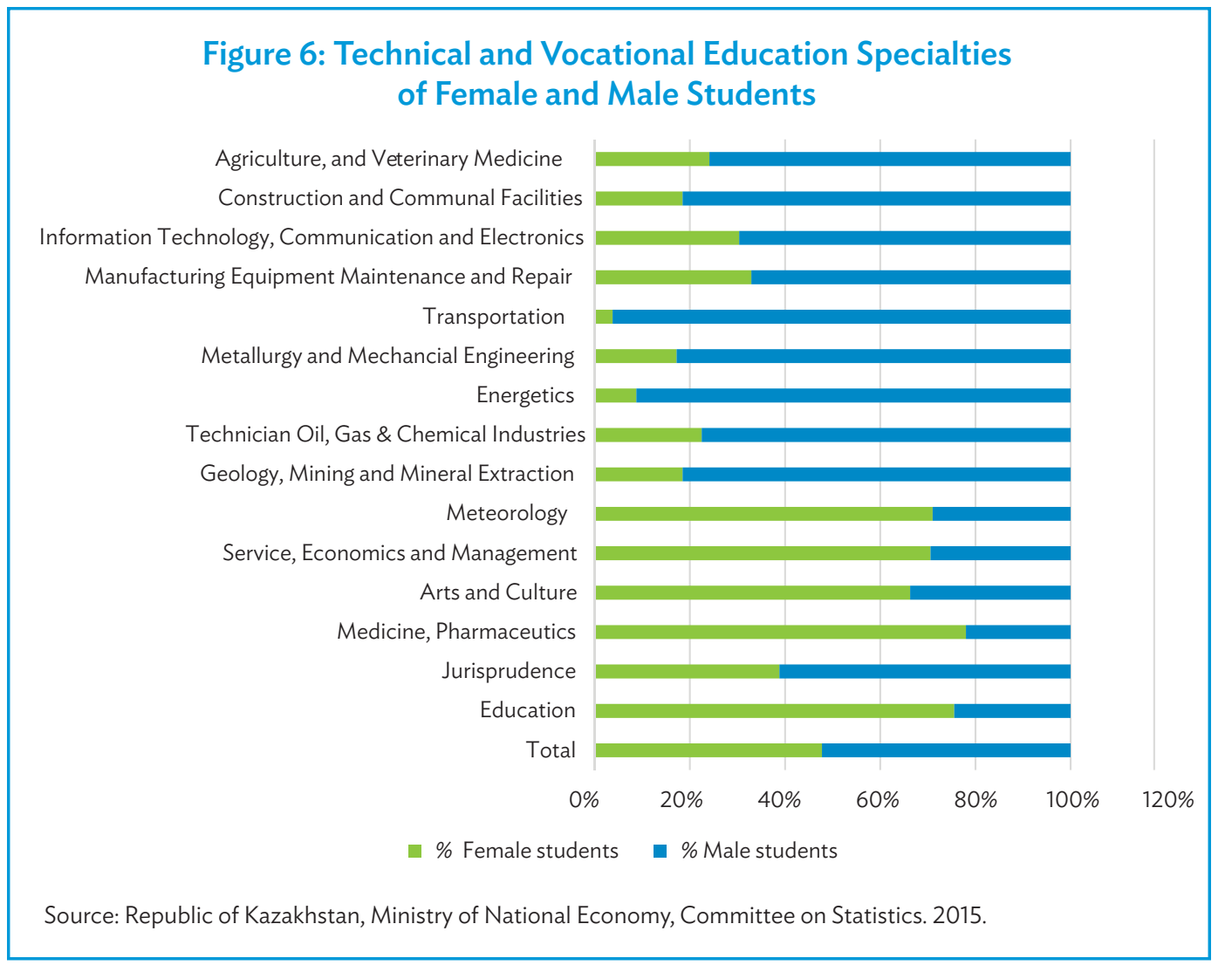

At the technical and vocational level, women were a much higher percentage of those studying in education, medicine/pharmacy, service and management, and meteorology. Men were more present in jurisprudence, fields related to geology and mining, energy and oil and gas extraction, transport, manufacturing, communications, information technology (IT), construction, agriculture, and veterinary care.

The pattern for university education is similar, as shown in Figure 7. Only business and management, and agriculture, fishery, and forestry are fairly gender-balanced. Otherwise, women are concentrated in education, arts and humanities, medicine, and health and welfare. Women also comprise the majority of students in natural sciences, mathematics, and statistics, which is notable since in other countries, women are often underrepresented in mathematics and sciences. However, the majority of engineering, communications, and IT students are men.

Despite women's higher representation of those with master's and doctoral degrees, women are a minority of professors in academic institutions. Women represent only $34 \%$ of university professors and more than half (57\%) of university assistant professors (footnote 29). 


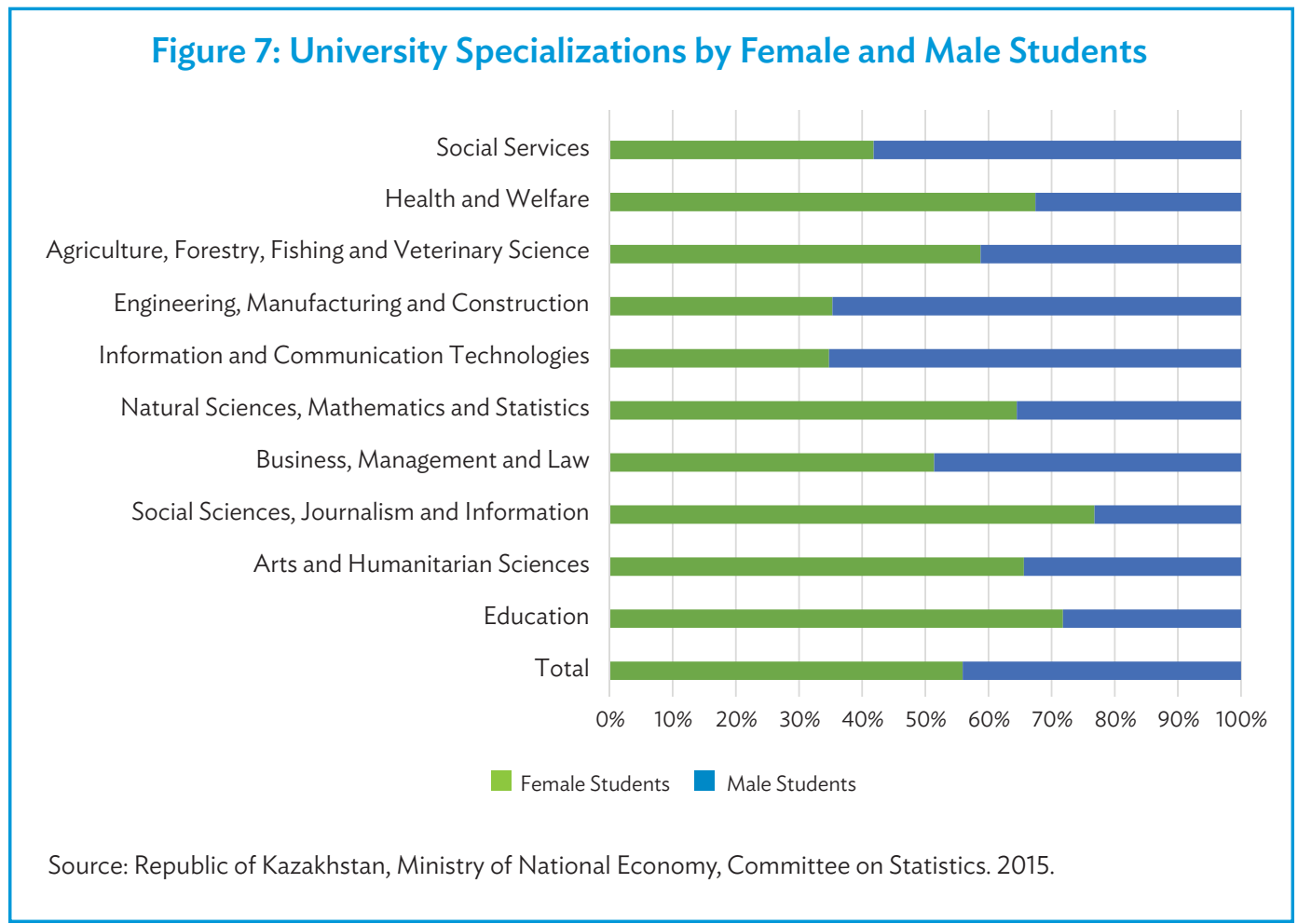

\section{Health}

Despite the steady improvements, compared to other OECD countries and post-Soviet states, Kazakhstan has relatively low population health indicators. All the regions, except the major cities, experience a shortage of physicians; the density of physicians is at least twice lower in regions compared with that in Astana or Almaty (footnote 8 ). This regional disparity is a key constraint which Kazakhstan needs to overcome to meet its SDG 3 commitment to promote healthy living. It also constrains progress on SDG 5 on gender equality as rural women continue to face limited health-care services.

Communicable diseases such as tuberculosis and chronic diseases are a concern. These health issues affect both women and men differently and so require a clear analysis of the gender dimensions in order to put in place appropriate health strategies.

Life expectancy. Kazakhstan has improved its population health indicators over the past decade and achieved its MDGs for the health sector. According to the UNDP Human Development Report, overall life expectancy increased from 65 in 2005 to 69.6 in 2015 (footnote 11). However, the country remains at the low end of life expectancy with a ranking of 111 out of 183 countries. The gender gap in life expectancy is high with almost 10 years of difference between men (at 64.8 years in 2015) and women (at 74.3 years) (footnote 2). Male life expectancy-with a ranking of 123 out of 183 countries-is of particular concern. The adult mortality rate, that is, the probability of 
dying between 15 and 60 years of age, is 279 per 1,000 men and 118 per 1,000 women. ${ }^{50}$ The gap in life expectancy between women and men is narrowing: men's life expectancy has increased by 6.9 years since 2000 compared to 4.8 for women in the same period. While women's life expectancy is higher than men's, its ranking at 105 out of 183 countries makes female health a concern (footnote 50).

Reproductive health. Kazakhstan achieved its MDG for improving maternal and child health. From 2000 to 2015, the country reduced maternal deaths from 65 per 100,000 live births to 12 . In the same period, infant deaths declined from 37.5 per 1,000 live births to 12.6 (footnote 35).

The official marriage age for women and men is 18 years, and only by the decision of local executive bodies can this be reduced by a period not exceeding 2 years for exceptional reasons: (i) pregnancy or (ii) birth of a child. Among women aged $15-49$ years, $0.1 \%$ of girls were married before age 15 , and among women aged $20-49$ years, $7.8 \%$ were married before age 18 (footnote 25).

Adolescent pregnancy is low but remains an issue, and rates are higher among rural women and women with lower levels of education. According to the Multi-Indicator Cluster Survey by UNICEF and UNFPA (footnote 25), women aged 15-19 in urban areas (3.2\%) and in rural areas (4.8\%) have had a live birth. Also, in the $15-19$ age group, $1.6 \%$ of urban women and $1.2 \%$ of rural women are pregnant with their first child (footnote 25$)$. Of the women (20-24 age group) who had a live birth, 2.2\% gave birth before age 18. Women 15-19 years old and with less than secondary education (15.7\%) are more likely to have had a live birth compared to those with higher education (0.5\%) (footnote 25). Among women aged 20-24, the figure ranges from $0.7 \%$ in the Aktobe region and Almaty city to $6.7 \%$ in the Kostanai region (footnote 25 ).

The main causes of maternal mortality are obstetric hemorrhage-accounting for every third maternal death-as well as eclampsia, complications of abortion, and infection. Data collected as part of the evaluation of the Gender Equality Strategy 2006-2016 indicate that only 16\% of deaths were not preventable (footnote 20). Migrant women from other countries are provided free care in the hospital for their birth but are not entitled to any prenatal or postnatal care (footnote 20).

The frequent recourse to abortion as a means of family planning is an issue affecting the health of women. In 2014, 83,700 induced abortions were registered, which is equivalent to 18.3 abortions per 1,000 women aged 15-49. This high figure indicates that, for many women, abortion rather than contraception is one of the main methods of family planning (footnote 20). Among vulnerable populations, the figure is even higher than the national average. For example, 28 abortions occur for every 1,000 women with disabilities, and for women living with HIV, the rate is 32 per 1,000 women (footnote 20). The high rate of abortion is characterized by low public awareness of family planning as well as low public access to facilities and services for reproductive health and family planning (footnote 20).

Of the 2 million adolescent girls and young women (under age 18) in rural areas, 33,051 pregnancies were registered over the last 5 years, with one-third of these ending in abortion. Teenage pregnancy and abortions are higher in rural areas. Approximately $0.1 \%$ of rural girls aged 15-18 are estimated to have had an abortion (footnote 25 ).

50 WHO. 2015. Country Profiles: Kazakhstan. Geneva. http://www.who.int/countries/kaz/en/. 
According to national legislation, a person reaches full adult capacity at the age of 18 . Although the age of sexual consent is 16, young people under 18 cannot make independent decisions regarding their sexual and reproductive health. According to a Ministry of Health regulation, a doctor is not allowed to conduct a full medical examination of a 16- or 17-year-old girl without her parents or legal guardians being informed and participating. ${ }^{51}$ Consequently, adolescents may make decisions about their participation in sexual activity, but avoid decisions about contraceptive use or treatment of sexually transmitted diseases because of reluctance to involve their parents or guardians (footnote 52). Access to confidential reproductive health education and services for adolescents is a pressing health issue, particularly for girls living in rural areas.

Communicable disease. While Kazakhstan has improved its main health indicators such as life expectancy, its overall health indicators are lower than those of other OECD countries and other post-Soviet states. In 2015, the country had a tuberculosis incidence of 89 per 100,000 persons..$^{52}$ The tuberculosis morbidity rate in 2015 was 47.4 per 100,000 for women and 70.2 for men (footnote 27). Kazakhstan leads in terms of the incidence of registered tuberculosis in Central Asia and Europe, and is one of 18 priority countries to combat the disease..$^{53}$

The United Nations Programme on HIV/AIDS estimates that Kazakhstan has 23,000 adults over age 15 living with HIV of whom 7,100 (30\%) are women. ${ }^{54}$ There are an estimated 2,300 new infections each year of which women represent $43 \%$ and men $57 \%$. Women's share of new HIV cases has increased since 2006 when it was $26 \%$ (footnote 54). Gender distribution of HIV infection differs as well. Among men, HIV is more often transmitted through shared needles, whereas women are more often infected through sexual intercourse (footnote 54).

\section{Persons with Disabilities}

Kazakhstan has a total of 637,217 people with disabilities: 278,663 women and 358,554 men (footnote 29). Just over $20 \%$ of people with disabilities of working age are employed (footnote 29). According to interviews conducted for this assessment, disability organizations have been advocating for more recognition of the productive role that both women and men can play in society. The previous state benefits emphasized social transfers to people with disabilities under the social protection system where every citizen is guaranteed a minimum wage in case of old age, disability, or other reasons. In the past, efforts to provide employment or advanced education for people with disabilities were largely made through charities.

Kazakhstan's policies on disability have been undergoing transformation. Increasingly, state programs are integrating measures for rehabilitation, social integration, and providing incentives to create employment for people with disabilities. In 2015, the government introduced a system of compulsory job quotas for people with disabilities that vary between $2 \%$ and $4 \%$ depending on the size of the firm. Special subsidies are allocated for upgrading workplace environments to make them accessible..$^{55}$

51 UNFPA. 2014. Child Marriage in Kazakhstan: An Overview. New York.

52 WHO. 2017. World Health Statistics 2017: Monitoring Health for the SDGs. Geneva.

53 Organisation for Economic Co-operation and Development (OECD). 2016. Multi-sector Review of Kazakhstan. Volume 1: Initial Assessment. Paris.

${ }^{54}$ Republic of Kazakhstan, Ministry of Healthcare and Social Development. Republican Center for Aids Prevention and Control. 2016. Report on Population Size Estimate of People, who Inject Drugs (PWID) in the Republic of Kazakhstan. Almaty.

55 OECD. 2017. Building Inclusive Labor Markets in Kazakhstan: A Focus on Youth, Older Workers and People with Disabilities. Paris. 
Under the Employment Roadmap 2020, the government will provide more vocational and technical training to persons with disabilities. In 2016, of the 5,200 disabled individuals who took part in trainings under the road map program, 4,800 were placed (footnote 56). However, the figure represents a very small proportion of the disabled population.

According to interviews with advocacy groups working on these issues, awareness of family members, employers, and even to some extent disabled persons themselves, on the potential of people with disabilities to integrate socially and economically is only emerging. More efforts are needed for education and awareness to break down stigmas about having a disability and build awareness on the value of inclusion in education, employment, and other societal institutions. Beyond the social stigma, women and men with disabilities face barriers such as means of transportation; accessible buildings; and lack of information, communication, and other technologies that would allow them to participate more fully in society. Transportation services for people with disabilities exist, but the services are limited or not available.

The situation of overcoming social stigmas and barriers to employment is experienced differently by women and men with disabilities. Few statistics are available on the number of people with disabilities in the labor market, or on the gender divisions in services, education, and labor market opportunities for women and men with disabilities.

According to interviews conducted as part of this assessment, those working on disability issues believe that the perception that domestic tasks are women's work often means that girls and women with disabilities are more likely to be confined to the home to assist with household chores. As a result, women with disabilities miss opportunities to seek education and employment opportunities and are consequently cut off from social interactions. Young women and men with disabilities are often not seen as being potential parents, and this affects reproductive health and family planning services. As a result, women with disabilities may face unwanted pregnancies or lack of services when they want to become pregnant.

Key informants also report that women with disabilities are more vulnerable to gender-based violence (GBV) and may lack the mobility to seek the support and social, medical, and justice services that they need.

Kazakhstan is taking the right steps to create a policy environment conducive to social and economic integration of disabled persons. However, more resources to ensure compliance of employers and services with laws on accommodation are required. In addition, using education and awareness to highlight the social and economic value that people with disabilities contribute to society is important to promote their increased integration. In addition, more gender analysis of the differing situations of women and men with disabilities is needed to develop accommodations and services suitable for their differing situations (footnote 56).

\section{Gender-based Violence}

GBV is prevalent in Kazakhstan. According to the Concept on Family and Gender Policy until 2030, one out of three women suffers from beating, sexual coercion, or other forms of violence during her lifetime (footnote 23). In 2015, more than 40,000 women applied to the specialized divisions for the protection of women within the Ministry of Internal Affairs. More than 3,500 were accommodated in crisis centers to receive legal and psychological assistance. Every year, approximately 35,000 individuals are reported for committing offenses in families, and an estimated 8,000 arrests are made (6). 
In 2015, the Committee on Statistics conducted a national survey to identify women's experience of violence by an intimate partner. The survey is part of ongoing efforts to monitor Kazakhstan's progress in meeting its commitment under SDG 5 to eliminate violence against women and girls.

As shown in Figure 8, 16.2\% of women reported experiencing physical violence during their lifetime and $4.5 \%$ reported such incidents in the past 12 months. For sexual violence, $3.6 \%$ of women reported an incident during their lifetime and $1 \%$ in the past 12 months. Almost onefifth of women reported suffering from psychological abuse during their lifetime and $7.1 \%$ in the past 12 months. Economic abuse, generally defined as depriving women of access and control over economic resources, affected $6.3 \%$ of women during their lifetime and $5.4 \%$ in the past 12 months.

Women who had experienced violence by an intimate partner were asked whether they had sought help to address the problem. More than half (51\%) reported that they never told anyone about the violence they suffered at the hands of their partner. Women who did disclose such incidents discussed it with family and friends, and very few women told authorities.

Domestic violence. The Law on the Prevention of Domestic Violence was passed in 2009 and includes definitions of domestic violence that encompass physical, psychological, sexual, and economic violence. The law requires local authorities to develop programs on domestic violence prevention, and provide victims with the needed services and protection. This law increases the penalties for crimes in the area of family relations, including for crimes committed against minors. It also amended the legislation on the rights of the child and on education with respect to the protection of the rights of children in difficult circumstances (footnote 19).

Figure 8: Reported Incidence of Violence against Women in Kazakhstan, 2015

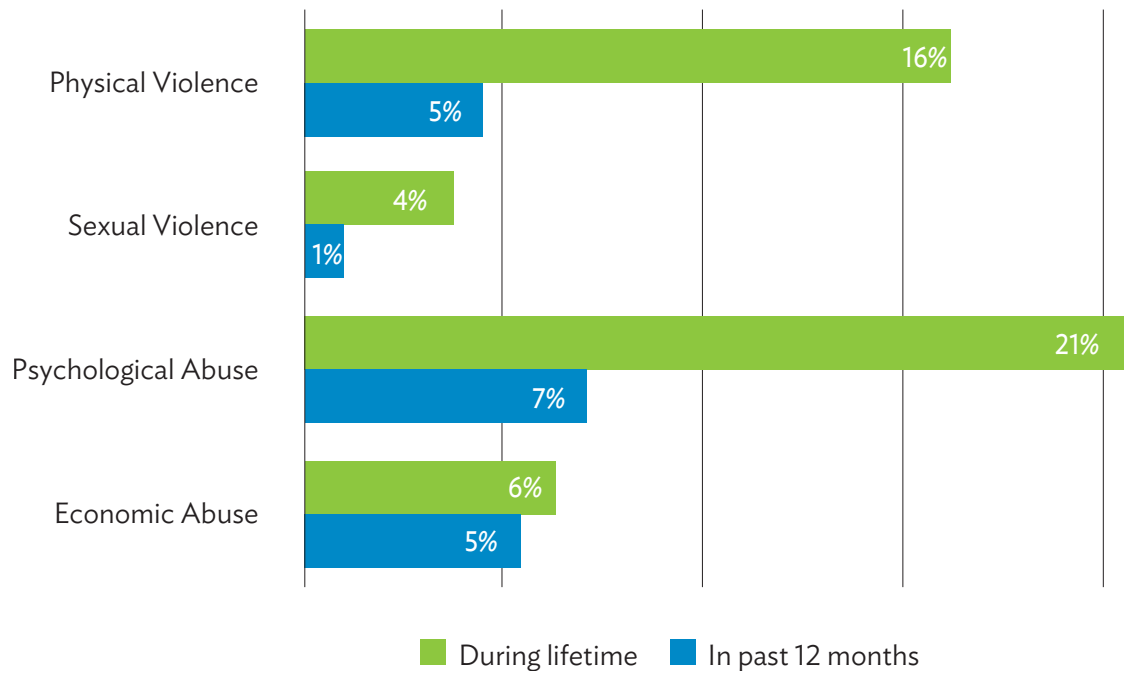

Source: A. Dossanova. 2017. Violence Against Women in the Home: What do Statistics in Kazakhstan Tell Us?. In H. Hemblade et al, eds. Femicide Volume VII: Establishing a Femicide Watch Watch in Every Country. Vienna: Academic Council on the United Nations System. 
The law stipulates that perpetrators can be placed in emergency administrative detention of up to 48 hours for noncompliance with a restraining order. Penalties for committing domestic violence are from 3 months to 3 years of imprisonment, or up to 10 years of imprisonment in very serious cases. The law includes a comprehensive implementation mechanism that mandates the responsibilities of the courts, police, local authorities, health-care providers, crisis centers, and social service providers. The Advocates for Human Rights note that some police officers have received special training to deal with domestic violence cases (footnote 19).

Kazakhstan's legal framework currently treats domestic violence as an administrative matter; the Law on Prevention of Domestic Violence does not establish it as a criminal offense. The procedures that women should use to report a situation, seek a prevention order, or receive other services are not clear. Although aggressors may be prosecuted under existing criminal provisions, a specific provision is needed to ensure that the justice system responds to such situations as with other serious crimes.

The provision to impose administrative fines as sanctions means the law is not treating domestic violence as a serious crime. In addition, there are no criminal sanctions for breach of a prevention order. The imposition of fines often negatively affects women and children as they deplete the family's overall resources. Women are therefore reluctant to report situations of domestic violence (footnote 18).

When women do report domestic violence, they are often faced with inappropriate responses despite the law's provisions to sensitize officials on how to better support women in this situation. While the law also stipulates that support services are to be made available to survivors of domestic violence, in reality, the provision of such services is extremely limited. For example, Kazakhstan has only 28 crisis centers; of these, only 17 include a shelter, which is far below demand. These shelters are run by civil society and depend largely on voluntary donations for funding. Since the enactment of the Law on Domestic Violence in 2009, no significant increase in resources has been made to address the urgent need for crisis centers and shelters or for legal assistance to victims of domestic violence.

Family and social pressures on the victim, potential threats from the accused and their relatives, fear, and stigma can influence whether a woman pursues legal redress. In 2015, the Multiple Indicator Cluster Survey (MICS) survey found that $15.1 \%$ of women believed that a husband or partner is justified to hit or beat his wife or partner in at least one of six situations when a woman does not comply with certain expected gender roles (footnote 25 ).

Despite the many constraints to implementation, the government has announced that the law is effective in reducing the rate of violence against women. A report from the Ministry of Internal Affairs states that the incidence of domestic violence has been reduced by $35 \%$ since 2011 due to provisions of the Law. ${ }^{56}$ However, no analysis is made of the extent to which this decrease represents a reduction in the incidence or a reduction in reporting. The government has applied the law, issuing more than 379,000 protection orders since 2010. However, the Minister's address on this issue propagates myths about domestic violence, noting that these are the result of conflicts in families with low incomes or are caused by intoxication (footnote 57).

Sexual assault. Rape is a criminal offense in Kazakhstan. The victim must register a complaint in order for criminal investigations to proceed. Once she has done so, the complaint cannot

${ }^{56}$ Z. Dyussembekova. 2017. Kazakh Domestic Violence Rate Decreases. Nation. 22 February. 
be withdrawn. This measure ensures that a woman cannot be intimated into withdrawing the complaint (footnote 18). Although the criminal code does not specifically mention marital rape, court decisions have established that the relationship between the perpetrator and the victim is not to be considered in the determination of rape or other acts of sexual violence. Penalties for rape range from 3 years to 15 years of imprisonment, depending on the severity of the attack, the number of perpetrators, and the age of the victim.

However, many sexual assaults are not treated as crimes by the law. The legal definition of sexual assault includes elements that are based on the inaccurate assumptions that a woman has consented to sexual contact unless she physically resists and must be overcome by force or by the threat of violence. The elements of physical force or a threat thereof must have occurred in the course of the act for sexual assault to be deemed a crime. As a result, rape clauses will not apply in situations where sexual contact is nonconsensual but is not accompanied by violence or an expressed threat of violence (footnote 18).

As a result, women are reluctant to report sexual assaults since coming forward places an undue burden on victims to prove that a crime occurred. Prosecution of sexual assault can only commence when proactively initiated by the victim, whereas in other crimes the State initiates proceedings. Also, while trained justice professionals are meant to be available to sexual assault survivors, in many regions such personnel are not available (footnote 18).

Sexual harassment is not specifically prohibited by law in Kazakhstan. During the visit of the Organization for Security and Co-operation in Europe (OSCE) Special Representative on Gender Issues to Kazakhstan, NGO representatives and parliamentarians recommended more education of the public and members of Parliament about the nature, seriousness, and frequency of sexual harassment. The OSCE's Special Representative on Gender Issues was presented cases of sexual harassment from women's rights organizations in 2012 and considered it to be a serious issue that was not being sufficiently addressed. ${ }^{57} \mathrm{~A}$ small-scale pilot survey carried out by the Feminist League of Kazakhstan in 2012 found that, of 750 women questioned, 70\% had experienced sexual harassment in some form (footnote 18). Key informants from CSOs and international development partners, interviewed as part of this assessment, highlighted that no further progress had been made in developing clear legal provisions to address sexual harassment since these findings were made public.

Women face barriers in seeking justice and legal accountability for sexual harassment due to the lack of clear legal provisions, onerous court procedures, and social stigma. For example, a case of sexual harassment reported in the media concerning a woman working in a small rural school was brought to court with support from international agencies. The court ruled in favor of the woman in 2011. In 2017, the woman still had not received the compensation the court deemed was owed her for the time off work and health issues she suffered. ${ }^{58}$

Trafficking in persons. Kazakhstan is a destination and, to a lesser extent, a source and transit country for human trafficking and forced labor. Domestic trafficking accounts for the most identified victims. Women and girls from Kazakhstan are subjected to sex trafficking in the Middle East, Europe, and the United States. Within the country, women and girls from neighboring

57 OSCE. 2012. Report of OSCE Special Representative on Gender Issues on Visit to Kazakhstan. 19-21 June. https://www.osce.org/cio/97292?download=true.

58 Sputnik Kazakhstan. 2017. School Cloakroom Attendant Hasn't Received 7 Million Tenges for Harassment. 28 July. https://news.mail.ru/society/30522635/?frommail=1. 
Central Asian and Eastern European countries, as well as from rural areas in Kazakhstan, are subjected to sex trafficking. ${ }^{59}$

Major cities such as Astana, Almaty, and the western oil cities of Aktau and Atyrau are destinations for rural migrants, some of whom become victims of labor trafficking and sexual exploitation. In 2013, 346 criminal cases were brought to court related to trafficking and sexual exploitation, including more than 40 involving minors. ${ }^{60}$

Kazakhstan has a Plan of Action to Combat and Prevent Offenses Involving Trafficking in Persons that was started in 2006 and has been updated in 3-year intervals. ${ }^{61}$ The plan does not fully meet international standards as it allows conciliation between parties, has insufficient systems to identify and support trafficking victims, and allows for their deportation. However, the government has been making increased efforts to address trafficking, including more frequent prosecutions of traffickers, prosecuting a case of police collusion, and establishing four shelters for victims (footnote 60). More progress in this area is becoming a pressing issue. An increasing number of foreigners are entering Kazakhstan, but the country has no legislation to deal with child sex tourism and little experience in combating the issue (footnote 62). More targeted legal provisions, specialized police, border, and prosecutorial human and financial resources are needed to scale up anti-trafficking efforts as the country opens its borders to more trade and tourism.

Forced marriage. Although rare, forcing minor girls into marriage without their consent, including bride kidnapping, does occur in Kazakhstan. Such acts are criminal offenses. Under Article 122 of the Criminal Code, sexual intercourse and other activities of a sexual character involving persons under 16 years of age can lead to up to 5 years of imprisonment. The Criminal Code stipulates 8-10 years of imprisonment for kidnapping (Article 125). However, in cases of bride kidnapping, perpetrators who "voluntarily release the abductee are absolved of criminal responsibility if in this action they did not commit another offence," meaning that bride kidnapping is not necessarily treated as a crime (footnote 18).

A total of $6 \%$ of women aged $20-24$ were first married or in union before age 18 (footnote 61 ). Specific programs or policies to protect children from early marriage have not been put in place, although the National Committee on Women's Affairs, Family and Demographic Policy has undertaken some awareness campaigns in targeted areas such as South Kazakhstan where the Commission considers a greater risk of occurrence exists (footnote 18).

Government responses to gender-based violence. Kazakhstan has recognized that its provisions for GBV need strengthening. Since 2016, the General Prosecutor, with support from the National Commission and in partnership with the United Nations Entity for Gender Equality and the Empowerment of Women (UN Women), UNFPA, and other international organizations, has piloted a multisector plan: "Kazakhstan Free from Domestic Violence" in South Kazakhstan. The plan aims to strengthen interdepartmental cooperation and create more support for survivors of violence, including increasing access to legal advice, psychological help, shelter, and information

59 US Department of State. 2016. Trafficking in Persons Report. Kazakhstan Country Profile. Washington, DC. https://www.state.gov/j/tip/rls/tiprpt/countries/2016/258794.htm.

60 UN Women. 2016. Ending Violence Against Women: Facts and Figures, Kazakhstan. New York.http://evaw-globaldatabase.unwomen.org/en/countries/asia/kazakhstan.

${ }^{61}$ ECPAT International. 2016. Access to Justice and Right to Remedies for Child Victims of Sexual Exploitation Research Project.Executive Summary: Kazakhstan. http://www.ecpat.org/wp-content/uploads/legacy/Ex_Summary_EU_ KAZAKSTAN_FINAL.pdf. 
services. According to UN Women, the pilot project is yielding results with more cases reported and more training provided to service providers. However, the plan is yet to be rolled out to other parts of the country. ${ }^{62}$

Key informants interviewed for this assessment reported that the National Commission has guided the General Prosecutors Office in preparing a new road map to improve implementation of the law. In addition, the road map calls for public education to increase awareness and encourage women to come forward to report GBV and seek assistance. The road map calls for more training of officials in the justice system, improved referral networks, and more cross-agency collaboration. The specific measures for ensuring implementation of cross-agency services is not yet fully elaborated. Also, the allocation of resources to expand the number of support services, such as shelters and crisis centers, has not been committed. The emphasis of the road map is to combat domestic violence under the government's emphasis on family policy. As a result, the actions proposed do not address the complete range of $\mathrm{GBV}$ issues that women experience.

\section{E. Reduced Vulnerability to Risks and Shocks}

\section{Economic Shocks}

Kazakhstan's economy has experienced a series of shocks resulting from economic crises, the fall in oil prices, and changes in valuation of its currency. These shocks have an impact on low-income households as job prospects shrink, consumer prices and loan rates rise, and lack of savings means no financial cushion. Women, particularly those from households headed by women with children and elderly women on their own, are vulnerable during periods of economic shocks.

Kazakhstan has a social protection system that includes universal transfers for families of all income groups with children and targeted transfers for those living below subsistence levels. This system is an important support for families but is in need of reform. A UNICEF study on the national social transfer system ${ }^{63}$ has shown that only $20 \%$ of those eligible for subsistence social transfers access their benefits. In many rural areas of the region, the figure is as low as $5 \%$. Access to social transfer benefits is limited by a lack of information on qualification for such benefits, complicated applications, and distances to travel in rural areas (footnote 64).

For those who do access social transfers, the amounts-at $40 \%$ of subsistence-are not adequate to meet their needs, in part because transfers do not always account for the number of children in the family or other circumstances. Kazakhstan's social protection system does not have specific measures for single-parent households, whether headed by women or men. This gap has a greater impact on women, with around one in four mothers of young children being sole parents. The government is reforming its social transfer system to increase the transfer level to $50 \%$ of subsistence, but this amount needs to be closer to $100 \%$ to meet requirements. More awareness on the social protection system among women and other vulnerable populations is needed. In addition, more decentralized centers would assist women to better deal with the impact of economic shocks (footnote 64).

\footnotetext{
62 UN Women. 2017. Kazakhstan's New Plan to End Domestic Violence Demonstrates Multi-disciplinary Action. Astana. http:// www.unwomen.org/en/news/stories/2017/8/feature-kazakhstans-plan-to-end-domestic-violence-demonstratesmulti-disciplinary-action.

63 UNICEF. 2015. Analysis of Social Transfers for Children and Their Families in Kazakhstan. Astana.
} 


\section{Disaster Risks}

According to a disaster profile prepared by the Global Fund for Disaster Risk Reduction, ${ }^{64}$ Kazakhstan's population and economy are exposed to earthquakes and floods, with floods posing the greater risk. Other risks include storms, landslide and slope collapse, epidemics, extreme temperatures, and forest fires. The province at greatest risk of floods is Atyrauskaya, and the one at greatest risk of earthquakes is Almaty City. The annual average population affected by flooding in Kazakhstan is about 300,000, and the annual average affected gross domestic product (GDP) is about $\$ 3$ billion (footnote 65). Floods in 2011 caused only two fatalities but damaged close to $\$ 70$ million in assets (footnote 65 ). The deadliest floods since Kazakhstan gained its independence in 1991 occurred in 2010, with 40 fatalities and close to $\$ 40$ million in damage. In April 2017, heavy floods hit regions across northern Kazakhstan, causing at least 7,000 people to be evacuated and damaging 1,500 buildings. ${ }^{65}$

The annual average population affected by earthquakes is about 200,000 and the GDP affected by earthquakes amounts to $\$ 1$ billion (footnote 65 ). The annual average of fatalities caused by earthquakes is 500 and capital losses amounting to about $\$ 400$ million. The most recent earthquake occurred in 2003 and affected 40,000 people and caused three deaths. Parts of the population are exposed to industrial risks, and past industrial accidents, such as radioactive pollution of the Semipalatinsk nuclear site, still affect the population (footnote 65).

Another risk is the drying of the Aral Sea during the past 40 years due to the rapid irrigation developments in Kazakhstan and Uzbekistan. These large-scale schemes that diverted water inflows to the sea resulted in serious economic, social, and environmental damage. Kazakhstan's water efficiency is very low due to outdated irrigation technology and poor practices. Some basins in Kazakhstan already face significant water shortages and a large portion of arable land is subject to drought. As a result of glacier degradation due to climate change, water flows from the mountain rivers will inevitably change, potentially leading to water shortages. ${ }^{66}$ Women and men have different roles in society, production, and household tasks, and, consequently, experience disaster and climate change impacts in different ways. The lack of gender statistics and sexdisaggregated data does not allow a clear picture of the impacts of disasters on women and men.

It is crucial to understand overall climate risks, and the risk for men and women separately. Women are active in agriculture, which is highly vulnerable to production losses due to the impact of climate change on temperature and water resources. Women spend more time than men collecting water, resulting in longer workdays when water sources dry up. ${ }^{67}$ Women may be more adversely affected when disasters strike. For example, women are more responsible for the care of young children and the elderly, putting them at greater risk when they need to evacuate with those in their charge. Despite women being the majority of those residing full-time in rural areas, they comprise a small minority of those who benefit from training programs and other forums to develop disaster preparedness and response systems. Since women are underrepresented in local government and community leadership roles, they are usually not selected for such types of training. The result is that women's perspectives and specific needs are often lacking in disaster risk reduction (DRR) plans.

${ }^{64}$ Global Fund for Disaster Risk Reduction, World Bank Group. 2015. Kazakhstan. Washington, DC. https://www.gfdrr.org/ kazakhstan.

${ }^{65}$ ECHO. 2017. Daily Flash. 20 April. Brussels.

${ }^{66}$ World Bank. 2013. Kazakhstan Overview of Climate Change Activities. Washington, DC.

67 UNISDR and UN Women. 2015. Gender Experts' Voice Heard at Regional Consultations. In Central Asia And South Caucasus On Disaster Risk Reduction For Post-2015 Agenda. Astana. 
Kazakhstan needs to take more measures to enhance women's participation in formal DRR processes at all levels, including policy and decision-making. Disaster preparedness and response plans must consider the specific needs of women and vulnerable groups such as women and men with disabilities. Up to now, gender mainstreaming issues are not addressed in national DRR policies and strategies (footnote 68). Similarly, the Concept on Gender and Family Policy until 2030 does not mention gender mainstreaming in the DRR sector. As Kazakhstan faces more disasters due to the impacts of climate change, it will be increasingly important to focus on gender mainstreaming in DRR plans. In addition, integrating measures to address gender equality in climate change adaptation planning is essential to ensure the relevance and effectiveness of these plans in reducing risks and meeting the needs of the whole population. 


\section{Mainstreaming Gender in ADB Operational Priorities}

$A D B$ contributes to the country's sustainable and equitable growth through three main pillars highlighted in its country partnership strategy (CPS) 2017-2021.

Pillar 1: Strengthening foundations for economic diversification. Under this pillar, ADB plans to support: (i) improving access to finance, and (ii) actively promoting private sector development. Operations will support the growth and expansion of SMEs, with a strong focus on promoting women's entrepreneurship, and the production of tradable goods and services that decrease the country's dependency on commodity exports. The key sector of portfolio investments will be in Finance and Micro, small, and medium-sized enterprise (MSME) development.

Pillar 2: Sustaining inclusive growth and reducing inequality: Under Pillar 2, the CPS for Kazakhstan aims to contribute to sustaining inclusive growth and reducing spatial and gender inequalities by (i) addressing the national and regional infrastructure bottlenecks; (ii) supporting the delivery of good quality social and public services while promoting inclusive and sustainable urbanization; and (iii) strengthening governance and institutions, and combating corruption. The main sectors of portfolio investment are planned for Agriculture, Health, and Transport.

Pillar 3: Promoting green growth in response to climate change. Under Pillar 3, ADB will promote green growth in response to climate change by (i) promoting energy efficiency and the use of renewable energy sources, and (ii) supporting climate change mitigation and adaptation efforts. ADB's key intervention will be to promote Green growth through sustainable energy and climate change mitigation and adaptation.

ADB also plans to support several knowledge-building initiatives that will contribute to Kazakhstan's emergence as a regional economic and transport hub linking Central Asia and Europe.

The following section reviews the overall context of each of the key programming areas, highlights the main gender issues, and identifies the government policies and programs in place. This section also reviews ADB's existing and planned investments in the sector, experiences to date with gender mainstreaming in ADB interventions, key lessons, recommendations for improving gender mainstreaming, and identification of potential gender entry points. The review of ADB's past experiences in gender mainstreaming covers (i) Finance and MSME development and (ii) Transport, as these sectors have been the two main areas of ADB's programming since the last Kazakhstan Country Gender Assessment in 2013. 


\section{A. Strategic Pillar 1: Economic Diversification}

\section{Micro, Small, and Medium-Sized Enterprise Development}

\section{a. Sector context}

MSMEs are a key foundation of Kazakhstan's business sector. In 2015, Kazakhstan had 1.1 million MSMEs, of which 930,000 were microenterprises (sole proprietorships), 176,000 small enterprises, and 2,900 medium-sized enterprises (footnote 27). Women are active in the sector: in $2015,42 \%$ of active SMEs were headed by women (footnote 26 ). This figure ranges from $48 \%$ in the Karagaranda region to 34\% in South Kazakhstan. MSMEs contribute 25.6\% of GDP and account for $36.5 \%$ of employment. Sole proprietors employed $49 \%$ of MSME labor, followed by small (39\%) and medium-sized (12\%) enterprises (footnote 27). MSMEs contributed $26 \%$ of GDP and $32 \%$ to employment (footnote 27 ). Women are most likely to be registered as sole proprietors rather than as legal corporations: $79.8 \%$ of women registered as individual entrepreneurs compared with $72.1 \%$ overall (footnote 26 ).

The MSME sector has continued to expand in the last several years despite the country's economic challenges. Since 2010, registered SMEs have expanded by $128 \%$ (footnote 26). Compared to 2010, SMEs have increased their share of GDP by $5.6 \%$ and increased the share of employment by $3 \%{ }^{68}$

The most common form of MSME, sole proprietorships, shows low productivity, with an annual output per worker of $\$ 3,170$ equivalent in 2015 . However, this category accounts for the highest share of MSME employment and is important for providing subsistence income to many households particularly those in rural areas. The majority of MSMEs are highly concentrated in a few sectors characterized by low risk and low start-up capital. The remaining SMEs are active in agriculture (23\%), transport and communications (8\%), and manufacturing (3\%).

While MSMEs contributed 26\% to GDP in 2015, loans to MSMEs represented only $9.8 \%$ of GDP in 2015. The country's experience of economic shocks during the 2008 financial crisis, followed by the drop in commodity prices and currency devaluations, has affected the performance and stability of the banking system. Despite the restructuring of some banks in the past few years, the banking sector continues to face difficulties. The effects of slower growth have resulted in a significant buildup of nonperforming loans. Banks are more inclined to lend to large businesses and state-owned enterprises, and many MSMEs are unable to meet the high collateral requirements and high interest rates of commercial borrowing. ${ }^{69}$

\section{b. Government strategies}

Enhancing the MSME sector is a key part of Kazakhstan's strategies to generate employment and diversify the economy away from its dependence on commodity exports. The national development strategy, the Kazakhstan 2050 Strategy, targets a 50\% increase in the contribution of SMEs to GDP by 2020. The Business Development Road Map 2020, Program on Effective

${ }^{68}$ ADB. 2016. Supporting Resilience of Micro, Small, and Medium-Sized Enterprises Finance Project. Report and Recommendation of the President to the Board of Directors. Manila.

${ }^{69}$ ADB. 2016. Sector Assessment Summary: Finance. Supporting Resilience of Micro, Small, and Medium-Sized Enterprises Finance Project (RRP KAZ 49076). Manila. 
Employment and Mass Entrepreneurship 2020, and the State Program of Industrial and Innovative Development (2015-2019) contain measures for MSME support, with stated objectives to expand entrepreneurship among women, youth, and people with disabilities (footnote 69).

The government has put in place programs with its development partners to enhance MSME growth through improved access to finance. The DAMU Entrepreneurship Development Fund is a government-owned agency established in 1997 to support MSME development. DAMU plays a key role as a financial agent, as well as the program coordinator of the Business Road Map 2020. The Road Map's main objectives are ensuring sustainable and balanced growth of businesses in the non-oil sectors of the economy, as well as sustaining existing and creating new employment (footnote 70).

DAMU's main activity is arranging lending to SMEs and microfinance organizations through commercial banks and leasing companies, using both DAMU's own and borrowed funds. DAMU supports enterprises that operate in or are being established in priority sectors, providing loans on commercial and concessional terms. In addition to lending, DAMU provides nonfinancial support for SMEs in the form of (i) training support for business start-ups, (ii) service and consulting support for existing entrepreneurs, (iii) training of top management of SMEs, and (iv) establishing business relations with foreign partners ("Business Connect") (footnote 70).

\section{c. Key gender issues}

Gender differences in profile and support needs of entrepreneurs. MSME development has high potential to contribute to gender equality in light of women's strong presence in this sector. Also, more support to women to develop micro and small business is critical to stimulating private sector growth. To be effective, MSME promotion programs need to take into account the differences that exist in characteristics and needs of female and male entrepreneurs.

A survey of male and female entrepreneurs completed under the technical assistance to prepare the Supporting Resilience of Micro, Small, and Medium-Sized Enterprises Finance Project, ${ }^{70}$ identified several factors that distinguish female entrepreneurs from their male counterparts. The majority of MSMEs headed by women (58.3\%) reported an average annual sales turnover at the lowest category of below $\$ 10,000$, whereas only $40 \%$ of MSMEs headed by men were in this category. An almost twice higher percentage of businesses headed by men reported annual revenues within the range of $\$ 10,000-\$ 50,000$ (38\% of enterprises headed by men vs. $18 \%$ headed by women) (footnote 71). Women are typically operating small businesses as individual entrepreneurs. This finding suggests that women would benefit more from programs that target microenterprises and support them as they grow their businesses.

Women launch businesses at different life stages than men. Women entrepreneurs, on average, are older, with the higher share of women being age 50 and above (footnote 71). A considerably higher share of women entrepreneurs is divorced, separated, or widowed compared to male entrepreneurs (footnote 71). These factors could signify that women need more services to balance family obligations. The findings may also suggest that women need greater incentives to start businesses at earlier stages in life. Such gender differences reveal a few of the elements

70 A. Jappar and J. Jandosova. 2013. Kazakhstan: Improving Capacity to Support SME Development - SME Survey- A Needs Assessment. Astana: Sange Research Center. 
in what distinguishes male and female entrepreneurs. More data are needed to fully understand gender differences in entrepreneurial development.

Balancing entrepreneurship and family responsibilities. The tendency for women entrepreneurs to be older than men on average suggests that entrepreneurship is a more difficult choice for younger women who tend to have more childcare responsibilities than men. A survey of women entrepreneurs conducted for this assessment did reveal that they considered combining family and business responsibilities to be one of their key challenges. Some benefits available to women for maternity and childcare leave, which are covered through programs paid by employers, are not available to self-employed women entrepreneurs. Women entrepreneurs are entitled to childcare services available to all families, but such services will not necessarily accommodate the irregular hours necessary to run a business. To increase the number of women who consider entrepreneurship a career option, more programs are needed to assist women entrepreneurs to balance work and family life. More outreach to ensure that women access information on the available support is also needed.

Enhancing women's access to credit. MSMEs need banks in order to expand and grow. In Kazakhstan, MSMEs represent only $16.3 \%$ of bank lending to the private sector (footnote 71 ). The survey conducted by ADB to prepare the Supporting Resilience of Micro, Small, and Medium-Sized Enterprises Finance Project found that $49 \%$ of rural respondents and $42 \%$ of urban respondents reported not using business loans from commercial banks within the last 3 years (footnote 71). On average, $13.6 \%$ of MSMEs are using loans from nonbank financial institutions with more rural MSMEs using this source of finance (27.6\% rural and $6.4 \%$ urban) (footnote 71 ).

Both women and men SME owners report challenges in accessing bank loans. A key concern for women was a lack of assets or undervaluing of their assets such as property. Constraints common to women and men were high interest rates, economic situation, and instability of the market (footnote 71). Also, the specific sectors that the majority of businesses headed by women were engaged in (i.e., retail trade and services) were more likely to require "fast and short money." As a result, delays in decision-making for loan consideration and approval prevented women from applying to commercial banks. While government programs make credit available through banks, sole proprietorships and microenterprises are more likely to benefit more from financing through small loans and microfinance institutions that make small, short-cycle loans (footnote 71).

Designing business development services tailored to women's needs. Women were also more likely than men to express concerns about the procedures required to set up a business both with banks and with regulatory authorities. Women-owned businesses cited the problems of excessive terms and conditions, paperwork, and prolonged and complicated procedures for commercial loan approval more often as a barrier (footnote 71). In interviews conducted as part of this assessment, women expressed concerns about their lack of familiarity with regulations involved in operating a business and problems dealing with local authorities. Key informant discussions with the Association of Business Women of Kazakhstan also revealed that women entrepreneurs considered getting information about how to set up a business as a key barrier. These findings suggest that women would benefit from more business advisory services that would guide them in launching a business or to take steps to expand their business. 


\section{d. ADB's portfolio}

Strengthening private sector development and improving finance for SMEs through DAMU is a core component of ADB's portfolio in Kazakhstan. Table 2 presents the projects that comprise ADB's portfolio in MSME development. Since 2010, ADB has provided sovereign loans of $\$ 500$ million to Kazakhstan through a multitranche financing facility (MFF). DAMU lends these funds to private financial institutions (PFIs) for loans to SMEs. The ADB funds contribute to DAMU's ability to support commercial banks to lend to SMEs at concessional rates. This intervention has been critical to assuring a flow of affordable loan funds to SMEs during the last few years when interest rates have been rising due to currency fluctuations and a shortage of loan capital.

As part of its CPS 2017-2020, ADB will continue to support (i) improving access to finance, and (ii) actively promoting private sector development. Operations will support the growth and expansion of MSMEs, and the production of tradable goods and services, thus helping the private sector expand while decreasing the country's dependency on commodity exports.

ADB's new program on Supporting Resilience of Micro, Small, and Medium-Sized Enterprises Finance Project, to be activated this year with DAMU, is focused on providing smaller loans to rural enterprises that correspond more to the characteristics of women entrepreneurs.

Table 2: ADB's Portfolio in Micro, Small, and Medium-Sized Enterprise Development

\begin{tabular}{|c|c|c|c|c|}
\hline & Description & Category & Status & $\begin{array}{c}\text { ADB } \\
\text { Financing }\end{array}$ \\
\hline \multirow[t]{2}{*}{1} & \multicolumn{4}{|c|}{ MFF: Small and Medium Enterprise (SME) Investment Program Tranche, 1, 2, and 3} \\
\hline & $\begin{array}{l}\text { The program is providing medium-term } \\
\text { loan finance to MSMEs, via the state-owned } \\
\text { DAMU Entrepreneurship Development } \\
\text { Fund. MSMEs make a sizable contribution } \\
\text { to the economy but lack funds needed to } \\
\text { expand their businesses. }\end{array}$ & $\begin{array}{l}\text { Effective } \\
\text { Gender } \\
\text { Mainstreaming }\end{array}$ & $\begin{array}{l}\text { Active } 2010 \\
\text { Closed June } \\
2017\end{array}$ & $\$ 500$ million \\
\hline \multirow[t]{2}{*}{2} & \multicolumn{4}{|c|}{ Supporting Resilience of Micro, Small, and Medium-Sized Enterprises (MSME) Finance Project } \\
\hline & $\begin{array}{l}\text { The proposed financial intermediation loan } \\
\text { will provide local currency credit to sustain } \\
\text { operations of and employment by MSMEs } \\
\text { during the current economic slowdown. The } \\
\text { technical assistance will strengthen credit } \\
\text { origination and management of selected } \\
\text { private financial institutions to better serve } \\
\text { MSMEs. }\end{array}$ & $\begin{array}{l}\text { Effective } \\
\text { Gender } \\
\text { Mainstreaming }\end{array}$ & $\begin{array}{l}\text { Approved } \\
\text { October } 2016\end{array}$ & $\$ 200$ million \\
\hline \multirow[t]{2}{*}{3} & \multicolumn{4}{|c|}{ Enhancing Insurance Market Efficiency and Outreach } \\
\hline & $\begin{array}{l}\text { The project will strengthen the policy } \\
\text { and regulatory framework for insurance } \\
\text { supervision and product design. }\end{array}$ & $\begin{array}{l}\text { No gender } \\
\text { elements }\end{array}$ & $\begin{array}{l}\text { Active } 2014 \\
\text { Closed July } 2017\end{array}$ & $\$ 940,000$ \\
\hline
\end{tabular}

$\mathrm{ADB}=$ Asian Development Bank; MFF = multitranche financing facility; MSMEs = micro, small, and medium-sized enterprises . Source: ADB. 2018. Kazakhstan Projects. www.adb.org. 


\section{e. Lessons learned from ADB projects}

Gender Action Plans are an effective instrument to promote gender equality outcomes and influence government counterparts to build ownership over the achievement. The ADB project Multitranche Financing Facility: Small and Medium Enterprise Investment Program implemented with DAMU was categorized as Effective Gender Mainstreaming. The gender action plan (GAP) for the MFF has been regularly updated with each tranche of financing. The GAP targets the following result areas:

- Improving DAMU's capacity to collect and report on sex-disaggregated indicators under its portfolio;

- Increasing the percentage of women entrepreneurs applying and borrowing through the program;

- Increasing the percentage of women accessing business development services;

- Enhancing integration of gender equality measures into DAMU's overall operations; and

- Increasing the profile of women entrepreneurs with PFIs.

DAMU provides reports on the status of implementation of the GAP. This progress is monitored by the ADB Project Officer for the investment, as well as by the Regional Gender Advisor.

ADB's experience to date shows that the GAPs developed with DAMU for each tranche of financing have increased the integration of gender equality into MSME development. Targets for women's representation in borrowing have increased with each tranche, and DAMU has been meeting its gender equality targets. For Tranche 1, started in 2011, ADB's MFF for SME development set a target of a $5 \%$ increase in the amount of finance provided to SME women entrepreneurs and a $5 \%$ increase in the number of women granted SME loans and leases. ${ }^{71}$ This target was exceeded as DAMU increased the share of its women clients from 16\% in 2009 to $30.9 \%$ by $2013 .^{72}$

The Tranche 1 GAP aimed for women to be at least $50 \%$ of those receiving business development services and included actions to ensure that services accommodate women's information and learning needs. By 2014, women represented more than $50 \%$ of those participating in enterprise awareness-raising programs and $46 \%$ of DAMU's business development services clients.

Tranche 2, agreed in 2014, targets an increase in the share of women borrowers from $10 \%$ to $24 \% .^{73}$ By the start of Tranche 3 in 2015, the baseline for percentage of women borrowers under DAMU programs was identified as $33 \% .^{74}$ However, rather than raise this target, Tranche 3 proposed to maintain it. By May 2017, DAMU reported that women represented 31.8\% of the borrowers across all three tranches of the program. However, under the ADB Tranche 3 financing, women represented $47 \%$ of borrowers, showing the trend was moving upward. ${ }^{75}$ These results show that the targeting of women by DAMU was continuing to rise even beyond the targets set in the GAP.

71 The baseline was not noted at start-up, but later identified as $16 \%$ in terms of share of women obtaining credit through the program.

72 ADB. 2015. Kazakhstan Small and Medium Enterprise Program. Tranche 1 Project Completion Report. Manila.

73 ADB. 2014. Kazakhstan Small and Medium Enterprise Program. Tranche 2 Project Agreement. Manila. Some discrepancies exist in the target setting as the Tranche 1 Completion Report states women were 30.19\% of DAMU borrowers by 2013.

74 ADB. 2014. Kazakhstan Small and Medium Enterprise Program. Tranche 2 Project Administration Manual. Manila.

75 DAMU. 2017. Kazakhstan Small and Medium Enterprise Program. Tranche 3 Report on Gender Action Plan. Almaty. 
The improved performance in targeting women entrepreneurs under this program has shown the effectiveness of establishing and following GAPs with project counterpart agencies. In key informant interviews for this assessment, DAMU has expressed a sense of ownership over its targets in order to be accountable for its commitments to ADB.

Tracking progress in gender equality in SME programs requires counterparts to develop effective databases and monitoring mechanisms. The provisions to better integrate gender into data management and DAMU operations were added to Tranches 2 and 3 . While the design documents established baselines for targeting women, for Tranche 1 and early in implementation of Tranche 2, the fact that DAMU did not maintain sex-disaggregated data on loan clients was a constraint to monitoring the GAP. By Tranche 3, DAMU had started to maintain this data to report to ADB but had not improved its overall capacity for disaggregating by sex in its management information systems to report such information for its entire portfolio.

Developing effective indicators and continuing to "raise the bar" on targets is important to continue to advance gender equality outcomes as some progress is achieved. The achievements for gender equality under the SME development show a positive trend that could be leveraged even further to promote women's economic empowerment. Women comprise $42 \%$ of SME owners in Kazakhstan. Credit targets for women could be increased further in line with their representation as SME owners. ADB financing is supporting DAMU to facilitate concessional loans allowing SME owners to borrow at 11\% instead of $18 \%$ - a significant financial benefit in the country's current high-interest environment. This reduction in interest rates can make the difference in whether a business person is able to take a commercial loan. While many women are participating, the ADB financing to DAMU is still disproportionately favoring men entrepreneurs. Overall, women are only one-third of those benefiting from the DAMU financing, whereas women represent more than $40 \%$ of the potential borrowers in the MSME sector. Higher targets for women's participation are possible and would allow women to benefit even more from ADB's financial support to MSMEs.

Kazakhstan has made strides in women's economic empowerment. Women's presence in the workplace and in business is accepted and encouraged by government, employers, and society as a whole. The opportunity exists to leverage the high presence of women in MSME development to set even higher targets for women's access to credit and make an even more significant contribution to women's economic empowerment.

Gathering qualitative information on how enterprise development programs and services correspond to women's specific needs is equally important as tracking quantitative indicators on their participation. Women entrepreneurs participating in the ADB-financed program through DAMU generally expressed positive views about the services in interviews conducted for this assessment. The majority learned of the program through a commercial bank. Most women surveyed agreed fully or partially that it was more difficult for women to access a loan and so having an intermediary service such as DAMU was helpful in their business start-up.

The women interviewed indicated that, without the DAMU financing, they would have been able to access a commercial loan - as they had already contacted the bank-but would have had difficulties with repayment. However, the finding indicates that women entrepreneurs who do not approach a bank because of the high interest rates or other constraints would not learn about DAMU's lower interest rate options. 
After joining the program, most women interviewed had contacted DAMU staff and found their service to be satisfactory. The main advantage of the program was the lower interest rate. Most women had not had training or consulting services through DAMU, but felt that some training would be useful to them. The women interviewees identified training in management, accounting, and finance as key priorities. These women believed that the loans needed to be simplified, and even more concessional products were necessary in the current finance environment. In addition, more women-owned businesses should be made aware of the opportunities available through DAMU.

The survey results show that while women are benefiting from the DAMU program, they have specific lending and service needs that should be regularly assessed and accommodated. Integrating indicators that assess how programs are appropriate and relevant to women entrepreneurs would enhance the quality of services.

More holistic and tailored support to women entrepreneurs-start-up advisory services, credit, and ongoing business development services to manage growth-is necessary to ensure that women fully access available opportunities. The gender analysis prepared for the 2012-2016 CPS ${ }^{76}$ proposed the following strategy for the finance sector: (i) support the mainstreaming of gender issues into general SME development programs, (ii) expand opportunities for women entrepreneurs to enter new sectors and to expand micro and smallscale businesses, and (iii) support business advisory services and training programs that respond to distinct characteristics of women's entrepreneurship. The design of the projects in this portfolio followed these recommendations for mainstreaming gender into programs to increase MSME credit opportunities. However, as ADB's portfolio focused on commercial financing, the recommendations to support credit products for small-scale businesses and to provide business advisory services for women's specific needs were not developed further in the project design. $A D B$ could further reduce the full range of barriers to the growth of women's entrepreneurship by developing more initiatives tailored to women as recommended in the 2012-2016 CPS, including getting information about available credit, training and business advisory services, and developing credit products that are tailored specifically to women's situation in terms of access to assets and risk level.

DAMU has just launched a new program with European Bank for Reconstruction and Development (EBRD) financing that will specifically target women-owned MSMEs. The new program will provide dedicated financing for women's businesses; provide technical assistance to PFIs to design credit products for women; and support women-led SMEs in accessing know-how, nonfinancial business development services, and networking opportunities. It is important to have a dedicated program for women entrepreneurs that recognizes women's specific needs and offers products and services that address those needs. EBRD is also supporting other programs that target microfinance for smaller loans to rural women entrepreneurs. ${ }^{77}$ By adopting such programs, DAMU aims to increase the range of financial products available to women through private financial institutions, including microfinance services. This step shows that ADB's initiative to promote gender equality in its work with DAMU is influencing the organization to develop more strategies to increase its services to women. It also demonstrates that ADB could go further in advancing gender equality outcomes by supporting a broader range of services that are designed to meet the specific needs of women entrepreneurs.

76 ADB. 2013. Kazakhstan Country Partnership Strategy 2012-2016. Gender Analysis. Manila.

77 EBRD. 2017. EBRD and Kazakhstan Join Forces Again for MSME Financing. http://www.ebrd.com/news/2017/ebrd-andkazakhstans-kmf-join-forces-again-for-msme-financing.html. 


\section{f. Recommendations for mainstreaming gender equality into ADB's micro, small, and medium-sized enterprise development}

Based on the key gender issues and lessons learned from ADB's experiences to date, the section below identifies recommendations for priority areas to strengthen gender equality through ADB's portfolio for SME development.

Establish indicators and targets in the Development Monitoring Frameworks program that ensure women's equitable access to benefits. The GAP is a tool to guide government counterparts in implementing concrete plans to achieve gender equality results. However, baselines and targets for women's enterprise development need to assess the share of women already present in the sector, and identify achievable levels to increase their relevant project benefits. Women represent $42 \%$ of business owners and so targeting their participation in ADB lending programs to SMES at 33\% underrepresents their share in the sector.

Women face more constraints to credit and so are likely to form a smaller share of entrepreneurs served by banks (sex-disaggregated data on bank lending is not available). However, concessional interest rates are meant to overcome barriers to access and so having the target of women borrowers equivalent to or higher than their proportion in the SME sector is necessary to achieve gender equality outcomes. Setting the target for women below their proportion as business owners creates the risk that $A D B$ concessional lending financing disproportionately assists male entrepreneurs. To contribute to SME development and job creation, DAMU-supported loans need to be geared toward those borrowers that otherwise might not access loans at normal commercial rates. Setting targets for women's participation in the program at a higher levelpossibly as a proportion of their share as SME owners (42\%)-would better ensure that women are gaining this project benefit.

Designing small and medium-sized enterprise development programs to focus on specific needs of women entrepreneurs. Setting targets for women's participation in project benefits is important. To build even more momentum, programs need to assess women's specific needs and design products and services accordingly.

To extend financial services for women, ADB could support a number of actions similar to those that EBRD is now financing, such as (i) developing a women's credit facility that considers the needs of micro and small entrepreneurs (i.e., lowers requirements for land and other non-movable assets as collateral); (ii) providing training on various business development services (e.g., loan proposal development, product development, marketing, etc.); (iii) developing women-friendly information kits on accessing credit and loans, including online resources; (iv) conducting gendersensitivity trainings to loan officers, bank officers, and microcredit officers; and ( $v$ ) making home support services available to women entrepreneurs, such as childcare services.

Promote gender-sensitive small and medium-sized enterprise policy development. ADB could also support the government to review its current SME policies and business road map with the goal of integrating more measures that make them gender-responsive. ADB has established strong relationships with DAMU, with the Ministry for Investments and Development, with women's business associations, and UN Women, as well as other partners active in the SME development sector. ADB also has extensive experience in women's entrepreneurial development from other countries to bring to Kazakhstan. ADB could initiate workshops to teach MSME development and identify priority areas to further improve women's business opportunities in promising sectors. 
Such initiatives could also be linked to ADB's entry into agriculture, where many rural women are already present as micro-entrepreneurs. Based on government feedback, such knowledgesharing initiatives could lead to more in-depth technical assistance to the government to design MSME promotion policies and services that are closely aligned with women entrepreneurs.

\section{Countercyclical Support}

\section{a. Sector context}

While Kazakhstan has pursued effective economic growth, the series of economic shocks experienced over the past decade - the global financial crisis in 2008, the oil price drop in 2014, and the currency depreciation in 2015-has increased structural risks to the economy. To weather the economic downturns, the Government of Kazakhstan reached out to its international development partners, such as ADB, for credit lines to stabilize the banking sector and ensure continued lending to the private sector. As shown in Table 3, ADB agreed on a countercyclical support loan that financed the government's fiscal stimulus expenditure starting in December 2015 and ending in January 2017. This financing also supported several social objectives including employment creation, reduced unemployment, and maintaining social transfer programs.

Table 3: ADB Countercyclical Support Project Description

\begin{tabular}{l|l|l|l|l}
\hline \multicolumn{1}{|c|}{\begin{tabular}{c}
\multicolumn{1}{c|}{ Description } \\
1
\end{tabular}} & Category & \multicolumn{1}{c}{ Status } & \multicolumn{1}{c}{$\begin{array}{c}\text { ADB } \\
\text { Financing }\end{array}$} \\
\hline & $\begin{array}{l}\text { Countercyclical Support } \\
\text { The loan will contribute to the government's } \\
\text { planned fiscal stimulus expenditure to } \\
\text { help Kazakhstan stabilize and continue its } \\
\text { economic growth trajectory while targeting } \\
\text { fiscal sustainability in the medium term. } \\
\text { The proposed loan will foster employment } \\
\text { creation, social services provision, and } \\
\text { low-income household support; expand } \\
\text { and modernize physical infrastructure; and } \\
\text { promote inclusive private sector development. }\end{array}$ & $\begin{array}{l}\text { Some gender } \\
\text { elements }\end{array}$ & Closed & December 2015- \\
January 2017 & & \\
\hline
\end{tabular}

$\mathrm{ADB}=$ Asian Development Bank.

Source: ADB. 2018. Kazakhstan Projects. www.adb.org.

\section{b. Government strategies}

Employment creation. Measures for promoting women's employment and social welfare were incorporated into the national programs to be financed under countercyclical support, in particular the Employment Roadmap 2020 and Nurly Zhol Development Program. The Nurly Zhol Development Program (Bright Path) was announced in November 2014 and represents a $\$ 9$ million stimulus program. The aim is to shift productivity toward agribusiness, manufacturing, trade and logistics, tourism, information technology, and finance, and away from the petroleum 
sector. The program also aims to increase lending to small and medium-sized business and domestic exporters. ${ }^{78}$

The Employment Roadmap 2020 has three objectives: (i) providing employment through investments in transport, housing, and community infrastructure; (ii) supporting private entrepreneurial activity; and (iii) training and job search assistance for internal and migrationrelated employment according to labor market demands. ${ }^{79}$ The national programs target a reduction in women's unemployment and specify rural women as priority participants.

Under the government's Employment Roadmap, which is part of the package financed under the countercyclical support, 563,000 people were permanently employed between 2011 and 2016, total employment increased by $6.3 \%$, and the number of employees grew by $16.6 \%$, with 150,400 of the new jobs created from mid-2015 to the end of 2016. The number of unemployed decreased by $9 \%$, and the figures for self-employed decreased by $14 \%$. A total of 5,712 infrastructure projects were initiated in 2016, 3,607 of which are implemented in the most remote rural areas of the country. The projects included repair of roads and educational facilities mainly in the East Kazakhstan, Karaganda, North Kazakhstan, and South Kazakhstan regions (footnote 80).

Social protection. Kazakhstan has a mix of social protection measures including (i) targeted social transfers and child allowances for those living below subsistence level; (ii) housing assistance for utility payments for low-income families; (iii) social allowances for people with disabilities and survivors having lost a breadwinner; (iv) special state benefits for mothers with many children, war veterans, and specific disaster victims; and ( $v$ ) other state benefits under specific programs for people with disabilities (footnote 64).

The government announced reforms to its social transfer programs to improve targeting for 2018 and to raise the threshold to assist those whose income reached only $50 \%$ of subsistence level..$^{80}$ This initiative demonstrates a positive direction for improving the access of poor householdsboth women and men-to targeted assistance. Women living at the subsistence level will benefit from the government commitment to maintaining social expenditures and from the reforms that will better target those in need. The government has started to draft these reforms and plans to introduce new social assistance measures in 2018 as envisioned under the Countercyclical Support Program. But details of the changes that would assess their potential and analyze the specific impacts on women and men have not yet been presented.

Ongoing government support for employment and social protection, assistance to people with disabilities, and outreach to households headed by women-headed households is essential to ensure that economic opportunities and safety nets are in place for those who are most vulnerable during economic downturns.

\section{c. Key gender issues}

Women's access to employment training and job creation programs. In keeping with the Employment Roadmap, ADB's countercyclical program targets a reduction in women's unemployment levels. However, the specific measures to stimulate job creation and training

78 Republic of Kazakhstan. Embassy of the Republic of Kazakhstan in the United States. 2017. Nurly Zhol: Economic Policy. http://www.kazakhembus.com/content/nurly-zhol-0.

79 Republic of Kazakhstan. 2017. E-gov: Government online, Employment Roadmap 2020. http://egov.kz/cms/en/articles/ zanyatost_2020.

80 World Bank. 2016. Kazakhstan MPO. Washington, DC. 
opportunities for women are not identified. The government is relying largely on infrastructure investment to create jobs. However, construction is one of the sectors of the economy where women are underrepresented, with only $20 \%$ of jobs in construction filled by women. In addition, women comprise only $18 \%$ of those graduating from construction-related fields in technical college.

Women are also prohibited from working in several construction-related jobs such as asphalt concrete work; metal pouring; boiler making; operating a bulldozer, hoist, or crane; and working as a track mechanic or electrician. While the government plans to update this list, ${ }^{81}$ it does not plan to eliminate this form of discrimination against women in the labor market. This situation disadvantages women's access to employment generated through infrastructure investment programs.

Data from the government statistics office on the number of persons placed by employment offices show an increase under the period of the Employment Roadmap. However, the increase is largely in placements for men. For example, in 2011, the employment office placed 235,013 people, of which $53 \%$ were women. By 2015, the employment office had made 304,247 placements, but women represented only $34 \%$ of those placed. The main differences in placements of women and men were in East Kazakhstan, Karaganda, and South Kazakhstan, which were some of the areas targeted for infrastructure investment by the Employment Roadmap (footnote 29).

Microcredit for rural women. The main strategy for increasing economic opportunities for women under the Employment Roadmap is through microfinance for rural women. The microcredit program provides advisory services for business start-ups, grants for equipment, and microloans. Key areas targeted for microcredit are animal breeding, crop production and marketing, and services that develop rural areas. Loans are available up to a maximum of T3 million $(\$ 8,800)$. The program is accessed by applying to the regional employment offices.

The government reports that between 2011 and 2016, 13,000 women received microcredit under the Employment Roadmap. ${ }^{82}$ The government also reports that a total of 29,000 people started a business under this program, ${ }^{83}$ indicating that while rural women's participation was a priority, they were not the majority of program beneficiaries.

While such a measure supports women to generate income, the number of beneficiaries for microcredit programs is smaller than under infrastructure investment job creation. The microcredit application procedures and requirements do not specify what measures are in place to facilitate access and ensure women's preferential treatment. Decisions on approvals of microcredit loan applications are left to local employment offices. In addition, the program beneficiaries remain among the self-employed in the labor market. In general, the government programs target a reduction in self-employment due to its instability and lack of benefits. Consequently, no strategies are developed to extend more social benefits to the self-employed or develop incentives that offer more stability to those who decide to take up microenterprises. This

81 Kazakhstan Pravda. 2017. List of Banned Occupations for Women Will Be Updated in Kazakhstan. 23 June.

82 Republic of Kazakhstan. 2016. Kazakhstan 2050: 563,000 Kazakhstanis Permanently Employed under the Employment Roadmap 2020. http://www.government.kz/en/chelovecheskij-kapital/1006480-563-000-kazakhstanis-permanentlyemployed-under-employment-roadmap-2020.html.

83 Republic of Kazakhstan. 2016. Ministry of Labor and Social Protection. Employment Roadmap: During the Implementation of “Employment Roadmap 2020" State Support Measures Covered 800 Thousand People. http://www.enbek.gov.kz/en/ node/343418. 
situation can create a trend where women accessing microcredit programs are being streamed toward a more volatile and vulnerable sector of employment.

While preferential microcredit programs for rural women enhance their economic opportunities, the benefits are only realized if they know how to access the program and are accompanied with support to balance work and family tasks as their businesses grow. In addition, such programs need to offer business advisory support and finance that goes beyond start-ups so that women move beyond informal subsistence activities to developing viable and sustainable enterprises.

Social protection for vulnerable women. Social transfers are an important protection for lowincome households, with almost half of the households in the bottom income quintile receiving some form of payment. In $2015,2.7 \%$ of women were living at subsistence level compared to $2.6 \%$ of men. Slightly more women than men receive any form of social assistance $(50.2 \%$ women compared to $49.8 \%$ men). A total of $0.6 \%$ of women are on targeted social assistance for those living below subsistence level compared to $0.5 \%$ of men (footnote 64 ).

As shown in the UNICEF study on social transfers, the majority of extremely poor households (i.e., those living on $40 \%$ of subsistence-level income) that are eligible for social assistance do not receive it (footnote 64). Amounts transferred under general categories (non-income-related, such as child benefit allowances) are higher than the amounts for social transfers targeting the poor. Women living in poverty, especially rural women, often have less information on government programs according to key informants interviewed as part of this assessment. As a result, while fewer women are counted as being at subsistence level, many women may not be registered to receive their benefits if they have few sources of information and limited mobility. An increase in social transfers from 3.8\% of GDP in 2015 to $4.0 \%$ in 2016 primarily benefited households receiving pensions. This change would have benefited a majority of women given women's longer life expectancy (footnote 64).

\section{d. ADB's portfolio}

ADB's 2009 Countercyclical Support Program helped the government fund postcrisis credit to ensure banks continued to lend to the private sector. Priority expenditures included sustaining jobs as well as ensuring that social expenditures were maintained. An additional Countercyclical Support Program, agreed in 2015, continued to support the government's measures to develop the non-petroleum private sector. The second Countercyclical Support Program financed a series of measures to mitigate the sudden and significant negative economic impact caused by the steep fall in oil prices and the economic slowdown. These measures included employment creation, private sector development, social protection, and infrastructure investment in line with the government's Employment Roadmap and Nurly Zhol program.

\section{e. Lessons learned from ADB's experiences with countercyclical support}

Countercyclical support targeting employment creation and social protection has high potential to advance gender equality outcomes. The Countercyclical Support Program was categorized as having some gender elements. As countercyclical support contributes to the government's national budget priorities, mainstreaming gender equality in this type of financing instrument leverages national resources to promote social and economic outcomes that strengthen women's strategic position in the economy. The areas of intervention, employment creation, increased credit programs, and social protection all have high potential to benefit women. Women have 
a higher unemployment rate than men, are active in the MSME sector, and represent a slightly higher percentage of those dependent on social transfers. ${ }^{84}$

The gender-specific targets under ADB's support to the Countercyclical Support Program were generally implemented as they mirrored the government's own targets under the national Employment Roadmap 2020. Women represented $45.1 \% 85$ of those who benefited from the training, placement, and other services in 2015 and 48.6\% of those benefiting between 2011 and $2016 .{ }^{86}$ Women's unemployment was reduced from 5.9\% in 2013 to $5.4 \%$ in 2016 (footnote 85). Overall, progress is being achieved in reducing women's unemployment, and women are accessing the microcredit programs and training services being financed under the Employment Roadmap 2020.

Gender-related indicators need to compare the situation of women and men to effectively measure gender equality outcomes. The Completion Report for the Countercyclical Program indicates that the women's unemployment target is achieved as it was reduced by $0.5 \%$ over 4 years. However, from 2013 to 2015 (2016 data are not available), unemployment for men was reduced from $4.6 \%$ to $4.3 \%$ (footnote 29 ) and the overall unemployment rate for 2016 was $5 \%$ (footnote 85 ). While the gender-related indicator of reducing women's unemployment was achieved, the reduction is more attributable to a decrease in the overall unemployment rate rather than a reduction in the gap in employment between women and men. Consequently, women are still more likely to be unemployed than men by the end of the financing.

Specific constraints women face in employment have not been recognized by the state programs that the countercyclical support is financing. The ongoing gender gap in unemployment levels suggests that investments in employment creation need to more effectively contribute to gender equality outcomes.

Gender-related indicators need to be integrated into all relevant labor market and social protection programs financed under countercyclical support to maximize their impact on gender equality. Having more indicators and sex-disaggregated data on the various labor, private sector development, and social transfer programs financed with countercyclical support would provide a more comprehensive picture of what was working and not working in terms of women accessing these opportunities. This information would assist in improving future programs, as well as in encouraging government to improve gender-based data systems.

In addition, more qualitative indicators that monitor what types of measures are improving women's access to employment, microcredit, and training are needed. This information would give a clearer picture of how national budget resources are advancing women's economic empowerment and what additional actions must be taken to reach the gender equality outcomes targeted under the countercyclical support. The Countercyclical Support Program did have a qualitative indicator related to improved targeting of social assistance programs. However, these activities did not specify any conditions related to ensuring access for women or tracking sexdisaggregated data. As a result, the impact of the program on ensuring gender equality in the disbursement of social expenditures was not tracked.

${ }^{84}$ ADB. 2015. Republic of Kazakhstan: Countercyclical Support. Report and Recommendation of the President to the Board of Directors. Manila.

85 The Astana Times. 2016. Kazakhstan Maintains 5 Percent Unemployment Rate. 10 October.

86 Republic of Kazakhstan, Ministry of Healthcare and Social Development. 2016. Systemic measures to ensure productive employment for Kazakhstan (presentation on the Road Map of Employment 2020). Ankara. 


\begin{abstract}
ADB and government need to have joint monitoring mechanisms of countercyclical support targets and regular dialogue on how key national programs can more effectively target gender equality outcomes. The Countercyclical Support Program did not review progress with the government on the conditions specified for ADB's continued financing of the tranches. ${ }^{87}$ Without reviews, dialogue with the government on measures for women's employment creation, microcredit access, and social protection is limited. For example, while it is possible to identify specific achievements such as reduced unemployment for women, the full impact of countercyclical support on women's economic empowerment is largely unknown due to a lack of collection of sex-disaggregated data on overall outcomes. Countercyclical support could allow $A D B$ to track the impact of economic growth and social protection measures on women that then could be linked to financing objectives and key national programs. With such knowledge, the countercyclical support could be used more effectively to raise the profile of women's economic empowerment in national priority programs.
\end{abstract}

\title{
f. Recommendations for mainstreaming gender equality in ADB's countercyclical programs
}

Develop more targeted gender-related indicators for countercyclical support programs. To better integrate gender equality into national programs, ADB could ensure that outcomes are more geared toward reducing gender gaps. Rather than adopting the gender-related indicators formulated under state programs, ADB could use discussions on countercyclical support to dialogue with the government on gender equality outcomes and women's economic empowerment. While the Government of Kazakhstan has committed to gender equality, policies that are under the responsibility of the National Commission for Women's Affairs, Family and Demographic Policy are not fully integrated into national programs under other ministries. $A D B$ could assist such integration by engaging with the National Committee when setting countercyclical program objectives and indicators. Such a step could ensure that gender equality outcomes are better articulated and more effectively formulated as key indicators within national development programs. In addition, more qualitative indicators would better ensure that women as well as men are benefiting from the investments.

Improve monitoring mechanisms to track gender equality targets. Data collection on women's and men's participation in state employment, microcredit, and social protection programs, and the resulting impacts, must be improved. To ensure equal access to benefits of national programs financed through countercyclical support, all quantitative indicators should be sex-disaggregated and regularly reported. ADB and the government need to review such data periodically to track how effective programs are in reaching women, and make any necessary adjustments. ADB could support the Gender unit of the Committee on Statistics to continue to improve sex-disaggregated data collection. Such support could be in the form of technical assistance or pilot programs to improve sex-disaggregated data collection, analysis, and reporting for key government programs such as the Employment Roadmap 2020.

Provide technical assistance on improved gender analysis for social protection, and job creation programs. The government is reforming social assistance, which is one of the conditions for receiving countercyclical support from ADB. Such changes affect very vulnerable groups in society and will have differential impacts on women and men given their varied family roles, income patterns, and interaction with the labor market. A careful sex-disaggregated analysis of

${ }^{87}$ ADB. 2017. Republic of Kazakhstan: Countercyclical Support. Project Completion Report. Manila. 
the impacts of such changes will be important to increasing positive impacts on women and other vulnerable groups. ADB has built up social protection expertise across Asia and has had some impact on social protection in Kazakhstan through its partnership in dealing with the economic crisis. Providing technical assistance and knowledge-sharing to improve gender and other types of analysis of social expenditures and their impacts on women and men would be a valuable measure to build into the ADB's programming.

\section{B. Strategic Pillar 2: Inclusive Development}

\section{Agriculture}

\section{a. Sector context}

With a significant rural labor force, and large areas of currently underutilized fertile land, agriculture in Kazakhstan has growth potential (footnote 7). In 2016, the agriculture sector employed approximately one-fifth of the population, comprising 714,400 women and 839,000 men (footnote 29), while accounting for only $4.8 \%$ of GDP.8 ${ }^{88}$ The majority of labor is concentrated in the small-farm sector, which produces $46 \%$ of agricultural output (footnote 89 ).

Kazakhstan's agriculture activity continues to be dominated by subsistence cotton and cereal farming with low productivity levels and high water demand. ${ }^{89}$ The current high level of food imports creates a strong potential for creation of more indigenous agribusinesses. However, increased productivity and competitiveness are hampered by poor infrastructure and lack of available water, weak integration of domestic food chains, limited access to modern processing equipment and technology, and distance to markets (footnote 90). Since 2005, land reform has allowed private ownership of land with full property rights to act as collateral (footnote 90). However, commercial banks have not developed credit products fully aligned with the needs of agricultural MSMEs (footnote 90).

Kazakhstan's arable area has shrunk due to deteriorated irrigation and drainage systems. About $55 \%$ of the total developed area is under full irrigation, with low operating and water use efficiency. ${ }^{90}$ About $70 \%$ of the national irrigated area is in the four southern oblasts (provinces), which also have the highest population densities (footnote 91). In arid conditions, the water deficit and inefficiencies of the irrigation infrastructure could lead to scarcity, especially in southern Kazakhstan, where the demand is highest (footnote 91).

Despite reform efforts, the state dominates agricultural services and finance. Strategies such as strengthening of farmer organizations, promoting SMEs, developing relevant rural credit and insurance products, improved veterinary and advisory service, and improved irrigation infrastructure are essential to unlock the rich potential of agriculture (footnote 67).

Over the last 20 years, agriculture output declined as a share of the economy as the country invested more heavily in energy and metal resources. Now, agriculture is a key sector for the government's strategy for economic diversification (footnote 7). In 2013, the government

${ }_{88}$ World Bank. 2017. Kazakhstan: Data: Agriculture Trends. http://data.worldbank.org/indicator/NV.AGR.TOTL.ZS.

89 Food and Agriculture Organization of the United Nations (FAO). 2014. Kazakhstan Country Strategy 2014-2017. Rome.

90 World Bank. Project Appraisal Document. Second Irrigation and Drainage Improvement Project. Washington, DC. 
launched the Agribusiness 2020 Program that promotes growth and diversification in agriculture. ${ }^{91}$ The strategy targets financial recovery, increased product affordability, improved infrastructure, services for agro-industrial enterprises, increased state support to agricultural producers, and improved efficiency in state-owned agro-industrial enterprises. The strategy covers specific master plans for enhancing competitiveness of key agricultural value chains such as wheat, dairy, and livestock. The plans also emphasize investments in enhanced productivity of agricultural land by the rehabilitation of irrigation systems and the adoption of an export-oriented policy. The Agribusiness 2020 policy document makes no mention about gender mainstreaming or the issues that women in agriculture face.

\section{b. Key Gender Issues}

Women's access to agriculture assets. Access to landholding is a fundamental issue for gender equality for rural women. Since the end of the Soviet era, Kazakhstan has introduced a series of reforms to restructure all landownership, including agricultural land. While women have equal rights to benefits of land reform, they often have less information on how the policy changes affect them and even more limited capital and legal channels. ${ }^{92}$

In the initial phases, the state maintained ownership of collective land and allocated shares to corporate farms, individual farms, commercial farms, and other entities. During this process, more farmland became concentrated in larger corporate enterprises. ${ }^{93}$ As women were underrepresented in key positions in the previous collective farm systems, they were less likely to gain management positions in the restructured corporate farms or gain access to individual farms. In a subsequent phase of reform, the Land Code passed in 2003 provided that "land plots shall be granted to the citizens of the Republic of Kazakhstan as a private property or as a temporary compensated land use (lease) for the management of peasant or agrarian economy." While "citizens" should include women, no specific mention of women's rights was made. The law also stipulated that land can only be granted to individuals with special agricultural knowledge or qualifications, or practical agricultural experience (footnote 95). Due to gender stereotypes, district officials tended to reject registration by women, on the grounds that they were not competent professional farmers or entrepreneurs. Such grounds ignored women having had previous professional positions, specialized training, or years of work experience on state or collective farms. One study completed a few years after the 2003 land reform found that many women felt their inferior bargaining power relative to men had caused them to receive more remote or poorer-quality land plots. ${ }^{95}$

Women were also less likely to obtain shares in agricultural enterprises when these state-owned or collective entities were transformed into private companies. By 2016, women represented only $12.9 \%$ of owners of registered agribusinesses (footnote 36 ).

91 Republic of Kazakhstan. Agribusiness Development Roadmap 2020. Astana.

92 FAO. 2014. Rural Women in Eastern Europe and Central Asia. Rome.

93 OECD. 2013. OECD Review of Agricultural Policies: Kazakhstan 2013. OECD Publishing. https://www.oecd-ilibrary.org/ agriculture-and-food/oecd-review-of-agricultural-policies-kazakhstan-2013_9789264191761-en.

94 Republic of Kazakhstan. 2003. Land Code of the Republic of Kazakhstan, Article 101:1. http://adilet.zan.kz/eng/docs/ K030000442

95 N. Dudwick, K.Fock, and D. Sedik. 2007. Land Reform and Farm Restructuring in Transition Countries: The Experience of Bulgaria, Moldova, Azerbaijan, and Kazakhstan. Washington, DC:World Bank Group. 
Representation in agriculture organizations. Having a lack of registered assets constrains women's economic opportunities in agriculture. Land and other assets are needed to qualify for agricultural loans and government services. For example, women's lesser agriculture land ownership and high demands on their time mean that they are often underrepresented in agriculture cooperatives, water-user groups, and irrigation management committees. As a result, women's specific needs are not fully addressed by such organizations, and many initiatives between the state and cooperative groups fail to consider large proportions of the population. Such a gap increases inefficiencies in the agriculture sector. ${ }^{96}$

Quality of work for women agricultural workers. Women represent $46 \%$ of all agriculture employees according to official statistics (footnote 29). Agriculture employs $17.1 \%$ of all women and $51 \%$ of self-employed women. In agriculture, women represent $28 \%$ of those working in medium-sized and large enterprises and $18 \%$ of those who own a small business (footnote 29).

The information suggests that rural women are more likely to be self-employed agricultural workers rather than employees of small, medium-sized, or large agricultural enterprises or registered owners of an agribusiness enterprise. The high self-employment category could signify that women tend to work on a farm enterprise registered to another family member, have a nonregistered microenterprise, or work as day laborers. In addition, the extent of women's work in the agriculture sector could be underreported given that women are less likely to hold wage-earning positions, hold land, or have agribusiness shares in their name. Women's work on family farms is often not viewed as an economic contribution and so remains underreported (footnote 93). Overall, women earn only $77 \%$ of what men earn in the agriculture sector (footnote 93 ).

Access to information about state programs and services for agribusiness development. As women are less represented in political bodies and in agriculture entities, they are also less likely to access information on subsidies, state programs, and changes to agricultural or land policies. The State Regulation of Development of Agro-industrial Complex and Rural Areas, enacted in July 2005 and amended in 2016, has no special provisions for gender equality in the sector, meaning no special provisions are being developed to ensure that women benefit from the government's direction. Rural women's organizations can play a key role in advocating women's interest in agriculture and disseminating information to rural women. However, rural women's organizations are relatively small-scale and dispersed. As a result, such organizations have difficulty providing a sufficient scale of services. The lack of rural women's organization networks also limits their capacity to advocate with subnational and national governments.

Women's integration in agricultural value chains. Restructuring the agriculture sector in Kazakhstan is important for promoting more efficiency through economies of scale and consolidating investments in competitive value chains. Women have a strong presence in agriculture, and their involvement is essential to improved production and competitiveness. Understanding the nature of women's economic activity in agriculture and their positioning in agricultural value chains is important to increasing competitiveness in ways that benefit women as well as men. Women have faced historical disadvantages during the land reforms. However, national agriculture development policies and programs are not designed with targeted measures to strengthen women's strategic positioning in key agricultural value chains. Specific activities are needed to enhance women's agriculture assets, provide them production technology, and enhance their roles in agribusiness development.

96 Republic of Kazakhstan. 2016. State Regulation of Development of Agro-industrial Complex and Rural Areas. July 2005. amended April 2016. http://adilet.zan.kz/eng/docs/Z050000066_. 


\section{c. ADB's portfolio}

Based on the government's goals to diversify the economy, the 2017-2021 CPS envisages improving production and competitiveness in agriculture, a sector that ADB had last financed from 2000 to 2010. The 2017-2021 CPS proposes improving irrigation systems, increasing agriculture diversification, and enhancing competitiveness of promising value chains. In addition, ADB will assist in developing knowledge solutions for modernizing the sector, including improving water use, enhancing production technology, upgrading extension services, expanding microfinance, and reinforcing cooperatives to provide agro-marketing and other related services.

At present, $A D B$ has one active project in the agriculture sector, a corporate loan to the dairy processor RG Brands Agribusiness Project. In the 2018 pipeline, ADB's portfolio for Kazakhstan includes $\$ 250$ million in financing for the Irrigation Rehabilitation Project. The project will finance the rehabilitation of irrigation systems in the five provinces (oblasts) of Aktobe, Zambyl, East Kazakhstan, Kyzylorda, and Karaganda, with a total irrigation area of 278,750 hectares. The project will also enhance water use and improve the quality and productivity of irrigated land. These investments will support the Government of Kazakhstan in its efforts to diversify the economic base, provide more rural employment for women and men, increase food security, and reduce poverty. Institutional development to reform and revitalize irrigation will be a core element to ensure more effective systems.

ADB's renewed financing to the agriculture sector in Kazakhstan offers new opportunities to contribute to gender equality given the importance of this sector to rural women's economic empowerment. For example, Irrigation Rehabilitation can generate new livelihood options for women farmers and reduce labor required for agriculture production. Institutional reform for irrigation and other agriculture entities creates openings for women's voice in decision-making. However, gender analysis and effective mainstreaming need to be central to the design of agricultural programs. The recommendations below outline measures to ensure that investments in agriculture contribute to rural women's economic empowerment and advance overall gender equality.

\section{d. Recommendations for mainstreaming gender equality in ADB's agriculture portfolio}

Key areas to ensure integration of gender equality into ADB's agriculture portfolio are as follows:

Ensure that women are actively involved in all stages of planning and implementing irrigation infrastructure investments. Investments in infrastructure, such as irrigation, are often seen as gender-neutral because entire farm families and communities benefit from improved agriculture productivity and water resources management. However, women and men have different roles in agriculture. Women are highly concerned with water use for fields and domestic use, and their involvement in decisions related to water management is important to efficiency efforts. Women's understanding of the priority needs for irrigation will vary from men's. For example, women are often involved in agricultural value chains (such as vegetables and livestock) that have specific water demands. Women are also concerned about how water is shared for production and for domestic use given the extent of their labor in both types of activities (footnote 93). 
It is important that irrigation rehabilitation includes women's perspectives. Agriculture investments need to be directed to irrigation schemes and rehabilitation works that women and men have identified as priorities. Involving women and men in the design and operation of systems will build ownership and enhance sustainability.

Enhance women's decision-making in cooperatives and water-user groups. The constraints that women have faced in accessing land and other agriculture assets undermine their leadership roles in rural cooperative structures and in water-user groups. Such groups are important for agribusiness networking, learning about government services and incentives, and developing leadership skills. Integrating measures to promote women's membership and leadership within programs to restructure and improve cooperatives, irrigation entities, and agribusinesses are needed to enhance women's positioning in agriculture.

Support government to conduct gender analysis of value chains to enhance agribusiness competitiveness. ADB projects could improve women's participation in agricultural value chains. Based on a gender analysis of agriculture, ADB could finance promising value chains that employ more women. Women are often less integrated into agricultural value chains since they have limited time and mobility and sometimes less technology for contact with other actors.

In designing projects, ADB could identify the key constraints, and opportunities for women at all steps in the chain, such as input provision and use, production, postharvest processing and storage, transportation, marketing, and sales. Access to information on new types of inputs and production techniques is also important for women producers. Value chain analysis that integrates a gender perspective could also identify women's landholdings, production, equipment, and their roles in trade and processing. Gender analysis can provide specific measures to integrate every step of value chain development, and ensure that women benefit from investments. ${ }^{97}$

Accounting for gender dimensions provides a more comprehensive picture of the important issues in the value chain and results in more insightful recommendations on the best options for investing increased competitiveness. Such analysis can inform the gender-specific components that need to be integrated into projects to support agricultural value chain development.

Strengthen rural women's access to microfinance and business development services. ADB's new agriculture projects need to identify rural women's constraints to enterprise development and support the government to design strategies for credit and business development services that are tailored to the specific needs of women in the different geographic regions (footnote 93). Globally and in Central Asia, women play an important role in stimulating growth through agribusiness enterprise development. ADB can support the national and regional government measures that facilitate women taking advantage of emerging opportunities as the state invests in key value chains such as dairy and agro-food processing. Women face specific barriers in terms of lack of collateral, lack of information on credit opportunities and incentives for agroentrepreneurs, more limited mobility, childcare, and high level of domestic tasks that need to be accommodated in designing effective rural enterprise development programs. ADB's existing experience with DAMU can be expanded to provide more rural women farmers and microentrepreneurs with credit products, information, and other business development services.

Enhance quality of work in the agriculture sector. Rural women depend on agricultural employment and self-employment, including working as daily wage earners. The structure of

97 GIZ. 2013. Gender in Value Chain Development. Berlin. 
the country's agricultural land ownership creates a risk that the benefits of improved profitability will be concentrated in the hands of top managers and agribusiness owners. To ensure that financing is widely distributed and reaches rural women, projects need to modernize farm and manufacturing processes to upgrade wages and the conditions of work, and invest in technology, equipment, and skills development. Measures are also needed to reduce the physical demands of farm labor, and promote better working conditions and facilities for all workers, with special attention to the needs of women.

Build capacity of rural women's civil society organizations. ADB could contribute to the capacity of rural civil society organizations to provide services to women and develop networks that would reinforce their role in influencing agriculture-related policy changes, state programs, and land reform. Strengthened rural networks would increase women's information on changes in agriculture, and allow women to improve their positioning accordingly. Such initiatives could include small pilot projects to increase information and communication technology for rural women's organizations, or workshops to engage them in agriculture policy feedback.

Build knowledge for gender analysis of agriculture policies and value chain investment. An in-depth gender analysis on the control over resources is needed to ensure women can fully participate in opportunities that emerge from a renewed agriculture economy. The government is continuing to analyze and introduce land reform initiatives, changes to agriculture subsidies, and restructuring of state control of agriculture-related assets to stimulate a regionally integrated market economy. Changes in agriculture have a differential impact on women and men. Integrating more analysis on gender impacts of varied models of agriculture reform and modernization into ADB's knowledge initiatives will improve women's positioning. Such analysis will also help highlight how women are positioned on key value chains and how investments in these areas would benefit women and the overall competitiveness of the value chains.

\section{Transport}

\section{a. Sector context}

Kazakhstan is a large landlocked country with an overall low-density population. As a result, the population relies on an expansive road network as the dominant transport means. Kazakhstan has three road networks, each under the responsibility of different levels of government and their respective road organizations: (i) the republican roads are under the responsibility of the Ministry for Investments and Development and managed by the Committee of Roads (COR), (ii) local or rural roads are under oblasts or provincial governments, and (iii) urban roads are under municipality or city authorities.

There are about 23,500 kilometers $(\mathrm{km})$ of republican roads, of which about $40 \%$ have an asphalt-based surface; and about $70,116 \mathrm{~km}$ of rural roads, of which $10 \%$ are asphalt-based. The feeder road network serving the rural population is not fully developed and is difficult to traverse, making it harder for the population to reach the main road network. According to the EBRD Life in Transition Survey, local roads were the main cause of dissatisfaction with public services, with around $66 \%$ of the population dissatisfied with local road conditions (footnote 32 ). Not all of the roads on the main international corridors meet international standards and, in some cases, traffic exceeds allowable loads. 


\section{b. Key gender issues}

Differential transport needs of women and men. The transport projects in which ADB, along with other development partners, invests are part of wider regional cooperation and national economic development policies. Government and development partners tend to view such projects as gender-neutral since they build the economy and bring benefits to the whole population. However, women and men have different transport needs that must be considered in transport investment planning and construction design. Women are more likely to be pedestrians than to own a vehicle, and their movements are predominantly for domestic tasks (shopping, taking children to schools, etc.) that require short local travel. ${ }^{98} \mathrm{As}$ a result, investments to improve rural roads more directly benefit women than financing of major highways (footnote 99).

While data are not available for Kazakhstan, in general, women comprise a higher percentage of users of public transport services and so will derive more benefits from improvements to public transport. Interviews with key informants familiar with the transport sector confirmed this pattern is similar for Kazakhstan. The country's republican road network spans many remote areas, and most villages are located along these routes. Improving the republican road network has potential to increase economic and social services for rural women. However, for women to benefit, road improvements need to facilitate safe pedestrian use (crossings, sidewalks, safety signage) and be accompanied with public transport services. Investments in organized public transport services and sheltered bus stops would increase women's road project benefits. Similarly, people with disabilities benefit from transport projects that include accessibility measures. Also, for longer highway travel, women are in greater need of public sanitation facilities that offer privacy.

Women's economic opportunities in transport. Women in Kazakhstan are active participants in many facets of the economy, including as business owners. Women will indirectly derive economic and social benefits from road improvements that increase trade and access to markets.

Identifying economic opportunities for women directly in transport is more challenging, as it is traditionally a male-dominated field, with entrenched gender stereotypes. In 2016, women represented only $19 \%$ of employees in the transport and storage sector.

According to an OECD case study, ${ }^{99}$ attitudes strongly influence the type of position women hold in public transport in Kazakhstan. Jobs such as bus driver or maintenance technician are still seen by women as traditionally male domains. The COR ${ }^{100}$ reported that $40 \%$ of their staff are women, mainly based in Astana and oblast capitals. However, for the personnel hired on road construction projects, including administration and construction jobs, only $10 \%$ were women (footnote 101).The women who are hired in road projects are mainly working in administration.

National SMEs can tender to provide supplies and services required for road construction and other transport projects. While no data are available on the number of women-owned enterprises in construction and transport, women represent $42 \%$ of SMEs overall. More potential exists for women entrepreneurs to benefit from road improvements from the supply and services contracts generated. In addition, women entrepreneurs can benefit from new economic opportunities created by improved trade routes. However, women would need more information to take advantage of such opportunities.

98 Asian Development Bank. 2013. Gender Tool Kit: Transport-Maximizing the Benefits of Improved Mobility for All. Manila.

99 OECD. 2015. Social Institutions and Gender Index. Paris. p. 52.

100 Interview with Committee of Roads, Ministry of Investment and Development, Republic to Kazakhstan, 22 May 2017, Astana. 
Road safety for women, men, boys, and girls. Kazakhstan has the highest road accident death rate per 100,000 passenger cars (24.2) of the 52 European countries that were mentioned in the World Health Organization Global status report on road safety 2015.101 Road traffic injuries are the leading cause of death in children over the age of 5 (footnote 102).

According to Kazakhstan's Committee on Statistics data on transport, 102 17,974 road accidents were registered in Kazakhstan in 2016, killing 2,390 people and injuring 23,389. Men are more likely to be killed in a road accident than women (1,729 men died from a road accident compared to 661 women in 2016), but the rate of injury from road accidents is similar between women and men (12,295 men compared to 11,094 women) (footnote 103).

The last 3 years have seen a decline in road accidents per 100,000 that peaked at 137 in 2013 (footnote 103). The Ministry of Internal Affairs reported a significant reduction in the number of accidents (13.2\% decrease), fatalities (27.2\% decrease), and accident-related injuries (10.4\% decrease) in 2016. ${ }^{103}$

Speeding is the number one cause of road accidents, followed by drivers hitting pedestrians at crosswalks. Drinking and driving and lack of seatbelt usage also contribute to high accident mortality rates (footnote 104).

Human trafficking. As outlined in section 4 on Violence Against Women, improving economic and transport corridors in Kazakhstan could add to the risks of routes being used for human trafficking or other crimes (footnote 62). Interviews with key informants conducted for this assessment indicated that, while improved transport is not directly linked to more human trafficking, the situation needs monitoring. Transport investments that include improvements to borders and custom controls, as planned in ADB's assistance to Kazakhstan, can reduce trafficking in persons and other cross-border crimes.

\section{c. Government strategies}

As Kazakhstan is located at the center of transport flows between Europe and Asia, the country is positioned to develop strategic arteries for emerging transcontinental routes, including between the fast-growing economies of Europe and the People's Republic of China. A number of strategic programs have been defined to have an efficient transport system that promotes Kazakhstan's regional positioning. These strategies include the Nurly Zhol program (2015-2019) and the State Program for the Development and Integration of Transport Infrastructure to 2020 (Transport Strategy 2020) that was adopted by the government on 13 January 2014. ${ }^{104}$ Through these strategies, Kazakhstan aims to form a modern transport system that (i) increases the flow of freight through the country by properly integrating and linking land, sea, and air systems;

101 WHO. 2016. Road Safety and Healthy Cities application discussed at the policy dialogue in Almaty. http://www.euro. who.int/en/countries/kazakhstan/news/news/2016/10/road-safety-and-healthy-cities-application-discussed-atthepolicy-dialogue-in-almaty.

102 Republic of Kazakhstan, Ministry of National Economy, Committee on Statistics. 2016. Official Statistics: Transport. http://stat.gov.kz/faces/wcnav_externalld/homeNumbersTransport;jsessionid=9QZcza4KJIH3zg50IOWFn7SjwHgeolx2IJ UnSAkJ7hjHwPTIWzXY!1738043929!-1234667160?_adf.ctrl-state=v165ij9x1_42\&_afrLoop=2059493148380372\#\%40\%3F_ afrLoop\%3D2059493148380372\%26_adf.ctrl-state\%3Dkgzvq0p4e_4.

103 Y. Uatknov. 2017. Kazakhstan Develops Road Safety Plan, Fatalities Decline. The Astana Times. 7 May. http://astanatimes.com/2017/05/kazakhstan-develops-road-safety-plan-fatalities-decline/.

${ }^{104}$ Republic of Kazakhstan, Ministry for Investments and Development. 2014. Transport Strategy 2020. Astana. 
(ii) provides connectivity between regional cities and towns; and (iii) allows the development of infrastructure centers within regions.

Along with the repair and construction of roads, the program focuses heavily on roadside service infrastructure and passenger traffic. By 2020, the government plans to build 260 roadside service centers. Also, 9 bus stations, 45 terminals, 155 service stations, and 1,048 passenger taxi stands will be built in the provincial areas of the country (footnote 105). Kazakhstan has adopted a range of road safety legislation, such as national speed limits, and drunk-driving, motorcycle helmet, and seatbelt laws with such practices being moderately to well enforced, according to the Global Road Safety Partnerships program. ${ }^{105}$

The government has also adopted the Concept for Transition of the Republic of Kazakhstan to a Green Economy, including the Energy Efficiency 2020 Program. This program identifies investment in energy-efficient public transport as one of the means to reduce transport fuel consumption by $30 \%$. The government's transport strategies make no reference to any issues related to gender mainstreaming and usage statistics, except for those on road accidents, are not sex-disaggregated.

Table 4: ADB's Transport Portfolio

\begin{tabular}{|c|c|c|c|}
\hline No. & Description & Status & $\begin{array}{c}\text { ADB } \\
\text { Financing }\end{array}$ \\
\hline \multirow[t]{2}{*}{1} & \multicolumn{3}{|c|}{ MFF CAREC Transport Corridor I (Zhambyl Oblast Section) 41121-013 } \\
\hline & $\begin{array}{l}\text { (i) Five highway sections between Almaty and Shymkent in } \\
\text { Zhambyl Oblast improved and open to traffic and (ii) Road } \\
\text { operations and maintenance facilities in Zhambyl Oblast } \\
\text { improved and operational. }\end{array}$ & $\begin{array}{l}\text { Effective July } \\
2009 \\
\text { Closed in } 2015\end{array}$ & $\begin{array}{l}\$ 812 \text { million in } \\
\text { four tranches }\end{array}$ \\
\hline \multirow[t]{2}{*}{2} & \multicolumn{3}{|l|}{ CAREC Corridor 1 (Taraz Bypass) Project } \\
\hline & & $\begin{array}{l}\text { Effective } \\
\text { February } 2013 \\
\text { Closed in } 2016\end{array}$ & $\$ 82.33$ million \\
\hline \multirow[t]{2}{*}{3} & \multicolumn{3}{|c|}{ CAREC Corridors 1 and 6 Connector Road (Aktobe-Makat) Reconstruction Project 43439} \\
\hline & $\begin{array}{l}\text { Outcome: Improved network operational performance, } \\
\text { increased transit potential, and improved social and } \\
\text { economic development of the western region of Kazakhstan } \\
\text { in particular. } \\
\text { (i) reconstruction of approximately } 299 \mathrm{~km} \text { of highway } \\
\text { between Aktobe and Makat, and (ii) improvements to } \\
\text { transport system operations with better provision of road } \\
\text { traffic safety and logistics effectiveness. }\end{array}$ & $\begin{array}{l}\text { Approved } \\
\text { August } 2016\end{array}$ & $\$ 240$ million \\
\hline
\end{tabular}

continued on next page

${ }^{105}$ Global Road Safety Partnership. 2016. Kazakhstan. https://www.grsproadsafety.org/programmes/countries/kazakhstan/. 
Table 4 continued

\begin{tabular}{|c|c|c|c|}
\hline No. & Description & Status & $\begin{array}{c}\text { ADB } \\
\text { Financing }\end{array}$ \\
\hline \multirow[t]{2}{*}{4} & \multicolumn{3}{|c|}{ MFF: CAREC Corridor 2 (Mangystau Oblast Sections) Investment Program 48424-002 } \\
\hline & $\begin{array}{l}\text { (i) reconstruction of } 790 \mathrm{~km} \text { of roads of CAREC Corridor } \\
2 \text { in Mangystau; (ii) strengthened capacity for planning, } \\
\text { project management, and asset management; and (iii) } \\
\text { improved cross-border infrastructure and facilities. }\end{array}$ & $\begin{array}{l}\text { Active since } \\
\text { December } \\
2012\end{array}$ & $\begin{array}{l}\$ 800 \text { million } \\
\text { in three } \\
\text { tranches }\end{array}$ \\
\hline \multirow[t]{2}{*}{5} & \multicolumn{3}{|c|}{ CAREC Corridor 3 (Shymkent-Tashkent Section) Road Improvement Project 46145} \\
\hline & $\begin{array}{l}\text { The project's impact will be improved regional cooperation } \\
\text { and trade along CAREC corridors. The outcome will be an } \\
\text { efficient transport network in the Shymkent-Tashkent road } \\
\text { section, and the output will be a } 37 \mathrm{~km} \text { rehabilitated road } \\
\text { section. }\end{array}$ & $\begin{array}{l}\text { Active since } \\
\text { October } 2015\end{array}$ & $\$ 125$ million \\
\hline
\end{tabular}

$\mathrm{ADB}=$ Asian Development Bank, $\mathrm{CAREC}=$ Central Asia Regional Economic Cooperation, $\mathrm{km}=$ kilometer $M M F=$ multitranche financing facility.

Source: ADB. 2018. Kazakhstan Projects. www.adb.org.

ADB is supporting Kazakhstan to construct its strategic road network in line with the national Transport Strategy 2020 and the interregional Central Asia Regional Economic Cooperation (CAREC) corridors. ADB is one of the partners in CAREC, an initiative to expand trade and competitiveness through a focused, action-oriented, and results-driven program of regional projects and initiatives in transport, trade facilitation, energy, trade policy, and economic corridor development. CAREC is an initiative to develop six identified transport and economic corridors that allow for the efficient and low-cost movement of goods across 11 member countries ${ }^{106}$ in routes that link two major global trading partners (the People's Republic of China and Europe), along with other countries of Central Asia and the Caucasus. CAREC represents a shared vision of transport and trade facilitation development with three transport goals: (i) establish competitive transport corridors across the CAREC region; (ii) facilitate efficient movement of people and goods across borders; and (iii) develop safe, people-friendly transport systems.

The strategy's action plan details both physical and nonphysical investments designed to improve the region's competitiveness, and expand trade-both among CAREC economies as well as regionally and globally. Table 4 summarizes the recently completed and ongoing transport projects that are part of ADB's portfolio in Kazakhstan.

The Committee of Roads (COR), under the Ministry for Investments and Development, is the main counterpart for the implementation of these programs.

\section{d. Lessons learned}

Gender equality components and key indicators must be documented in the design and monitoring frameworks of transport projects to ensure that measures for mainstreaming are implemented and monitored throughout the project cycle. The Gender The analysis for the

${ }^{106}$ Afghanistan, Azerbaijan, Georgia, Kazakhstan, the Kyrgyz Republic, Mongolia, Pakistan, the People's Republic of China, Tajikistan, Turkmenistan, and Uzbekistan. 
Transport Sector prepared for the 2012-2016 CPS proposed a number of measures to address transport gender equality:

- $\quad$ supporting a gender-sensitive approach for transport planning and analysis;

- building better understanding among officials, municipal leaders, and transport companies of the needs and preferences of women and men in terms of transport and road use;

- identifying the implications of transport deficiencies for women and men and appropriate measures in project designs;

- ensuring women's participation in consultations on road improvements, and providing inputs into priority investments and design measures that meet their specific needs;

- identifying how investments in road improvement and transport projects can generate opportunities for income generation and employment for men and women; and

- expanding project monitoring and assessment processes to gain understanding of how women are affected by improvements to road and transport systems.

Similar measures are also reflected in the Summary Poverty and Social Strategy for the ADB CAREC corridor improvement projects:

(i) invite women as well as men to participate in public consultations;

(ii) consider gender-sensitive road design measures (ensuring lighting, roadside rest areas with separate male/female toilets, bus stops, and sidewalks);

(iii) integrate provisions for equal employment opportunity for women and men (i.e., advertise that women are encouraged to apply, equal pay for women and men, having job site toilet facilities for women and men, etc.); and

(iv) address gender issues in social safeguards such as land acquisition and resettlement planning and preventing HIV/AIDS, and human trafficking.

Based on interviews with stakeholders responsible for these projects in ADB and in the government, the above gender equality measures are appropriate for gender mainstreaming in transport in Kazakhstan. However, the measures have not been fully operationalized. While gender issues are seen as conceptually relevant, transport projects are seen as being predominantly about "hard elements," i.e., the engineering and construction requirements. "Soft elements" such as gender equality issues are often put aside as other priorities consume project management efforts. Gender equality measures need to be detailed as activities in the design and monitoring framework to ensure that they are operationalized along with other key activities of the project. Also, having sex-disaggregated indicators in the design and monitoring framework will emphasize operationalizing gender equality measures and tracking their progress.

Beyond avoiding negative impacts, transport investments should bring equal economic and social benefits to women and men. ADB has experience from several countries on how to incorporate measures to enhance the positive impacts of transport investments for women (footnote 99). For example, in Uzbekistan, ADB has added gender components to transport projects to enhance women's livelihoods along transport corridors or build marketplaces near highways so that women vendors can benefit from more trade. Other examples such as improvements to public transport, building bus stops, and constructing highway rest stops are key design features that can improve travel for women.

In Kazakhstan, the COR is the counterpart for ADB's transport portfolio. According to the government structure, the COR is mandated to construct roads, but not other types of community 
infrastructure that come under the purview of local governments. The COR is reluctant to add extra activities that would reduce investment in their core mandate of constructing or rehabilitating roads. Even when gender-sensitive road design features are accepted at the design stage, the agreed actions may not be implemented. Without concrete examples in place, transport continues to be seen as a gender-neutral sector in Kazakhstan. Implementing pilots and showing the benefits of gender-sensitive transport design is a critical step to overcoming this challenge.

Better documentation of women's participation and inputs during public consultations is an opportunity to ensure that women's voices are heard in transport investment decisions. The CAREC corridor includes highways that, while facilitating regional connectivity, will result in direct impacts, both positive and negative, on local travel patterns. The COR ensures that public consultations are held on the impacts of road projects in line with both government and ADB policies. Key informants in the transport sector observed, from their attendance at public forums, that women participants are active in public consultations during discussions on road design features. Women's active participation in regular public transport consultations creates a key opportunity for the development of more gender-sensitive road design. However, no sexdisaggregated data are collected on participation in the public consultations and no assessments are made of how the recommendations of either women or men community members influence decisions. Information on whether gender-sensitive road design features are adopted in the final design and construction are not systematized in a way that allows for monitoring gender integration.

Road designs need to incorporate specific measures to avoid negative impacts of highways on women's mobility and travel time. Women key informants living near the CAREC Corridor 3 Shymkent-Tashkent Road Improvements interviewed for this assessment reported that the increased economic opportunity and mobility for the population was a positive benefit of this project. Despite their overall positive impacts, road projects do have some negative impacts, such as noise, increased traffic, and safety barriers, that affect local travel patterns in both rural and urban/peri-urban centers. The barriers to highway crossings are important for safety reasons, but may limit community mobility. Women are more affected as they are more often pedestrians and take shorter trips for daily tasks. Highways can increase women's local travel time depending on their design. Key informants involved in ADB's transport portfolios indicate that listening to these concerns and taking appropriate measures is essential to designing effective roads. Similarly, women, including women with disabilities, have perspectives to share on road safety measures, appropriate signage, and accessibility of crossings and sidewalks. More documentation of the results of consultations and the follow-up actions is needed to identify good practices, and monitor how negative impacts on women and people with disabilities are being avoided.

Engaging more women on road construction projects requires first attracting more women to work in transport. As per their own policies and ADB's safeguard measures, the COR requires contractors to offer equal employment opportunities to women and men, guarantee equal pay for equal work, and other measures aligned with labor laws. These provisions for nondiscrimination have not increased women's employment in road construction.

The COR has the authority to require contractors to give women's employment preferential treatment. However, as women comprise only about one-fifth of those working and studying in construction-related fields, identifying women candidates to engage for road construction would be difficult particularly in rural areas. Also, road construction in Kazakhstan is carried out along large, low-density population areas. Often, work crews are not from the local area but are comprised of teams that travel to complete sections of the road. 
Such opportunities are more difficult for women to pursue given their higher level of domestic duties, and stereotypes that reinforce that such jobs are inappropriate for women. Those interviewed as part of this assessment explained that increasing women's employment on road construction projects is only feasible with more information. Feedback from women on the types of jobs and working conditions that interest them is necessary to facilitate such opportunities. In addition, better collaboration with education institutions is necessary to draw more women into construction and transport and increase the pool of trained women workers and professionals entering this sector of the economy.

\section{e. Recommendations for strengthening gender integration in transport}

Develop measures with the Committee of Roads to increase women's voice in public consultations. Women express their views about road and transport issues in public consultations. However, a sex-disaggregated monitoring system for consultations is needed to ensure their concerns and recommendations are documented. Also, surveys of women on their transport needs and priorities are essential for effective transport planning. Equally important is having mechanisms to track follow-up actions in response to women's views. ADB could work with the COR and other government counterparts to collect more information and analysis of women's views on transport planning and road design. Such information would support more gender-sensitive planning in the transport sector. Better systematization could support the COR to develop systems to collect sex-disaggregated data on attendance and recommendations from public consultations, and report on concerns and actions taken.

Incorporate gender components into transport investments. Women's differential transport needs should be more fully addressed by integrating gender components into transport project designs. ADB could engage with government counterparts and other development partners to design gender-specific components for major transport investments such as the CAREC Corridor improvements. Activities under the gender-specific components would include more consultations and surveys with women on their transport use and needs. The components might also cover construction of infrastructure such as rest stops, bus shelters, and roadside marketplaces that would enhance the benefits of roads for women. Additional activities for gender-sensitive transport design might also include investments in improving public and private common transport services that are more frequently used by women.

Promote increased employment and training opportunities for women in transport. Having more women working in transport will lead to a greater consideration of gender equality measures in transport planning and design. Women working in transport will bring knowledge informed by their own perspective on transport usage. ADB could work with the COR to develop more proactive approaches to women's hiring in the transport sector beyond the current practice of requiring contractors to advertise that women are encouraged to apply. Measures could include support to technical colleges to attract women into transport engineering and project management, and increasing incentives for contractors to hire and create conducive working conditions for women. The Ministry for Investments and Development is responsible both for transport investment and employment generation. The ministry could be a strong partner for ADB to design more targeted programs to improve women's representation in transport infrastructure projects.

Develop programs to enhance women's entrepreneurial opportunities in transport. ADB could leverage its existing partnership with DAMU and its network of women's business development service providers to promote new business opportunities for women in nontraditional areas such 
as transport. Specific initiatives could include workshops and training programs to introduce women to transport-related business opportunities. The Association of Business Women of Kazakhstan and other networks could help ensure that information on contract opportunities in the transport sector is circulated among women. This agency and other organizations could be mobilized to more proactively seek women's participation in road construction and postconstruction-related businesses. Women's economic empowerment could also be promoted by creating more explicit linkages between business development programs and the economic corridor. Such support would enhance women's capacity to take advantage of new economic opportunities.

Scale up regional responses to human trafficking and irregular migration. Within Central Asia, Kazakhstan is a destination for human trafficking, particularly for domestic labor, and, to a lesser extent, a source and transit country for men, women, and children subjected to sex trafficking and forced labor. ${ }^{107}$ In parallel to facilitating the legitimate movement of goods and people, highway transport projects increase the risk of human trafficking and irregular migration and require a scale of response in keeping with the level of risk. Kazakhstan is a leader in the region in promoting women's participation in the economy and would be a key center to champion increased representation of women's views and gender equality measure into CAREC and other regional initiatives.

Develop capacity-building programs to generate and share knowledge on gender integration in the transport sector. ADB's financing of roads in Kazakhstan is part of national and regional strategies in which the government and several other development partners are investing. As an entry point to better promote gender in transport, $A D B$ could leverage these existing partnerships to draw more attention to gender mainstreaming in transport. Specific actions could include conducting research or other knowledge-building initiatives to make government and other stakeholders more aware of the key gender issues that need to be addressed in transport. It could also include regional workshops with other CAREC member countries to share experiences on gender-specific measures that have been applied in other investments. Engaging women's civil society groups in such knowledge-building efforts would build their capacity to influence how investments are prioritized to address gender equality issues.

\section{Health}

\section{a. Sector context and key gender issues}

An overview of the health sector context and key gender issues is discussed in section D: Human Development - 2 Health (p. 28). Key gender issues highlighted in this section are summarized below:

(i) Access to reproductive health services in rural areas. A further reduction in maternal mortality requires improved clinical services, especially in rural areas, to address the main causes: obstetric hemorrhage, which accounts for every third maternal death; eclampsia; complications of abortion; and infection. Increased services are also needed to improve access to contraceptives and reduce the rate of abortion.

(ii) Gender gap in life expectancy. Men's life expectancy of 64.8 years is low for a middle-income country, and women's life expectancy of 74.3 years, while better, is still

107 International Organization for Migration. 2015. Mapping on Irregular Migration in Central Asia - 2014. Astana. 
a concern. More public education and health-care services are needed to address the main health risks for both women and men. Changing women's and men's behavior to seek treatment for health problems in early stages, and specific measures to detect and treat the main causes of morbidity among affected women and men, are pressing health issues.

(iii) Gender differences in main health risks. The Government of Kazakhstan needs to implement gender-responsive approaches to reducing health risks given their varied factors. Simply assessing the health risks to the population without a gender breakdown means that key health issues that are specific to men or women can be missed. The attention to men's lower life expectancy is important as is further addressing women's reproductive health. Efforts need to be made in parallel to maintain a gender-balanced approach to improved health.

(iv) Affordable health care. The introduction of private medical services and increasing the number of fee-based clinics risks stratifying services. Those who cannot afford fee-based clinics go to polyclinics, which are sometimes inferior. ${ }^{108}$ In addition, rural women, who are also responsible for the health care of children and elderly, must travel to access hospitals and district health centers. Mangystau, South Kazakhstan, and Almaty have fewer hospital beds compared to the rest of the country (footnote 8). New approaches, such as public-private partnership (PPP), are needed to increase affordable, quality health services.

(v) Gender-based violence. While Kazakhstan is only beginning to collect data on the extent of the problem, integrating specialized services for women affected by gender-based violence (GBV) to ensure they receive the support they need is key to combating violence against women.

\section{b. Government strategies}

The government has recognized the need for improving its health services. It has introduced health system reform through the Salamatty Kazakhstan 2011-2015 program and the Ministry of Healthcare and Social Development's updated Strategic Plan for 2014-2018.109 Major health concerns such as reducing cardiovascular disease; addressing higher-than-average levels of cancer, especially in industrial areas; reducing non-disease-related health problems related to road safety; reducing substance abuse; and decreasing suicide rates, particularly among teenagers are analyzed based on key health indicators. The government's reforms emphasize restructuring health investments to reduce hospital-based services, and increase primary health care. The Ministry of Healthcare and Social Development is also planning programs to promote healthy lifestyles. The most recent government initiative, the Healthcare Program Densaulyk 2016-2019, aims to reduce risk factors for infectious and noncommunicable diseases.

The key measures of these health programs include (i) educating the population about healthy lifestyles; (ii) influencing the formation of new behaviors that reduce risk factors (smoking, alcohol abuse, low physical activity); (iii) promoting healthy diets and exercise; (iv) reducing road accidents; (v) providing people with disabilities equal access to health services; (vi) ensuring sustainable safe drinking water; and (vii) reducing air, water, noise, and soil pollution. The health strategies put forward contain very little gender analysis of health issues.

\footnotetext{
108 Key informant interviews conducted with women and medical professionals in Almaty and Shymkent in July 2017.

${ }^{109}$ Republic of Kazakhstan. Ministry of Healthcare and Social Development. 2014. Strategic Plan for 2014-2018. Astana.
} 
The program targets social marketing and evidence-based research in behavioral psychology, attitudes to health, and communication and media techniques to reach different segments of the population. Integrating gender perspectives into the analysis of education and behavior change approaches will be key to effective outcomes.

The state health program also targets improved services to address regional disparities. Different outreach models are proposed, including privatization and enhancing universal health insurance. These are key reforms that require in-depth analysis of how to assure outreach and affordability for both women and men.

\section{c. ADB's portfolio}

Under the rubric of Sustaining inclusive growth and reducing inequality, ADB will support the government to increase the quality, efficiency, and accessibility of health care. Support will also include providing knowledge and other assistance to enhance delivery and facilities through the development of PPPs, particularly for care through polyclinics at the oblast level.

ADB's support will start with technical assistance to design new or improved primary health care initiatives. The Integrated Health Care Development Project proposes an integrated and modernized network through improvements to both facilities and services. The technical assistance also includes assessing PPP capacity. ${ }^{110}$

By investing in primary health care, $A D B$ will be increasing affordable, quality care for women who are more likely to access community-based services. Ensuring the health portfolio contributes to women's empowerment and gender equality outcomes will require removing gender barriers to affordable health care, and addressing gender differences in health risk factors.

\section{d. Recommendations for mainstreaming gender equality into ADB's health portfolio}

The following recommendations outline key entry points for leveraging ADB's upcoming investment in the health sector to advance gender equality and women's empowerment:

Support increased reproductive health service as part of polyclinics focused on primary health. ADB could further reduce maternal and infant health risks by addressing the remaining regional service disparities and supporting more vulnerable groups, such as migrants and persons with disabilities. Sharing information on practices that have contributed to Kazakhstan's progress in reproductive health could also be integrated into ADB's knowledge experience programming, in particular the context of CAREC. In addition, supporting research and developing models for contraceptive services is another key area of support.

Enhance knowledge on gender aspects of health risks and primary health care needs of women and men. The Kazakhstan CPS envisages entering the health-care sector to contribute to the government's planned reforms. These reforms will reorient services to focus more on primary health care. This knowledge-based entry point creates an opportunity to add a gender lens to the analysis of health risks, prevention strategies, and the types of primary health care

${ }^{110}$ ADB. 2017. Republic of Kazakhstan: Preparing the Integrated Health Care Development Project. Manila. 
models needed to address the different needs of women and men. As part of the shift in focus to prevention, the Ministry of Healthcare must deepen its capacity to undertake and apply research on the differing health attitudes, behaviors, risks, and information needs of women and men. For example, improving reproductive health is a key priority for women and analyzing the models of care that would improve family planning services, particularly for young women, is a priority. More research could uncover the reasons why men are more likely to let health problems reach late stages before seeking treatment. Such sex-disaggregated information could form the basis of healthy lifestyle campaigns. By developing studies and primary health care models that fully take into account gender differences, ADB could add value to reforms and ensure that services and public campaigns are well targeted to the health needs of women and men.

Strengthen health sector data collection and monitoring and evaluation. More rigorous efforts should be directed to systematic collection and analysis of sex-disaggregated data that reflect women's health-care needs. At present, much of the analysis of women's and men's disease incidence is done by global studies that access national statistics. This suggests that the data are available, but are not sufficiently analyzed, disseminated, and used in national health programs. In addition, more information on service access and delivery is needed for better monitoring of the national health programs. As Kazakhstan shifts to models of primary health care that include PPPs, having national systems to monitor delivery to both women and men will be even more important. In its efforts to diagnose and support PPPs, ADB could address the development of monitoring and evaluation systems that have a strong gender-based analysis capacity.

Provide technical assistance and training programs to increase health sector capacity to respond to gender-based violence. The government has plans to improve services for GBV under the road map to respond to domestic violence. The plan to raise awareness on this issue and encourage women to come forward and seek justice and assistance is a positive development. But if awareness campaigns do succeed in encouraging women to come forward, it will become even more critical to ensure the services are in place to address women's safety and other needs. Health services are a key component of the support network for women affected by GBV.

Primary health care centers are the first service many women will approach when they have a problem, and so are often on the front line of dealing with GBV. Health-care professionals need to learn specialized intervention approaches and treatment techniques to ensure a supportive environment. Such support would include providing victims with necessary referrals, coordinating with the criminal justice system, and applying protocols for documenting criminal evidence. ADB could support the Ministry of Healthcare to train medical professionals in GBV case identification and management, and in issues surrounding gender and power relations. ADB could also bring technical assistance through a pilot project or knowledge-building initiative to support the National Commission of Women's Affairs, Family and Demographic Policy; the Ministry of Healthcare; and the Prosecutor General's Office to develop and test coordination mechanisms and comprehensive support packages for treating GBV victims in specific regions. Such an initiative could be made in coordination with UN Women which is undertaking a pilot to improve services to victims of domestic violence in targeted oblasts. 


\section{Strategic Pillar 3: Sustainable Growth}

\section{Green Growth and Sustainable Energy}

\section{a. Sector context}

Kazakhstan's economy is highly dependent on petroleum which accounts for approximately a quarter of GDP and $60 \%$ of total exports (footnote 77). Kazakhstan became a net gas exporter in 2003 and is the second-largest coal producer in the region (after the Russian Federation). The national economy is highly energy-intensive and uses 2-3 times more energy than the average for the OECD countries. Despite the country's 100\% electricity access rates, access to Kazakhstan's network of gas and district heating systems remains uneven between urban and rural households. As a result, many rural households still rely on coal, wood, and liquid petroleum gas for heating and cooking. ${ }^{111}$ At least $70 \%$ of the country's electricity generation comes from coal. ${ }^{112}$

With coal dominating its energy sector, Kazakhstan is also the largest emitter of greenhouse gases (GHGs) in Central Asia, and its emissions per capita are among the highest in the world. Industrial carbon intensity is five times the European Union average. To address this issue, the country intends to assume its role in mitigating the impacts of climate change through voluntary emissions reduction targets (footnote 113).

Kazakhstan is also vulnerable to climate change, particularly in agriculture and water resources. Climate experts forecast a rise in the country's average mean annual temperature of $1.4^{\circ} \mathrm{C}$ by $2030,2.7^{\circ} \mathrm{C}$ by 2050 , and $4.6^{\circ} \mathrm{C}$ by 2085 (footnote 65 ). By mid-century, an increase in winter (9\%) and spring (5\%) precipitation is projected, and intensity of rainfall and variability is expected to increase (footnote 65). Climate change is expected to increase water resources in the mountain areas and decrease them in the plains areas. This will potentially have negative consequences on river flows and on already scarce water in the main agriculture growing region (footnote 67 ).

\section{b. Government strategies}

Kazakhstan's Green Economy Concept sets a voluntary target for an unconditional 15\% reduction in GHG emissions below the 1990 level by the end of 2030. It also targets a 25\% reduction in GHG emissions by the end of 2030 conditional upon receiving international support. ${ }^{113}$ Kazakhstan's Second Biennial Report to the United Nations Framework Convention on Climate Change lists more than 15 policy documents on climate change mitigation which have been in force since 2016 or planned for the period after 2017 (footnote 114). These strategies include increasing renewable electricity generation as well as developing green technologies and promoting renewable energy. Kazakhstan has only started its adaptation planning process. In July 2016, the government requested support from the United Nations Development Programme (UNDP) to develop a National Adaptation Plan as a way to facilitate effective planning mitigation to climate change, ${ }^{114}$ a process that is still underway.

111 A. Kerimray et al. 2017. Household Energy Consumption and Energy Poverty in Kazakhstan. IAEE Energy Forum. Quarter 1.

112 EBRD. 2017. Green Economy in Transition: Case Study Renewable Energy in Kazakhstan. Brussels.

113 OECD. 2016. First Policy Dialogue Under the Kazakhstan Green Action Platform: Discussion Notes. Astana. https://www.oecd.org/env/outreach/Discussion\%20notes\%20for\%20KAZ\%20GAP\%20Meeting\%20(Oct\%20 2016)\%20ver02.pdf.

114 UNDP. 2017. National Adaptation Plans. New York. http://www.adaptation-undp.org/explore/central-asia/kazakhstan. 


\section{c. Key gender issues}

Gender differences in energy demands and energy reform impacts. Efforts to promote green growth while ensuring energy for household and enterprise needs will have impacts that differ for women and men. Women are responsible for most of the daily household tasks. Electricity and household appliances help make women's daily household tasks less labor-intensive and thus less time consuming. Power outages, which are a frequent problem in rural areas, can substantially add to women's workload.

Residential coal consumption per capita in Kazakhstan is one of the highest in the world. Coal is the primary heating source for close to one-third of all households, increasing to $67 \%$ in rural areas. Incidences of death due to carbon monoxide poisoning in households are reported periodically during winter in the local media (footnote 112). Very few studies have documented patterns of household energy consumption and impacts of energy sources on human health or the environment. It is essential for decision makers and the general public to understand the patterns, determinants, and implications of household energy consumption. Constant power outages force women to spend more time doing household work. Poor households, often those headed by women, are concerned about the cost of electricity. These households are unable to afford a consumption-based meter unless supported through subsidies.

Women's voice in energy decisions. According to an EBRD case study, ${ }^{115}$ women in a number of rural districts have been found to be active in attending community meetings related to district heating. However, women are underrepresented at senior levels in local government and so are often left out in decision-making. Because women are the main users of energy in the household, they often find themselves dealing with the electric company more often. The lack of female employees is a constraint to receiving services in some areas where women are reluctant to open their doors to male technicians.

\section{d. ADB's portfolio for green growth}

In the energy sector, ADB is aiding the government's efforts to promote efficiency and foster green growth, and to develop institutional capacity for sustainable, safe, and energy-efficient operations. ADB's investments in this sector, shown in Table 5, create opportunities to increase women's access to energy in ways that can render their domestic and productive tasks more efficient and less labor-intensive. The green energy sector also offers new employment and business opportunities that can be leveraged to advance women's economic empowerment. Capacity-building of energy stakeholders in gender mainstreaming and emphasis on gender analysis during project design will ensure that the gender equality measures are well integrated into the energy portfolio.

115 EBRD. 2014. Gender Assessment of District Heating Projects in Kazakhstan financed by the Clean Technology Fund (CTF). Astana. 
Table 5: ADB's Energy Portfolio

\begin{tabular}{|c|c|c|c|c|}
\hline No. & Description & Category & Status & $\begin{array}{c}\text { ADB } \\
\text { Financing }\end{array}$ \\
\hline 1 & \multicolumn{4}{|c|}{ Akmola Electricity Distribution Company and Central-Asian Electric Power Corporation } \\
\hline 2 & \multicolumn{4}{|c|}{ Akmola Electricity Distribution Network Modernization and Expansion Project } \\
\hline & $\begin{array}{l}\text { The projects target accelerated upgrading of the } \\
\text { transmission and distribution network in order to } \\
\text { supply sufficient electricity to promote sustainable } \\
\text { economic growth, and (ii) promotion of private } \\
\text { sector investment in electricity distribution. The } \\
\text { project will rehabilitate } 19 \text { substations, and build } \\
\text { one substation and two transformers. }\end{array}$ & $\begin{array}{l}\text { No gender } \\
\text { elements }\end{array}$ & Active 2013 & $\$ 40$ million \\
\hline 3 & \multicolumn{4}{|l|}{ Fostering the Development of Renewable Energy } \\
\hline & $\begin{array}{l}\text { The project is a technical assistance to assist the } \\
\text { Kazakhstan Electricity Grid Operating Company to } \\
\text { strengthen its capacity in power system planning } \\
\text { for the integration of renewable energy sources } \\
\text { into the national grid. }\end{array}$ & $\begin{array}{l}\text { No gender } \\
\text { elements }\end{array}$ & Active 2017 & $\$ 1$ million \\
\hline
\end{tabular}

$\mathrm{ADB}=$ Asian Development Bank.

Source: ADB. 2018. Kazakhstan Projects. www.adb.org.

The country partnership strategy also identifies the need to address vulnerabilities such as climate change and disaster risks, potentially through regional initiatives to better manage water resources. As noted in Reduced Vulnerabilities to Risks and Shocks (section E), the gender divisions of tasks and social roles in Kazakhstan often render women and girls more vulnerable to disasters and climate change impacts. Integrating gender-responsive risk reduction and adaptation measures into ADB's regional portfolio of programs for disaster risk management and climate change can directly benefit women and girls. The following section outlines entry points to ensuring such gender equality outcomes are realized.

\section{e. Recommendations for mainstreaming gender equality into ADB's green growth portfolio}

Enhancing women's role in renewable energy. Energy projects, especially renewable energy projects, have the potential to address gender issues. Feasibility studies for every energy project should include a gender assessment and consider the needs of end users. To improve access to affordable electricity, payment schemes that could enable poor households to have their own consumption-based meters can be explored. Women in poor households should be included in consultations.

Women's employment and enterprise development in the energy sector. Kazakhstan's targets for reducing emissions will require new investments in renewable energy and green growth technologies to mitigate the impacts of climate change. ADB is a lead development partner financing private sector investment in green growth technologies and enterprise initiatives. Within its green growth portfolio, $A D B$ could set up pilot programs to support women entrepreneurs to learn new technologies and start MSMEs in the renewable energy and green growth sector. 
The Organization for Security and Co-operation in Europe (OSCE) is working on green growth entrepreneurship and could be a key collaborator to identify practices to expand to other women. Projects could also demonstrate the effectiveness of employing women in energy companies, not only as meter readers and in customer care, but also as technicians and managers.

A longer-term gender initiative is to encourage female students to take on energy-related technical courses and to employ them in the sector. Several initiatives are under way, including one by OSCE, to promote green technology enterprises by women. Training on various renewable energy enterprise initiatives could be provided for enterprising women under ADB's SME programming.

Promotion of gender analysis and representation of women in adaptation planning. Adaptation planning is at its early stages in Kazakhstan. Ensuring that women are engaged in this process and that efforts are made early on to address specific adaptation needs of women is critical to developing inclusive adaptation strategies that contribute to gender equality and reduce climate change impacts on women, men, boys, and girls.

\section{Urban Infrastructure and Services}

\section{a. Sector context}

As part of its drive for modernization, Kazakhstan is devolving increasing responsibility to subnational governments that need to develop planning and improve municipal services. Most of the water supply, solid waste treatment, district heating, and urban road infrastructure in secondary provincial centers is badly in need of improvements to provide adequate services to the population. The task of dealing with aging infrastructure, dated public utility tariff systems, and insufficient public transport will fall to municipal public officials who have limited resources and expertise to face the challenges of modernizing infrastructure systems.

Kazakhstan's population has a high level of access to water and sanitation services. According to monitoring data from UNICEF, $99.3 \%$ of households are reported to have water sources, with $73.1 \%$ piped and $26.2 \%$ non-piped. Overall, $89.1 \%$ of households have an improved water supply on the premises, with the figure dropping to $81.3 \%$ for rural households. For sanitation, UNICEF's monitoring data show that $99.9 \%$ of Kazakhstan's population lives in households using improved facilities, with $38.3 \%$ using sewer connections, $9.1 \%$ using septic tanks, and $52.4 \%$ using latrines. In rural areas, $86.5 \%$ of the population uses latrines.

While water and sanitation access are high, Kazakhstan's aging infrastructure affects the quality of these services. One study found that $67 \%$ of those surveyed considered their water source to be unreliable or not safe. All households in urban and rural areas have electricity. For internet services, $86 \%$ of urban residents had access compared to $66 \%$ of rural residents.

Despite a growing housing stock, affordability is a problem for many families, particularly in urban areas. Rapid population growth in large and medium-sized cities has led to a shortage of housing for low-income residents, incoming migrants, and even middle-class households. Only $4 \%$ of the overall housing stock is social housing, and the rental market is underdeveloped. This situation particularly affects households headed by women that may have less capital and resources to invest in housing. 


\section{b. Key gender issues}

Water collection tasks for rural women and girls in remote areas. In those $10 \%$ of households where drinking water is not available on the premises, water collection adds a time burden for women and girls, especially in remote rural areas. Also, households using a public water supply need to spend time obtaining water due to frequent disruptions in service, a task that generally falls to women given their higher domestic workload.

Impacts of disruptions in public utilities on women. Women have more responsibility for domestic tasks that depend on public utilities such as water, electricity, and gas. The frequent disruptions in these services add to women's already high time burden. Women caring for the elderly and infants need to find alternative sources of energy to ensure proper care. The use of coal as a source of energy has a negative impact on the health of the whole family, but more so for women as they are in the home for longer periods.

Women's voice in decision-making in urban development. Women's lower representation in local leadership roles and in senior roles in the civil service results in a lesser voice for women in urban planning services. Consequently, urban plans often do not fully address women's specific needs. For example, women more often walk or use public transport than drive a vehicle. Women benefit from initiatives to create more pedestrian-friendly cities, with accessibility for prams and people with disabilities. Women also benefit more from investments in public transit systems. Lighting on streets and in public areas makes women feel safer walking at night and increases their mobility. Ensuring that women's perspectives are incorporated into planning is essential to ensure that women fully benefit from investments in urban infrastructure and services.

\section{c. ADB's portfolio}

ADB has committed to support Kazakhstan's urban infrastructure and services. The Kazakhstan CPS indicates that ADB will support knowledge building to inform policy, legal, regulatory, and institutional reforms and mitigate the risks of private investment in urban development, making it more attractive for the private sector to participate. ADB has also been assisting the government to appraise the Kyzylorda Integrated Urban Development Project that would expand residential and industrial areas in part of a municipal center located along the new Western Europe-Western China highway.

Creating improved, safe, and inclusive urban environments can expand social, economic, and political opportunities for women. Consequently, investments in urban development contribute to women's empowerment and gender equality. The following recommendations outline entry points for $A D B$ to mainstream gender equality as it develops the urban infrastructure and services portfolio with the government. Two key elements will support gender equality outcomes: (i) capacity building of government counterparts, CSOs, and municipal officials on gender mainstreaming; and (ii) comprehensive gender analyses at the design stage so that genderspecific measures are fully integrated into all phases of implementation. 


\section{d. Recommendations for mainstreaming gender equality into ADB's portfolio for urban infrastructure and other services}

Build capacity for gender mainstreaming at the municipal level. Municipal planning takes place at various levels with national frameworks setting directions that are implemented largely by local planners. A gender analysis of the policies and programs of central agencies and local government bodies on urban planning and infrastructure could assess the responsiveness of services, identify training needs of staff, and improve representation. As a next step, ADB could use this analysis to design a training program for municipal officials. The rollout of such training could become a technical assistance or a component in a project planned under ADB's urban infrastructure and services portfolio. Such initiatives would demonstrate how to integrate gender-responsive features in municipal plans that could be later scaled up through national guidelines for urban planning.

Develop guidelines on gender-sensitive urban planning. The international literature and best practices on urban planning has many lessons on how to mainstream gender. For example, initiatives to invest in women- and child-friendly urban spaces, with adequate lighting on streets and in public buildings, safe transport shelters, separate male and female toilet facilities in public spaces, and accessibility for baby carriages and wheelchairs in urban planning, can make important differences in women's lives and well-being (footnote 99). ADB could assist the agencies responsible for urban planning and infrastructure to identify those practices relevant to Kazakhstan in coordination with women's organizations and other civil society groups. These measures could then be incorporated as guidelines for use in policies and programs guiding urban infrastructure investments.

Promote representation of women and civil society organizations in forums and public consultations on urban infrastructure and services. To enhance women's voice, ADB could prioritize the inclusion of women's groups and civil society groups in the planning of urban infrastructure investments and services. Planning rural public services needs to be decentralized given the diversity of geographic areas, and women have low representation in regional bodies where local infrastructure decisions are made. While women are underrepresented in government, they are highly represented in CSOs, many of which work on gender equality.

ADB could include specific measures in project preparation and implementation to ensure that women's groups and civil society groups working with women are represented in public consultations. Gender action plans in the project plans could be designed to ensure regular follow-up on the outcomes of consultations and track how such gender-responsive measures are integrated into investment decisions and technical designs.

Identify specific gender equality measures in urban project design. Technical assistance projects or small grants could build capacity of government, women's groups, and CSOs in assessing urban infrastructure investment needs. Such technical assistance would identify the options available to mainstream gender equality and inclusion for people with disabilities and other groups. Themes could cover the breadth of urban development issues to identify specific measures that are appropriate for Kazakhstan. Such technical assistance could also be integrated, as a component, into any upcoming ADB project to identify specific measures in the urban development subsectors that ADB will support. Such inputs would bring valuable perspectives on how to mainstream gender and inclusion in urban infrastructure and services for diverse groups. 


\section{Cross-Cutting Themes: Knowledge Building}

\section{Context}

Between 1990 and 2006, Kazakhstan transitioned from being a lower-income country to being in the upper middle-income group. While growth has been more gradual over the last decade, the country is aspiring to join the ranks of the 30 most developed countries by 2050. Kazakhstan needs knowledge support to expand its capacity to improve economic diversification. Public sector management is another area where knowledge support is required, particularly in implementing civil service reform, budget planning, and public audit. Knowledge building through strengthened academic institutions, workforce skills development, and private sector research and development are at the core of Kazakhstan's strategies.

\section{Key Gender Issues}

Gender balance in fields of tertiary education. Kazakhstan has developed a Higher Education Roadmap to 2020 that outlines the role of education and research institutions in developing a knowledge economy and a modern skilled labor force. The transition to a more knowledgebased economy has strong gender-equality implications. Kazakhstan's labor force is highly gender segregated, a tendency that begins as students enter higher education. The differences are particularly pronounced for technical and vocational education. To meet future labor force demands, vocational and educational schools must attract a gender-balanced pool of students to high-demand fields of study. More choice for students, free of the restrictions of gender stereotyping, allows for a better match of aptitudes and interests to fields of study and leads to better education outcomes.

Mainstreaming gender equality in civil service reform. In addition, developing a knowledgebased economy and modernized, professional civil service is integral to the country's plans to diversify its economy and modernize the state. Kazakhstan's strategy of 100 concrete steps sets out the country's plans to create a professional state apparatus that is results-oriented and capable of implementing long-term development priorities. Restructuring of the civil service will have a larger impact on women, who represent the majority of the state employees. As women are more likely to be in administrative and lower-level positions, they could be impacted by plans to restructure the civil service. This gender structure of the civil service is not referred to in the government plans or programs. The emphasis in the Concept of Family and Gender is on political representation. Increasing women's representation in senior political and civil service roles is critical to ensuring involvement of women in policy planning and government decision-making.

Platforms for women's voices in the regional knowledge hub. As part of its knowledge agenda, Kazakhstan is also seeking to build its status as a regional knowledge hub in Central Asia. As representatives to regional entities such as CAREC are often men, particularly in fields such as transport, energy, and trade where much of the cooperation occurs, ensuring women have a voice in these forums will be important to generating knowledge that draws from diverse perspectives. Kazakhstan has a core gender equality strategy as part of its development agenda, and the active role of women in its economy contributes to its success in building a stable, inclusive economy. Highlighting gender equality in diverse sectors is an important theme to be mainstreamed into initiatives to build regional knowledge platforms. 


\section{ADB's Knowledge Portfolio}

In 2013, the government and ADB agreed to establish the joint Knowledge and Experience Exchange Program (KEEP) aimed at facilitating various cutting-edge strategic knowledge options and global best practices. The implementation of the first phase of KEEP began with a technical assistance (TA) project approved in July 2013. Phase 1 of KEEP has helped the government with studies in six areas: (i) market concentration and competition, (ii) economic diversification with a focus on the service sector, (iii) support for the development of the government's new economic policy, (iv) economic costs of road traffic accidents in Kazakhstan, (v) procurement of performance-based road maintenance services, and (vi) capacity building for SME financing. ${ }^{116}$

In the second phase of KEEP in 2015-2018, the scope of the TA covers the following main themes: (i) inclusive growth and economic diversification, (ii) institutional and policy development, (iii) regional cooperation and integration, and (iv) competitiveness and efficiency enhancement. The TA will support macro, sector, and thematic subprojects that enable or promote knowledge solutions, capacity development, and exchange of best practices. Due to the dynamic nature of government demand for advisory and other knowledge products and services, the selection of subprojects and the implementation approach will be flexible (footnote 117).

Under its Knowledge Plan 2017-2019, ADB's program in Kazakhstan will support the government with studies, policy dialogue, workshops, and capacity-building activities for enhancing civil service reform and public sector management, reducing governance and procurement risks, strengthening technical and vocational education, and enhancing regional trade integration. As well as country-based knowledge-building initiatives, $A D B$ is also implementing the Regional Technical Assistance on Strengthening Gender Inclusive Growth in Central and West Asia. In addition to providing regular support to gender analysis and mainstreaming gender actions into ADB's portfolio, this TA is contributing to knowledge building such as holding a conference on prevention of violence against adolescent girls, as well as of early and forced marriages in the countries of Central Asia and Caucasus.

\section{Recommended Strategies for Mainstreaming Gender Equality in Knowledge Building}

ADB's knowledge-building initiatives provide a key entry point to further contribute to gender equality in Kazakhstan. As Kazakhstan advances on its development path, providing knowledge solutions will be a more central element of ADB's portfolio. Key areas where ADB could leverage knowledge solutions to enhance gender equality are outlined below.

Leadership training for women civil servants. Women comprise the majority of civil servants but are underrepresented in senior management. Support to civil service reform could include assisting the government to develop proactive policies on increasing women's representation in management, based on international best practices. As ADB collaborates with government on more capacity-building initiatives, training women for management positions could be identified as a knowledge area where ADB brings added value from its internal gender equality network and its experiences in diverse countries. In addition, incorporating modules on gender analysis and

${ }^{116}$ ADB. 2015. Republic of Kazakhstan: Joint Government of Kazakhstan and the Asian Development Bank Knowledge and Experience Exchange Program, Phase 2: Report and Recommendations to the President. Manila. 
gender mainstreaming within management courses will ensure that gender is more systematically considered in decision-making processes.

Training on gender equality and gender-based budgeting. Capacity-building initiatives targeting central- or oblast-level civil servants could increase understanding of the rationale, benefits, and approaches behind the state's gender equality strategy. UN Women has launched a program with the Government of Kazakhstan to pilot gender-based budgeting, starting with agriculture. ADB has expertise in key areas of public expenditure reform and improving public financial management and could strengthen planning and implementation of gender-based budgeting. Incorporating training on gender-based budgeting and other themes needs to be part of the programs that civil servants must take as they progress in their careers.

Strengthening career counseling services for male and female tertiary students. ADB will support studies, diagnostics, and capacity-building activities for training and vocational education. Gender segregation in education systems limits male and female career choices and, ultimately, detracts from the important role that technical and vocational education and training (TVET) plays in preparing a skilled workforce for a diversified economy. ADB could support the government with research and analysis on the dynamics of gender segregation in education and create incentives for women and men students to take nontraditional courses through scholarships, stipends, and/or with internship and job placement support.

A gender-lens review of current curricular offerings in tertiary institutions, as well as in TVET, could address modern labor market needs and how to work toward a gender-balanced occupational profile for the country's future development. Supporting TVET institutions to develop strong linkages with women and men mentors and with industries could influence women and men in making educational choices that are in line with current and future workforce demands. Developing media programs could encourage more girls into nontraditional courses and build positive images of women in various nontraditional occupations.

Increasing women's voice and representation in regional knowledge hubs. Building synergy between ADB's support to regional knowledge hub initiatives and for strengthening genderinclusive growth could catalyze gender equality in Kazakhstan, as well as in the region. Such initiatives could improve capacity in government, academic institutions, and civil society for undertaking gender-related research and analysis in diverse sectors strategic to ADB's, the government's, and regional investment programs. 


\section{Conclusion}

With more than a decade of experience implementing a comprehensive gender equality strategy and a renewed policy introduced in 2017, Kazakhstan has shown a continued commitment to advancing equality of women and men in the country. As Kazakhstan continues on its path toward a high economic and human development status, efforts to remove barriers to women's full economic, social, and political participation must continue to deepen. It is important that achieving a certain level of progress does not become a reason to maintain the status quo, but rather underlines the need to take on more complex issues and advance even further toward gender quality and women's empowerment.

The emerging association of gender and family creates opportunities to develop new norms where women's and men's contributions to the family and workplace are better balanced and equally valued. However, it is important that the country maintains its focus on the intrinsic value of gender equality by recognizing women's rights as human rights and by identifying measures that allow for their full participation in the economic and public sphere as well as their shared role in the family.

To further gender equality, Kazakhstan has to ensure that all women, including those with disabilities and those who experience GBV, can secure their rights. Ensuring women have more voice in forums that shape how laws and policies address their priorities and needs is also paramount. To empower women economically, the country needs to narrow the gap in women's and men's labor force participation, break down educational and occupational stereotypes, reduce the wage gap, and create incentives and mechanisms that promote women's career advancement to decision-making positions. Improving social protection and health-care access in rural areas is also crucial, along with ensuring that preventive programs consider the specific risks and behavior change influences of women and men.

ADB has the potential to advance gender equality due to its positioning in key economic and social sectors. Leveraging women's existing presence in the SME sector could further contribute to women's economic empowerment, particularly for rural women in agriculture. Enhancing women's voice and economic activity in critical areas of infrastructure investment is also critical. ADB's goals to support Kazakhstan to become a regional knowledge hub, along with an ongoing commitment to strengthening gender-inclusive growth, creates a strong foundation to lead in building higher capacities for gender analysis and gender mainstreaming. Kazakhstan is at a critical stage in setting its national development agenda for the coming decades. Further integrating gender equality across laws, policies, and programs will be an important condition to achieving the country's long-term goals for a sustainable and inclusive economy and promoting the well-being of the entire population. 


\section{REFERENCES}

Asian Development Bank (ADB). 2013. Gender Tool Kit: Transport-Maximizing the Benefits of Improved Mobility for All. Manila.

_-_. 2013. Kazakhstan Country Gender Assessment. Manila.

-- - 2014. Kazakhstan Small and Medium Enterprise Program. Tranche 2 Report and Recommendations to the President. Manila.

- - 2015. Kazakhstan Small and Medium Enterprise Program. Tranche 1 Project Completion Report. Manila.

- - 2015. Republic of Kazakhstan: Countercyclical Support. Report and Recommendation of the President to the Board of Directors. Manila.

_-_. 2016. Sector Assessment Summary: Finance. Supporting Resilience of Micro, Small, and Medium-Sized Enterprises Finance Project (RRP KAZ 49076). Manila.

- - - 2016. Supporting Resilience of Micro, Small, and Medium-Sized Enterprises Finance Project. Report and Recommendation of the President to the Board of Directors. Manila.

-- - 2017. Kazakhstan Country Partnership Strategy 2017-2021. Manila.

A. Auelbekova. 2017. How Many Female Chiefs in Kazakhstan? Forbes. April. https://forbes.kz/ stats/jenskoe_otstuplenie_1.

A. Dossanova. 2017. Violence Against Women in the Home: What do Statistics in Kazakhstan Tell Us?. In H. Hemblade et al, eds. Femicide Volume VII: Establishing a Femicide Watch Watch in Every Country. Vienna: Academic Council on the United Nations System.

Committee on the Elimination of Discrimination against Women. 2014. Concluding Observations on the Combined Third and Fourth Periodic Reports of Kazakhstan (CEDAW/C/KAZ/CO/34). 10 March.

DAMU Entrepreneurship Development Fund. 2016. Report on the State of Development of Small and Medium Enterprises in Kazakhstan and its Regions. Almaty.

A. Danzer, B. Dietz, and K. Gatskova. 2013. Kazakhstan Migration and Remittances Survey: Migration, Welfare and the Labor Market in an Emerging Economy. Regensberg, Denmark: Institute for East and South East European Studies. 
N. Dudwick, K. Fock, and D. Sedik. 2007. Land Reform and Farm Restructuring in Transition Countries: The Experience of Bulgaria, Moldova, Azerbaijan, and Kazakhstan. Washington, DC: World Bank Group.

Z. Dyussembekova. 2017. Kazakh Domestic Violence Rate Decreases. Nation. 22 February.

ECHO. 2017. Daily Flash. 20 April. Brussels.

ECPAT International. 2016. Access to Justice and Right to Remedies for Child Victims of Sexual Exploitation Research Project. Executive Summary: Kazakhstan. http://www.ecpat.org/wpcontent/uploads/legacy/Ex_Summary_EU_KAZAKSTAN_FINAL.pdf.

European Bank for Reconstruction and Development (EBRD). 2014. Gender Assessment of District Heating Projects in Kazakhstan financed by the Clean Technology Fund (CTF). Astana.

- - . 2016. Life in Transition: Kazakhstan. Brussels. http://www.ebrd.com/what-we-do/ economic-research-and-data/data/lits.html.

-_- 2017. Green Economy in Transition: Case Study Renewable Energy in Kazakhstan. Brussels.

Food and Agriculture Organization of the United Nations (FAO). 2014. Kazakhstan Country Strategy 2014-2017. Rome.

- - 2014. Rural Women in Eastern Europe and Central Asia. Rome.

GIZ. 2013. Gender in Value Chain Development. Berlin.

Global Fund for Disaster Risk Reduction, World Bank Group. 2015. Country Profile: Kazakhstan. Washington, DC. https://www.gfdrr.org/kazakhstan.

Global Road Safety Partnership. 2016. Kazakhstan. https:/www.grsproadsafety.org/programmes/ countries/kazakhstan/.

A. Ilyasova. 2016. Assessment Report Strategy for Gender Equality of the Republic of Kazakhstan 2006-2016. Astana.

Inter-parliamentary union. Women in National Parliaments. http://archive.ipu.org/wmn-e/arc/ classif311206.htm. Tables for June 2017 and December 2006.

International Commission of Jurists. 2013. Women's Access to Justice in Kazakhstan: Identifying the Obstacles \& Need for Change. Geneva.

International Labour Organization. 2014. Maternity Protection and the Childcare Systems in Central Asia: National Studies in Kazakhstan and Tajikistan. Moscow.

International Organization for Migration. 2015. Mapping on Irregular Migration in Central Asia 2014. Astana.

A. Jappar and J. Jandosova. 2013. Kazakhstan: Improving Capacity to Support SME Development SME Survey- A Needs Assessment. Astana: Sange Research Center. 
A. Kabdiyeva. 2015. Development of NGOs in Kazakhstan. European Journal of Business and Social Sciences. 4 (2). pp. 159-169. http://www.ejbss.com/Data/Sites/1/ vol4no02may2015/ejbss-1569-15-developmentofngosinkazakhstan.pdf.

Kazakhstan Committee on Statistics. Women and Men in Kazakhstan 2015. Astana.

Kazakhstan Pravda. 2017. List of Banned Occupations for Women Will Be Updated in Kazakhstan. http://www.kazpravda.kz/en/news/society/list-of-banned-occupationsforwomen-will-be-updated-in-kazakhstan/. 23 June.

A. Kazbay. 2013. President Signs Pension Reform Law Raising Women's Retirement Age from 2018. The Astana Times. Astana. 26 June.

A. Kerimray et al. 2017. Household Energy Consumption and Energy Poverty in Kazakhstan. IAEE Energy Forum. Quarter 1.

Organisation for Economic Co-operation and Development (OECD). 2012. Starting Strong IV: Early Childhood Education and Care Data Country Note: Kazakhstan. Paris.

- - . 2013. Review of Agricultural Policies: Kazakhstan. Paris. http://dx.doi. org/10.1787/9789264191761-en.

- - 2016. First Policy Dialogue Under the Kazakhstan Green Action Platform: Discussion Notes. Astana. https://www.oecd.org/env/outreach/Discussion\%20notes\%20for\%20 KAZ\%20GAP\%20Meeting\%20(Oct\%202016)\%20ver02.pdf.

- - 2016. Multi-sector Review of Kazakhstan. Volume 1: Initial Assessment. Paris.

- - . 2016. Social Institutions and Gender Index: Regional Report Europe and Central Asia. Paris.

- - . 2017. Building Inclusive Labor Markets in Kazakhstan: A Focus on Youth, Older Workers and People with Disabilities. Paris.

- - 2017. Early Childhood Education and Care Staff Recruitment and Retention: A Review of Kazakhstan. Paris.

- - 2017. Review of Gender Policy Delivery in Kazakhstan. Paris.

- - 2017. Urban Policy Reviews: Kazakhstan. Paris.

Organization for Security and Co-operation in Europe. 2012. Report of OSCE Special Representative on Gender Issues on visit to Kazakhstan. 19-21 June.: https://www.osce.org/ cio/97292? download=true.

Republic of Kazakhstan. 1995. Constitution of the Republic of Kazakhstan. Almaty. Article 14, part 2.

- - 2006. Strategy on Gender Equality 2006-2016. Astana.

- - . 2003. Land Code of the Republic of Kazakhstan, Article 101:1. http://adilet.zan.kz/eng/ docs/K030000442_. 
-_-. 2014. Agribusiness Development Roadmap 2020. Astana.

- - 2015. Strategy 2050. Astana.

- - 2016. Kazakhstan 2050:563,000 Kazakhstanis permanently employed under the Employment roadmap 2020. http://www.government.kz/en/chelovecheskijkapital/1006480-563-000-kazakhstanis-permanently-employed-under-employmentroadmap-2020.html.

-_- 2016. Kazakhstan in Figures 2015. Astana. www.stat.gov.kz.

- - 2016. Ministry of Labor and Social Protection. Employment Roadmap: During the Implementation of "Employment Roadmap 2020" State Support Measures Covered 800 Thousand People. http://www.enbek.gov.kz/en/node/343418.

- - 2016. State Regulation of Development of Agro-industrial Complex and Rural Areas. July 2005; amended April 2016. http://adilet.zan.kz/eng/docs/Z050000066_.

- - . 2016. Statement by the Republic of Kazakhstan on the Agenda item 27 "Advancement of Women," Third Committee, 71st session of the UN General Assembly, 11 October.

- - . 2017. E-gov: Government online, Employment Roadmap 2020.http://egov.kz/cms/en/ articles/zanyatost_2020.

Republic of Kazakhstan, Ministry of National Economy, Committee on Statistics. 2016. Official Statistics: Transport. http://stat.gov.kz/faces/wcnav_externalld/homeNumb ersTransport;jsessionid=gQdchxGwcWWGn1hueorNyx_IORWI3uY8RFHAm3eb_ pa7nij014u2!1738043929!-1234667160?_adf.ctrl-state=v165ij9x1_42\&_ afrLoop=2054865602750493\#\%40\%3F_afrLoop\%3D2054865602750493\%26_adf. ctrl-state\%3Dspsoin1w8_4.

- - Women and Men in Kazakhstan 2015. Astana.

- - Statistical Yearbook: Kazakhstan in 2015. Astana.

Republic of Kazakhstan, Embassy of the Republic of Kazakhstan in the United States. 2017. Nurly Zholl: Economic Policy. http://www.kazakhembus.com/content/nurly-zhol-0.

Republic of Kazakhstan, Ministry of Healthcare and Social Development. 2014. Strategic Plan for 2014-2018. Astana.

Republic of Kazakhstan, Ministry of Healthcare and Social Development. 2016. Systemic measures to ensure productive employment for Kazakhstan (presentation on the Road Map of Employment 2020). Ankara.

Republic of Kazakhstan, Ministry of Investment and Development. 2014. Transport Strategy 2020. Astana.

Republic of Kazakhstan, National Committee for Women's Affairs, Family and Demographic Policy. 2017. Concept of Family and Gender 2017-2030. Astana. 
R. Sarsembayeva. 2017. Implementation of Strategy for Gender Equality in the Republic of Kazakhstan for 2006-2016: The Sociological Analysis. Astana: Association of Women in Business.

N. Shedenova and A. Beimisheva. 2013. Territorial Availability of Social and Economic Infrastructure in Kazakhstan: Comparative Analysis of Urban and Rural Households. World Academy of Science, Engineering and Technology. International Journal of Social, Behavioral, Educational, Economic, Business and Industrial Engineering. 7 (2).

Sputnik Kazakhstan. 2017. School Cloakroom Attendant Hasn't Received 7 Million Tenges for Harassment. 28 July. https://news.mail.ru/society/30522635/?frommail=1.

The Equal Rights Trust. 2014. Written submissions to the 57th session of the Committee on the Elimination of Discrimination against Women in relation to the combined third and fourth periodic reports submitted by Kazakhstan. Presentation to the United Nations Committee on the Elimination of Discrimination against Women. Geneva.

Trading Economics. 2017. Kazakhstan Labor. https://tradingeconomics.com/kazakhstan/ retirement-age-men.

Y. Uatkhanov. 2017. Kazakhstan Develops Road Safety Plan, Fatalities Decline. The Astana Times. 7 May. http://astanatimes.com/2017/05/kazakhstan-develops-road-safety-planfatalities-decline/.

UN Women. 2016. Ending Violence Against Women: Facts and Figures, Kazakhstan. New York. http://evaw-global-database.unwomen.org/en/countries/asia/kazakhstan.

- - 2017. Kazakhstan's New Plan to End Domestic Violence Demonstrates Multi-disciplinary Action. Astana. http://www.unwomen.org/en/news/stories/2017/8/feature-kazakhstansplan-to-end-domestic-violence-demonstrates-multi-disciplinary-action.

United Nations Development Programme (UNDP). 2010. Millennium Development Goals in Kazakhstan. Astana.

-_- 2016. Human Development Reports: Gender Inequality Index. New York. http://hdr.undp. org/en/content/gender-inequality-index-gii.

- - 2016. Human Development Report: Human Development Index. New York. http://hdr. undp.org/en/data.

-- - 2016. Human Development Report: Kazakhstan Country Profile. New York. http://hdr. undp.org/en/data.

-_- 2016. Human Development Data (1990-2015). http://hdr.undp.org/en/data.

- - 2017. National Adaptation Plans. New York. http://www.adaptation-undp.org/explore/ central-asia/kazakhstan. 
United Nations Children's Fund (UNICEF). 2014. Migration Profiles: Kazakhstan. New York.

- - . 2015. Analysis of Social Transfers for Children and Their Families in Kazakhstan. Astana.

UNICEF and UNFPA. 2016. Multi-Indicator Cluster Survey 2015: Kazakhstan. Astana.

UNISDR and UN Women. 2015. Gender Experts' Voice Heard at Regional Consultations in Central Asia and South Caucasus on Disaster Risk Reduction for Post-2015 Agenda. Astana.

United Nations CEDAW Committee. 2007. Concluding comments of the Committee on the Elimination of Discrimination against Women: Kazakhstan. CEDAW/C/KAZ/CO/2. New York.

United States Department of State. 2016. Trafficking in Persons Report. Kazakhstan Country Profile. Washington, DC. https://www.state.gov/j/tip/rls/tiprpt/countries/2016/258794. htm.

Z. Urankayeva. 2016. The Difference in Salary between Men and Women in Kazakhstan Is Reported. Pravda News. 12 April. http://www.kazpravda.kz/news/ekonomika/ozvuchenaraznitsa-v-zarplate-mezhdu-muzhchinami-i-zhenshchinami-v-kazahstane/.

Whiteshield Partners. 2016. Sustainable Development Goals and Capability Based Development in Regions of Kazakhstan: National Human Development Report.Astana: UNDP.

World Bank. 2013. Kazakhstan Overview of Climate Change Activities. Washington, DC.

--—. 2016. Kazakhstan MPO. Washington, DC.

- - . 2016. Poverty and Equity. Country Dashboard: Kazakhstan. Washington, DC. http:// povertydata.worldbank.org/poverty/country/KAZ.

- - - 2017. Kazakhstan: Data: Agriculture Trends. https://data.worldbank.org/indicator/ NV.AGR.TOTL.ZS.

- - - Project Appraisal Document. Second Irrigation and Drainage Improvement Project. Washington, DC. www.sesric.org/imgs/news/1507-Kazakhstan.pptx.

World Economic Forum. 2017. Global Gender Gap Report. Geneva. www.stat.gov.kz..

World Health Organization (WHO). 2015. Country Profiles: Kazakhstan. Geneva. http://www. who.int/countries/kaz/en/.

- - . 2016. Road Safety and Healthy Cities Application Discussed at the Policy Dialogue in Almaty. http://www.euro.who.int/en/countries/kazakhstan/news/news/2016/10/roadsafety-and-healthy-cities-application-discussed-at-the-policy-dialogue-in-almaty.

YK-News. 2017. Free Medical Care in Kazakhstan Is Not Provided for the Citizens of the EAEC. March. http://yk-news.kz/news/бесплатное-медицинское-обслуживание-вказахстане-для-граждан-еаэс-не предусмотрено. 


\section{Appendix 1}

\section{Summary of Recommendations}

\begin{tabular}{|c|c|}
\hline I & Micro, Small, and Medium-sized Enterprise Development \\
\hline 1 & $\begin{array}{l}\text { Establish indicators and targets in program Development Monitoring Frameworks } \\
\text { that ensure women's equitable access to project benefits: Setting targets for women's } \\
\text { participation in the program at a higher level-possibly as a proportion of their share as SME } \\
\text { owners ( } 42 \%) \text {-would better ensure that women are gaining equitable access to this project } \\
\text { benefit. }\end{array}$ \\
\hline 2 & $\begin{array}{l}\text { Design SME development programs to focus on the specific needs of women } \\
\text { entrepreneurs: Setting targets for women's participation in projects is important. To build even } \\
\text { more momentum, programs need to support women to reach their business goals by assessing } \\
\text { their specific needs and designing products and services accordingly. }\end{array}$ \\
\hline 3 & $\begin{array}{l}\text { Promote gender-sensitive SME policies: ADB could also support the Government of } \\
\text { Kazakhstan to review its current SME policies and business road map with the goal of making } \\
\text { them gender-responsive. }\end{array}$ \\
\hline II & Countercyclical Support Programs \\
\hline 4 & $\begin{array}{l}\text { Develop more targeted gender-related indicators for countercyclical support programs: } \\
\text { ADB could ensure that countercyclical program outcomes are more geared toward reducing } \\
\text { gender gaps. ADB could assist the government by engaging with the National Committee when } \\
\text { setting countercyclical program objectives and indicators. Such a step could ensure that gender } \\
\text { equality outcomes are better articulated and more effectively formulated as key indicators for } \\
\text { national programs. }\end{array}$ \\
\hline 5 & $\begin{array}{l}\text { Improve monitoring mechanisms to track gender equality targets: To ensure that women } \\
\text { and men have equal benefits from national programs financed through countercyclical support, } \\
\text { all indicators on number of persons benefiting from the programs should be sex-disaggregated } \\
\text { and reported on a regular basis. Such data need to be reviewed by ADB and government } \\
\text { periodically to track how effective programs are in reaching women and make adjustments as } \\
\text { needed. }\end{array}$ \\
\hline 6 & $\begin{array}{l}\text { Gender Entry Points } \\
\text { Improving sex-disaggregated data collection and reporting. } \\
\text { Provide technical assistance on gender analysis for social protection, and job creation programs. }\end{array}$ \\
\hline III & Agriculture \\
\hline 7 & $\begin{array}{l}\text { Ensure that women are actively involved in all stages of planning and implementing } \\
\text { irrigation infrastructure: Agriculture investments need to be directed to irrigation schemes } \\
\text { and rehabilitation works that women as well as men have identified as priorities. Involving } \\
\text { women and men in the design and operation of systems will build ownership and sustainability } \\
\text { of project investments. }\end{array}$ \\
\hline
\end{tabular}


Appendix 1 continued

8 Enhance women's decision-making in cooperatives and water-user groups: Integrating women's membership and leadership within programs to restructure and improve cooperatives, irrigation management entities, and agribusinesses are needed to enhance women's strategic positioning in the agriculture sector.

9 Support government to conduct gender analysis of agricultural value chains to enhance agribusiness competitiveness: ADB projects in agriculture could improve women's participation in agricultural value chains. Accounting for gender provides a more comprehensive picture of the value chain issues and results in more insightful recommendations on the best options for investing in value chain competitiveness. Such analysis can inform the gender-specific components that need to be integrated into projects to develop agricultural value chains.

10 Strengthen rural women's access to microfinance and business development services: New $A D B$ projects in agriculture need to undertake detailed consultation with rural women's groups to identify their constraints to enterprise development, and support the government to design credit and business development strategies that are tailored to the specific needs of women throughout Kazakhstan.

11 Enhance quality of work in agriculture: To ensure that financing is widely distributed and reaches rural women, projects need to modernize farm and manufacturing processes, invest in technology, equipment, and skills, and promote better conditions and facilities for all workers, with special attention to the needs of women.

12 Build capacity of rural women's civil society organizations: ADB could increase the capacity of rural CSOs to provide services to women, increasing women's access to information on changes in the agriculture sector, and supporting women to interpret how to respond to such changes.

13 Gender Entry Points:

Build knowledge for gender analysis of agriculture policies and value chain investment. Conduct workshops or other forums to engage rural women's organizations in agriculture policy development and feedback.

\section{Transport}

14 Develop measures with the Committee of Roads to increase women's voice in public consultations: It is important to collect sex-disaggregated information on the views expressed in public consultations, as well as conduct surveys with women on their transport needs and priorities. Equally important is tracking follow-up actions in response to women's views. ADB could work with the Committee of Roads and other government counterparts to collect more information and analysis of women's views on transport planning and road design. Better systematization of this information could support the Committee of Roads to enhance women's voice in transport planning.

15 Incorporate gender components into transport investments: Consultations with CSOs working with women, interviews with women business leaders, focus group discussions, key informant interviews, and transport surveys targeting women are needed to more deeply understand how transport can best contribute to women's access to social services and increase their participation in the economy. ADB could engage with government counterparts and other development partners in transport to design gender-specific components to integrate into investments such as the CAREC corridor. Additional investments for gendersensitive transport design might also include public and private common transport services that are more frequently used by women. 
Appendix 1 continued

16 Promote increased employment and training opportunities for women in transport:

Increasing women's representation in transport would provide women with more employment, particularly in rural areas. More proactive approaches beyond requiring contractors to encourage women to apply for jobs are needed. Measures could include support to technical colleges to attract women into transport engineering and project management courses, and increasing incentives for contractors to hire and create conducive working conditions for women. The Ministry of Investment could be a strong partner for ADB to work with to design more targeted programs to improve women's representation in transport projects.

17 Develop programs to enhance women's entrepreneurial opportunities in transport: ADB could leverage its existing partnership with DAMU and its network of women's business development service providers, workshops, and training programs to introduce women to transport business opportunities. Ensuring that information on contract opportunities in the transport sector are circulated to women could be facilitated through Association of Business Women of Kazakhstan and other such networks. This agency and other organizations could be mobilized to more proactively seek women's participation in road construction and postconstruction businesses. Women's economic empowerment could also be promoted by creating more explicit linkages between business development programs and the economic corridor and trade facilitation being enabled through transport investment.

18 Scale up regional responses to human trafficking and irregular migration: By facilitating the legitimate movement of goods and people, highway transport projects also increase the risk of human trafficking and irregular migration and require a scale of response in keeping with the level of risk. Kazakhstan is a leader in promoting women's participation in the economy and would be a key champion of increased representation of women's views and gender equality into CAREC and other regional initiatives.

19 Gender entry point:

Develop capacity-building programs to generate and share knowledge on gender integration in transport. Specific actions could include conducting research or other knowledge-building initiatives to make government and other stakeholders more aware of the key gender issues that need to be addressed in Kazakhstan's transport sector. It could also include regional workshops with other CAREC member countries on gender-specific measures that have been applied in other investments.

\begin{tabular}{c|l} 
V & Health Care \\
\hline 20 & $\begin{array}{l}\text { Support increased reproductive health service as part of polyclinics focused on primary } \\
\text { health: Additional support for maternal and infant health could focus on further addressing } \\
\text { the remaining regional disparities in services and identifying and supporting more vulnerable } \\
\text { groups, such as migrants and persons with disabilities, who may have more difficulty accessing } \\
\text { appropriate care. Sharing information in the region on successful practices could also be } \\
\text { integrated into ADB's knowledge experience programming, including supporting research and } \\
\text { developing models to fulfill the unmet need for contraceptive services. }\end{array}$ \\
\hline 21 & $\begin{array}{l}\text { Strengthen health sector data collection and monitoring and evaluation: More data on } \\
\text { service access and delivery are needed for monitoring how the national health programs and } \\
\text { the investment in health are meeting the needs of both women and men, both urban and } \\
\text { rural. In its efforts to support PPPs, ADB could address the development of monitoring and } \\
\text { evaluation systems that have a strong gender-based capacity. }\end{array}$ \\
\hline 22 & $\begin{array}{l}\text { Assist government to implement public health campaigns using gender-based approaches } \\
\text { to reducing health risks: A gender analysis of available health indicators would show how } \\
\text { addressing health risks and disease incidence for women and men requires a gender-based } \\
\text { approach. As part of its plans to support knowledge, ADB could assist the government with } \\
\text { healthy lifestyle campaigns, including how to integrate gender into health awareness campaigns. }\end{array}$ \\
\hline
\end{tabular}


Appendix 1 continued

23 Gender Entry Points:

Enhance knowledge on gender aspects of health risks and primary care needs of women and men.

Provide technical assistance and training programs to increase health sector capacity to respond to GBV.

\begin{tabular}{c|l}
\hline VI & Green Growth and Sustainable Energy \\
\hline 24 & $\begin{array}{l}\text { Enhancing women's role in renewable energy: Feasibility studies for every energy project } \\
\text { should include a gender assessment and consider the needs of end users. To improve access } \\
\text { to affordable electricity, payment schemes could enable poor households to have their own } \\
\text { consumption-based meters. Women in the households should be included in planning and } \\
\text { implementation. }\end{array}$ \\
\hline 25 & $\begin{array}{l}\text { Women's employment and enterprise development in energy: A long-term gender initiative } \\
\text { is to encourage female students to take on energy-related technical courses and to employ } \\
\text { them in the sector. Training on various renewable energy enterprise initiatives could be } \\
\text { provided for enterprising women under ADB's SME programming. }\end{array}$ \\
\hline
\end{tabular}

26 Promotion of gender analysis and representation of women in adaptation planning: Ensuring that women are engaged in adaptation planning and that efforts are made early on to address specific needs of women and include gender perspectives will promote effective strategies.

\section{Gender Entry Point:}

Analysis of women's enterprise development opportunities in renewable energy and green energy growth sector.

\section{Urban infrastructure and services}

28 Build capacity for gender mainstreaming at the municipal level: A gender analysis of the policies and programs of central agencies and local government bodies on urban planning and infrastructure could identify training needs of staff, and improve gender balance. As a next step, ADB could design a training program for municipal officials on gender-responsive services and urban planning. The rollout of such training could become a gender-equality technical assistance or component in a project planned under ADB's urban service and infrastructure portfolio.

29 Develop guidelines on gender-sensitive urban planning: ADB could assist the agencies responsible for urban planning and infrastructure development to identify those practices relevant to Kazakhstan in coordination with women's organizations and other civil society groups. These measures could then be incorporated in policies and programs guiding municipal infrastructure investments.

30 Promote representation of women in forums and public consultations on urban planning: ADB could prioritize women's groups and civil society groups in the planning of municipal services. ADB could include specific measures in project preparation technical assistance and implementation to ensure that women's groups and civil society groups working with women are represented in public consultations on upgrades and changes to municipal services. Gender action plans could be designed to ensure regular follow-up on the consultations and track how such gender-responsive measures are integrated into investment decisions and technical designs.

\section{Gender Entry Point:}

Enhancing role of civil society in gender-responsive urban development with technical assistance or small grants that support CSO networks to research and provide inputs into municipal planning. 
Appendix 1 continued

\begin{tabular}{|c|c|}
\hline VIII & Knowledge building \\
\hline 32 & $\begin{array}{l}\text { Leadership training for women civil servants: Support to civil service reform could include } \\
\text { assisting the government to increase women's representation in management, based on } \\
\text { international best practices. As ADB collaborates with government in supporting more } \\
\text { capacity-building initiatives, training women for management positions could bring added } \\
\text { value from its internal gender equality network and its experiences in diverse countries. In } \\
\text { addition, incorporating modules on gender analysis and mainstreaming in policy and program } \\
\text { development within management courses is necessary to ensure that gender is considered in } \\
\text { decision-making processes. }\end{array}$ \\
\hline 33 & $\begin{array}{l}\text { Training on gender equality and gender-based budgeting: Capacity-building initiatives } \\
\text { targeting central- or oblast-level civil servants could introduce gender equality modules to } \\
\text { increase understanding of the rationale, benefits, and approaches behind the state's gender } \\
\text { equality strategy. UN Women has launched a program with the government of Kazakhstan to } \\
\text { pilot gender-based budgeting, starting with agriculture as a pilot. ADB has expertise in key areas } \\
\text { of public expenditure reform and improving public financial management and could add value } \\
\text { to strengthening planning and implementation of gender-based budgeting. }\end{array}$ \\
\hline 34 & $\begin{array}{l}\text { Strengthening career counseling services for male and female tertiary students: ADB could } \\
\text { support the government with research and analysis on gender segregation in education and } \\
\text { create incentives for women and men students to take on nontraditional courses through } \\
\text { scholarships, stipends, or with internship and job placement support. A gender-lens review of } \\
\text { current curricular offerings in tertiary institutions, as well as in TVET, could address modern } \\
\text { labor market needs and how to work toward a gender-balanced occupational profile for the } \\
\text { country's future development. Supporting TVET institutions to develop strong linkages with } \\
\text { women and men mentors and with industries could address the issue of influencing women and } \\
\text { men in making educational choices that are in line with current and future workforce demands. } \\
\text { Developing media programs could encourage more girls into nontraditional courses and build } \\
\text { positive images of women in various nontraditional occupations. }\end{array}$ \\
\hline 35 & $\begin{array}{l}\text { Increasing women's voice and representation in regional knowledge hubs: Building synergy } \\
\text { between ADB's support to regional knowledge hub initiatives and its strengthening gender- } \\
\text { inclusive growth could catalyze gender equality in Kazakhstan as well as in the region. Such } \\
\text { initiatives could include improving capacity in government, academic institutions, and civil } \\
\text { society for undertaking gender-related research and analysis in diverse sectors strategic to } \\
\text { ADB's, the government's, and regional investment programs. }\end{array}$ \\
\hline
\end{tabular}

$\mathrm{ADB}=$ Asian Development Bank, $\mathrm{CAREC}=$ Central Asia Regional Economic Cooperation, $\mathrm{CSO}=$ civil society organization, $\mathrm{GBV}=$ gender-based violence, $\mathrm{PPP}=$ public-private partnership, $\mathrm{SME}=$ small and medium-sized enterprise, TVET = technical and vocational education and training. 


\section{Appendix 2}

\section{Agencies Participating in Key Informant Interviews}

\section{Government Ministries and Agencies}

- DAMU

- Ministry of Agriculture

- Ministry of Energy

- Ministry of Finance

- Ministry of Health

- Ministry of Investments and Development - Committee of Roads

- Ministry of Labor and Social Protection

- Ministry of National Economy

- National Commission for Women's Affairs and Family and Demographic Policy

\section{Development Partners}

- Eurasia Foundation

- Islamic Development Bank

- Organization for Security and Co-operation in Europe

- United Nations Entity for Gender Equality and the Empowerment of Women (UN Women)

- United Nations Development Programme

- United States Agency for International Development

\section{Asian Development Bank}

- Country Director

- Regional Gender Advisor

- Resident Mission Gender Focal Point

- Resident Mission Civil Society Liaison

- Central Asia Regional Economic Cooperation (CAREC) Coordinator

- Project Officers/Specialists responsible for investments in the Finance and Transport sectors based in resident mission and headquarters 


\section{Key informant interviews were also held with}

- Civil Society Organizations working on women's issues, disability issues, women's entrepreneurship, and combating violence against women in Astana, Almaty, and Southern Kazakhstan

- Medical professionals and academics based in Almaty

- Trade Union Representatives in the Transport Sector

- Women Entrepreneurs in Almaty and in Southern Kazakhstan

- Subnational Transport Officials 


\section{Kazakhstan Country Gender Assessment}

This publication develops a strategic focus for integrating gender concerns into programs and operations of the Asian Development Bank (ADB) in Kazakhstan. This assessment reviews ADB's experiences in implementing gender mainstreaming in its portfolio in recent years. The assessment method has two main components. The first is a review of the status of gender equality and women's empowerment in the country, based on a literature review, key statistics, policy documents, and key informant interviews. The second analyzes the achievements and challenges in mainstreaming gender equality in ADB's programs and operations, and recommends the way forward to improve outcomes.

\section{About the Asian Development Bank}

ADB is committed to achieving a prosperous, inclusive, resilient, and sustainable Asia and the Pacific, while sustaining its efforts to eradicate extreme poverty. Established in 1966, it is owned by 67 members48 from the region. Its main instruments for helping its developing member countries are policy dialogue, loans, equity investments, guarantees, grants, and technical assistance. 